\title{
A Calcium Oxide Sorbent Process for Bulk Separation of Carbon Dioxide
}

\author{
Annual Report \\ September 1989 - August 1990
}

\section{D.P. Harrison}

September 1990

Work Performed Under Contract No.: DE-AC21-89MC26366

For

U.S. Department of Energy

Office of Fossil Energy

Morgantown Energy Technology Center

Morgantown, West Virginia

By

Louisiana State University

Department of Chemical Engineering

Baton Rouge, Louisiana 


\section{DISCLAIMER}

This report was prepared as an account of work sponsored by an agency of the United States Governmeni. Neither the United States Government nor any agency thereof, nor any of their employees makes any warranty, express of implied, or assumes any legal liability or responsibility for the accuracy, completeness or usefulness of any information, apparatus, product, or process disclosed, or represents that its use would not infringe privately owned rights. Reference herein to any specific commercial product, process, or service by trade nanze, trademark, manufacturer, or otherwise, does not necessarily constitute or imply its endorsement, recommendation, or favoring by the United States Government or any agency thereof. The views and opinions of authors expressed herein do not necessarily state or reflect those of the United States Government or any agency thereof.

This report has been reproduced directly from the best available copy.

Available to DOE and DOE . ntractors from the Office of Scientific and Technical Information, P.O. Box 62, Oak Ridge, TN 37831; prices available from (615)576-8401, FTS 625-8401.

Available to the public from the National Technical Information Service, U.S. Department of Commerce, 5285 Port Royal Rd, Springfield, VA. 22161. 
A Calcium Oxide Sorbent Process for Bulk Separation of Carbon Dioxide

\author{
Annual Report \\ September 1989 - August 1990
}

D.P. Harrison

Work Performed Under Contract No.: DE-AC21-89MC26366

\author{
For \\ U.S. Department of Energy \\ Office of Fossil Energy \\ Morgantown Energy Technology Center \\ P.O. Box 880 \\ Morgantown, West Virginia 26507-0880 \\ Louisiana State University \\ Department of Chemical Engineering \\ Baton Rouge, Louisiana 70803-7303
}

September 1990 
Table of Contents

rage

Executive Summary

Task 1: Introduction and Preliminary Effort . . . . . 4

Literature Survey . . . . . . . . . 5

Sorbent Selection . . . . . . . . . . . . . . 17

High-Temperature High-Pressure Electrobalance $\quad$. . . 21

Task 2: Reaction Screening Test.s . . . . . . . . . 28

Characteristics of the Calcination - Carbonation

Reactions . . . . . . . . . . . . . . . 29

The Effect of Temperature . . . . . . . . 29

The Effect of Gas Compositicn . . . . . . . 32

Comparison of Sorbent Reactivity . . . . . . . . 43

Task 3: Two-Cycle Test Series . . . . . . . . . 55

Reaction Reproducibility . . . . . . . . . . 59

The Effect of Calcination Temperature . . . . . . 59

The Effect of Carbonation Temperature . . . . . . 64

The Effect of $\mathrm{CO}_{2}$ Composition . . . . . . . . . $\quad 68$

The Effect of Pressure . . . . . . . . . 70

Direct Comparison of Three Base Sorbents . . . . 72

Task 4: Detailed Parametric Tests . . . . . . . . 76

Task 5: Multicycle Tests . . . . . . . . . . . 77

T'ask 6: Structural Property Measurements . . . . . . 78

Refierences . . . . . . . . . . . . . . . . . . 91 
List of Figures

Page

Figure 1. Equilibrium $\mathrm{CO}_{2}$ Pressure as a Function of

Figure 2. Calcination-Carbonation Test Results from Barker (1973)

Figure 3. Porosity of the Calcine as a Function of the Porosity of the Precursor (Hartman et al., 1978)

Figure 4. The Extent of Calcium Oxide Sulfation as a Function of the Porosity of the Precursor

(Hartman et al., 1978). . . . . . 15

Figure 5. Electrobalance Reactor Schematic . . . . 23

Figure 6. Typical Electrobalance Response: One Complete Calcination-Carbonation Cycle . . . .

Figure 7. The Effect of Temperature on Calcination

Kinetics: Sample $1.0 . \quad . \quad . \quad . \quad 30$

Figure 8. The Effect of Temperature on Carbonation

Kinetics: Sample $1 . . \quad . \quad . \quad . \quad 31$

Figure 9. Long-Term Carbonation Results: Sample 1 . . 33

Figure 10. The Effect of $\mathrm{CO}_{2}$ Composition on Carbonation

Kinetics: Samplê 1 . . . . . . 34

Figure 11. The Effect of Gas Composition on Carbonation Kinetics, The Addition of $\mathrm{CO}$ and $\mathrm{H}_{2}$ : Sample 1 . 36

Figure 12. The Effect of Gas Composition on Carbonation Kinetics, The Addition of $\mathrm{CO}, \mathrm{H}_{2} \mathrm{O}$, and $\mathrm{H}_{2}$ : Sample 1

Figure 13. Testing for the Presence of the Shift Reaction: Sample 1

Figure 14. Carbonation Kinetics With Constant $\mathrm{CO}_{2}$ Concentration and Varying Background Gas Composition: Sample 1 Figure 15. Carbonation with $\mathrm{No}_{2} \mathrm{CO}_{2}$ in the Feed Gas:
Sample 1

Figure 16. Comparison of Calcination Kinetics: 
Figure 17. Comparison of Calcination Kinetics:

Samples 1, 3, and 6 . . . . .

Figure 18. Comparison of Carbonation Kinetics:

Samples $1,2,4$, and $5 . \quad . \quad . \quad . \quad 46$

Fjgure 19. Comparison of Carbonation Kinetics:

Samples 1, 3, and $6 \quad . \quad . \quad . \quad . \quad . \quad$. 47

Figure 20. Decomposition-Carbonation Kinetics: Sample $7 \quad$. 49

Pigure 21. Decomposition-Carbonation Kinetics: Sample 8 . 51

Figure 22. Calcination-Carbonation Kinetics: Sample $9 . \quad$. 53

Figure 23. Comparison of First Cycle Carbonation Kinetics:

Samples 1,7 , and $9.0 . \quad . \quad . \quad 54$

Figure 24. Reaction Reproducibility: Runs $4 P 067$ and HPO68

U: ing Sample 7 . $7 \quad$. $\quad . \quad . \quad . \quad . \quad$. 60

Figure 25. The Effect of Calcination lemperature on FirstCycle Carbonation Kinetics: Sample 9. .

Figure 26. The Effect of Calcination Temperature on SecondCycle Carbonation Kinetics: Sample 9. .

Figure 27. The Effect of Carbonation Temperature on Carbonation Kiretics: Sample 1. . .

Figure 28. Comparison of First- and Second-Cycle Carbonation kinetics at $550^{\circ} \mathrm{C}$ : Sample $7 \quad$. $\quad . \quad . \quad . \quad 66$

Figure 29. The Effect of $\mathrm{CO}_{2}$, Composition on First-Cycle Carbonation Kinetics: Sample 1 . . .

Figure 30. The Effect of Pressure at Constant $\mathrm{CO}_{2}$ Mol Fraction: Sample 9 . . . . 2.

rigure 31. The Effect of Pressure at Constant $\mathrm{CO}_{2}$ concentration: Sample $1 . \quad . \quad . \quad$. . . .

Figure 32. Comparison of Carbonation Kinetics: Three Sorbents Through T'wo Cycles

Figure 33. Pore Size Distribution Before and After Calcination: Sample 1 . . . . . . .

Figure 34. The Effect of Calcination Temperature on Pore Size Distribution: Sample 7 


\section{List of Figures}

Figure 35. The Effect of Calcination Time on Pore Size Distribution: Sample 7

Figure 36. Pore Size Distribution of Sample 1: As-Received, After Calcination, and After Carbonation . . 86

Figure 37. Pore Size Distribution of Sample 7: As-Received, After Calcination, and After Carbonation . .

Figure 38. Pore Size Distribution of Sample 9: As-Received, After Calcination, and After Carbonation. . 
Thable I: Description of Calcium-Based Sorbent Precursors.

Table II: Chemical Analysis of Mallinckrodt Analytical

Reagent $\mathrm{CaCO}_{3}$ (Sample 1)

Table III: Chemical Analysis of Mallinckrodt Analytical Reagent Calcium Acetate (Sample 7) . . . 20

Table IV: Chemical Analysis of Dolomite (Sample 9) . . $\quad 22$

Table V: Task 3 Test Matrjx for Sample 1 . . . . . 56

Table VI: Task 3 Test Matrix for Sample 7 . $\quad$. $\quad$. 57

Table VII: Task 3 Test Matrix for Sample 9 . . . . 58

Table VIII: Comparison of First-and Second-Cycle Fractional Carbonation After Twenty Minutes as a Function of: Carbonation T'emperature

Table IX: Comparison of Surface Areas and Pore Volumes of Calcium-Based Sorbents: Uncalcined and Calcined Forms 
EXECUTIVE SUMMARY

This research effort is designed to investigate the technical feasibility of a high-temperature, high-pressure process for the bulk separation of $\mathrm{CO}_{2}$ from coal-derived gases. The two-year contract was awarded in siptember 1989 as a result of solicitation number DE-RA21-89MC26040 entitled "Novel Concepts for Bulk Separation of Gases in Coal Gasification systems." This report describes the research effort and results obtained during the first year of the effort. The overall project consists of 6 tasks, four of which were active during year 0.1 . Tasks 1 and 2 were completed during the year while activity in Tasks 3 and 6 will carry over into year 02. Tasks 4 and 5 will be initiated during year 02 .

Three primary objectives were met in Task 1. A literature search on the calcination-carbonation reactions of $\mathrm{CO}_{2}$ with calcium-based sorbents was completed. A high temperature, high pressure (HTHP) electrobalance reactor suitable for studying the calcination and carbonation reactions was constructed. This reactor system is now fully operable and we are routinely collecting kinetics data at temperatures in the range of $550-900^{\circ} \mathrm{C}$ and pressures of 1 to $15 \mathrm{~atm}$. Samples of nine candidate calcium-based sorbents were acquired and tested. These samples were subjected to reaction screening tests as part of a...ik 2 . On the basis of the screening results, three sorbents were selected for more detailed kinetic tests under Task 3 .

During the time required to secure components and construct the HTHP reactor, an existing atmospheric pressure electrobalance reactor was used to gain general familiarity with the characteristics of the calcination-carbonation reactions and to obtain comparative kinetic behavior from the nine test sorbents. Six of the test sorbents were 
composed primarily of calcium carbonate. One of these samples was chemically pure $\mathrm{CaCO}_{3}$ (99.97\%) while the other five were commercial carbonates obtained from producing quarries. The calcination-carbonation behavior of these samples was found to be qualitatively similar. Complete calcination was easily achieved but the subsquent carbonation reaction effectively stopped at a fractional conversion of approximately 0.8

The limitation on fractional carbonation could be largely overcome by changing the chemical composition of the calcium oxide precursor. Both chemically pure calcium acetate and a commercial dolomite composed of $54.5 \% \mathrm{CaCO}_{3}$ and $45.0 \% \mathrm{MgCO}_{3}$ (by weight) were completely calcined, and greater than $90 \%$ of the calcium was subsequently converted to calcium carbonate. As a result of these screening tests, chemically pure calcium carbonate, chemically pure calcium acetate, and the commercial dolomite were selected for more detailed kinetic testing.

In Task 3, the HTHP electrobalance reactor is being used to study the calcination-carbonation behavior of the three base sorbents as a function of calcination temperature, carbonation temperature, carbonation pressure, and $\mathrm{CO}_{2}$ concentration. Each test consists of two complete calcination-carbonation cycles to provide kinetics data and to obtain first indications of sorbent performance in multicycle operation. In addition to studying the effects of the primary reaction parameters listed previously, limited tests have been or will be conducted to examine the effect of calcination pressure, calcination gas composition, and background gas composition during carbonation. At this half way point in the overall project, approximately one-half of the Task 3 testa have been completed. 
Tasks 4 and 5 have not yet been initiated. In this effort, one of the three sorbents tested in Task 3 will be selected for more detailed kinetic testing including additional cycles and the effect of typical coal-gas impurities such as $\mathrm{H}_{2} \mathrm{~S}$.

structural property characterization of the sorbents as-received, after calcination, and after carbonation comprise Task 6 activities. Testing to date has concentrated upon pore volume and pore size distribution measurements using mercury porosimetry and BET surface area determination. This work will be extended during year 02 to include helium pycnometry and scanning electron microscopy. In all of the test sorbents, calcination produced an increase in pore volume as the volatile components, primarily $\mathrm{CO}_{2}$ except in the case of calcium acetate, were driven off. Surface area changes following calcination were less predictable; both increased and decreased surface areas have been measured. Subsequent carbonation of the sorbent causes a decrease in pore volume as $\mathrm{CO}_{2}$ enters the solid phase. In the case of the pure calcium carbonate sorbent where carbonation stops well short of completion, the pore volume of the final carbonated product is extremely small. For both the calcium acetate and dolomite sorbents where complete carbonation is closely approached, the carbonated product. retains appreciable pore volume, thereby providing paths of access for the $\mathrm{CO}_{2}$ to the interior of the solid. 


\section{TASK 1: INTRODUCTION AND PRELIMINARY EFFOR'T}

An important responsibility of the U.S. Department of Energy is the development of new technology which will promote the use of the nation's vast reserves of coal, thereby decreasing our dependence on imported petroleum. Coal gasification technology offers the opportunity for achieving the above objective, while at the same time improving process energy efficiency and reducing the adverse environmental impact associated with present coal utilization processes. Prior DOE research has concentrated upon the development of novel gasification processes, improving existing processes, and in developing technology for the removal of trace impurities present in the coal-derived gas.

The current DOE program seeks to develop novel concepts for the bulk separation of gases from product streams which will provide further improvements in gasification process efficiency and economics. Gas stream components subject to bulk separation include carbon dioxide, carbon monoxide, hydrngen, nitrogen, and methane; separation processes should operate within a temperature range of 100 to $700^{\circ} \mathrm{C}$.

This particular project is examining the technical feasibility of a HTHP process for the bulk separation of $\mathrm{CO}_{2}$ based upon the reveribible reaction between $\mathrm{CO}_{2}$ and $\mathrm{CaO}$.

$$
\mathrm{CaO}(\mathrm{s})+\mathrm{CO}_{2}(\mathrm{~g}) \longrightarrow \mathrm{CaCO}_{3}(\mathrm{~s})
$$

The ability to achieve HTHP bulk separation of $\mathrm{CO}_{2}$ may have a positive effect on a number of processes in which coal-derived gas is utilized. These include heating value, upgrade, hydrogen production, ammonia or methanol synthesis gas manufacture, and the operating efficiency of molten carbonate fuel cells. In addition, $\mathrm{CaCO}_{3}$ decomposition may 
produce high-purity $\mathrm{CO}_{2}$ which can be marketed as a refrigerant, for use in fire extinguishers, for beverage carbonation, or for improved petroleum recovery.

The research is limited to a laboratory-scale experinental effort using an electrobaiance reactor to identify appropriate ranges of temperature, pressure, and gas composition for both the forward and reverse reactions. A number of CaO-based sorbents having different chemical composition and structural properties are being investigated to define those properties required to achieve both high reactivity and acceptable sorbent durability.

\section{LITERATURE SURVEY}

The calcination of limestone for lime production is one of the largest tonnage commercial reactions carried out world-widle. Modern lime kilns operate at atmospheric pressure with temperature in the range of 1200 to $1300^{\circ} \mathrm{C}$. This temperature, which is well in excess of the minimum decomposition temperature, is necessary to insure that limestone lumps are completely calcined during their passage through the kiln. The calcination reaction, of course, forms the basis of the sorbent regeneration step in the proposed $\mathrm{HrHP}^{\mathrm{CO}} \mathrm{CO}_{2}$-separation process. The primary $\mathrm{CO}_{2}$ removal reaction, which is the reverse of the calcination reaction, is not carried out commercially.

The propused HTHP $\mathrm{CO}_{2}$ separation process is based upon a thermodynamic analysis of the reversible reaction. The equilibrium constant, expressed in terms of component activities. may be calculated from the Gibbs free energy by the well-known equation 


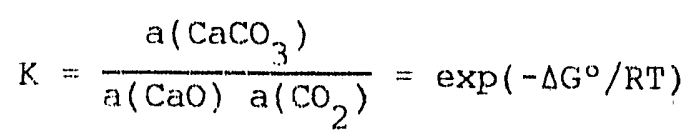

If one assumes that pure solid phases are present, $\mathrm{a}\left(\mathrm{CaCO}_{3}\right)=\mathrm{a}(\mathrm{CaO})=$ 1, and if the gas phase is ideal, $\mathrm{a}\left(\mathrm{CO}_{2}\right)=\mathrm{P}\left(\mathrm{CO}_{2}\right)$, so that

$$
\mathrm{P}\left(\mathrm{CO}_{2}\right)=\mathrm{K}^{-1}=\exp \left(\Delta \mathrm{G}^{\circ} / \mathrm{RT}\right) \text {. }
$$

Figure 1 shows calculated values of $\mathrm{P}\left(\mathrm{CO}_{2}\right)$ over $\mathrm{CaO}$ as a function of temperature using thermochemical data from Hougen et al. (1959). At $650^{\circ} \mathrm{C}, \mathrm{P}\left(\mathrm{CO}_{2}\right) \sim 0.008 \mathrm{~atm}$. Therefore, at that temperature whenever $\mathrm{P}\left(\mathrm{CO}_{2}\right)>0.008$ atm, the reaction should proceed to the right (carbonation). When $\mathrm{P}\left(\mathrm{CO}_{2}\right)<0.008 \mathrm{~atm}$, thermodynamics would favor carbonate decomposition. If an entering gas at $650^{\circ} \mathrm{C}$ and 15 atm contained 15\% $\mathrm{CO}_{2}$, it is theoretically possible to achieve $99.6 \% \mathrm{CO}_{2}$ removal. With lower temperatures, higher pressures, and/or higher inlet $\mathrm{CO}_{2} \mathrm{mo}$. fractions, still greater $\mathrm{CO}_{2}$ removal efficiencies are theoretically possible.

The possibility of using the forward carbonation reaction for $\mathrm{CO}_{2}$ separation was considered at least as early es the 1920's. Gluud et al. (1931) patented a process for producing hydrogen via a water-gas shift. reaction using calcined dolomite. The Mgo component of the calcined dolomite was claimed to be responsible for the shift catalysis while Cao reacted with the $\mathrm{CO}_{2}$ product, thereby continually shifting the reaction to the right and permitting essentially complete removal of carbon oxides from the gas stream, and the production of high-purity hydrogen.

Squires (1967) revived the concept by suggesting the use of dual. fluidized-bed reactors to permit steady-state operation and to overcome some of the heat transfer problems associated with Gluud's fixed-bed 


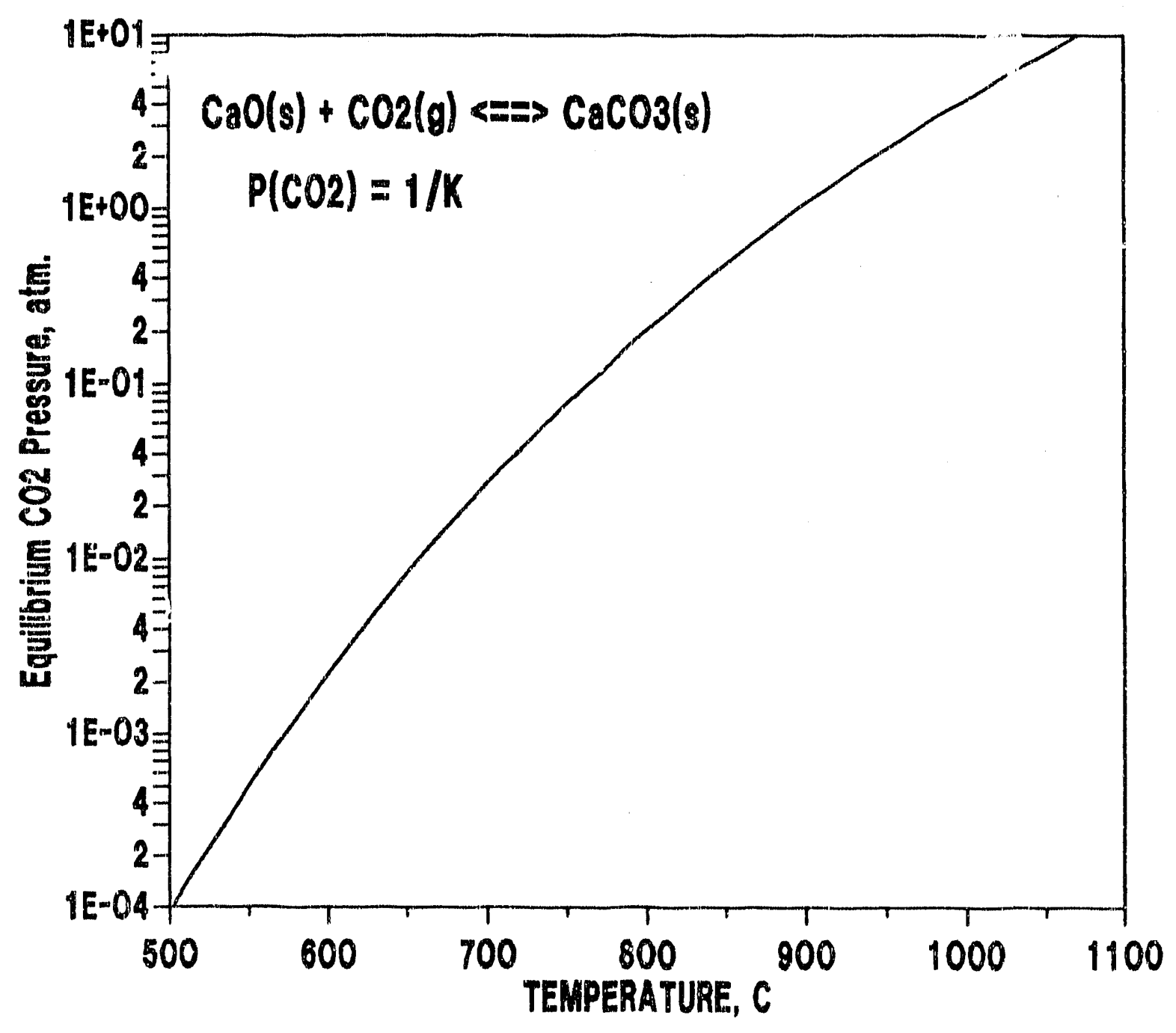

Figure 1. Equilibrium $\mathrm{CO}_{2}$ Pressure as a Function of Temperature. 
concept. Squires also proposed the use of calcined dolomite with Mgo serving as the shift catalyst aind $\mathrm{CaO}$ used to react with $\mathrm{CO}_{2}$. Also in the 1960's, the $\mathrm{CO}_{c}$, acceptor process (Curran et al., 1967) was studied as a possible means for the simultaneur; removal of $\mathrm{H}_{2} \mathrm{~S}$ and $\mathrm{CO}_{2}$ from coal-derived gases. Dolomite was used in a fluidized-bed reactor and the sorbent gas was subjected to numerous carbonation-calcination cycles. Each of these studies concentrated upon the process aspects and little or no fundamental kinetics data were reported. Reliable and highly efficient. low temperature processes for $\mathrm{CO}_{2}$ removál wers available, and research on the high-temperature process was terminated.

On a more fundamental level, Dedman and Owen (1962) studied the reaction of $\mathrm{CO}_{2}$ with calcined limestone over the temperature range of 100 to $600^{\circ} \mathrm{C}$ and the pressure range of 10 to $600 \mathrm{mmHg}$. The initial reaction was found to be very rapid followed by an abrupt transition to a much slower reaction. The slower second stage was attributed to a Frocess controlled by diffusion of $\mathrm{CO}_{2}$ in the pores of the solid. An activation energy of $9.5 \pm 2 \mathrm{kcal} / \mathrm{mol}$ between 200 and $600^{\circ} \mathrm{C}$ was reported for the diffusion-controlled second stage. It is interesting to note that this is the first instance in which the carbonation reaction was reported to occur in two stages. Such behavior has been regularly reported since.

Two studies by Barker (1973 and 1974) on the $\mathrm{CaO}-\mathrm{CO}_{2}$ reaction provide results which are revelvant to the current study. The reaction was studied in an electrobalance reactor at $866^{\circ} \mathrm{C}$ and 1 atmosphere using calcium carbonate particles in the range of 2 to 20 micron diameter. Figure 2 (from Barker, 1973) shows a typical electrobalance response to numerous calcination-carbonation cycles (curve b). Calcination, which is 


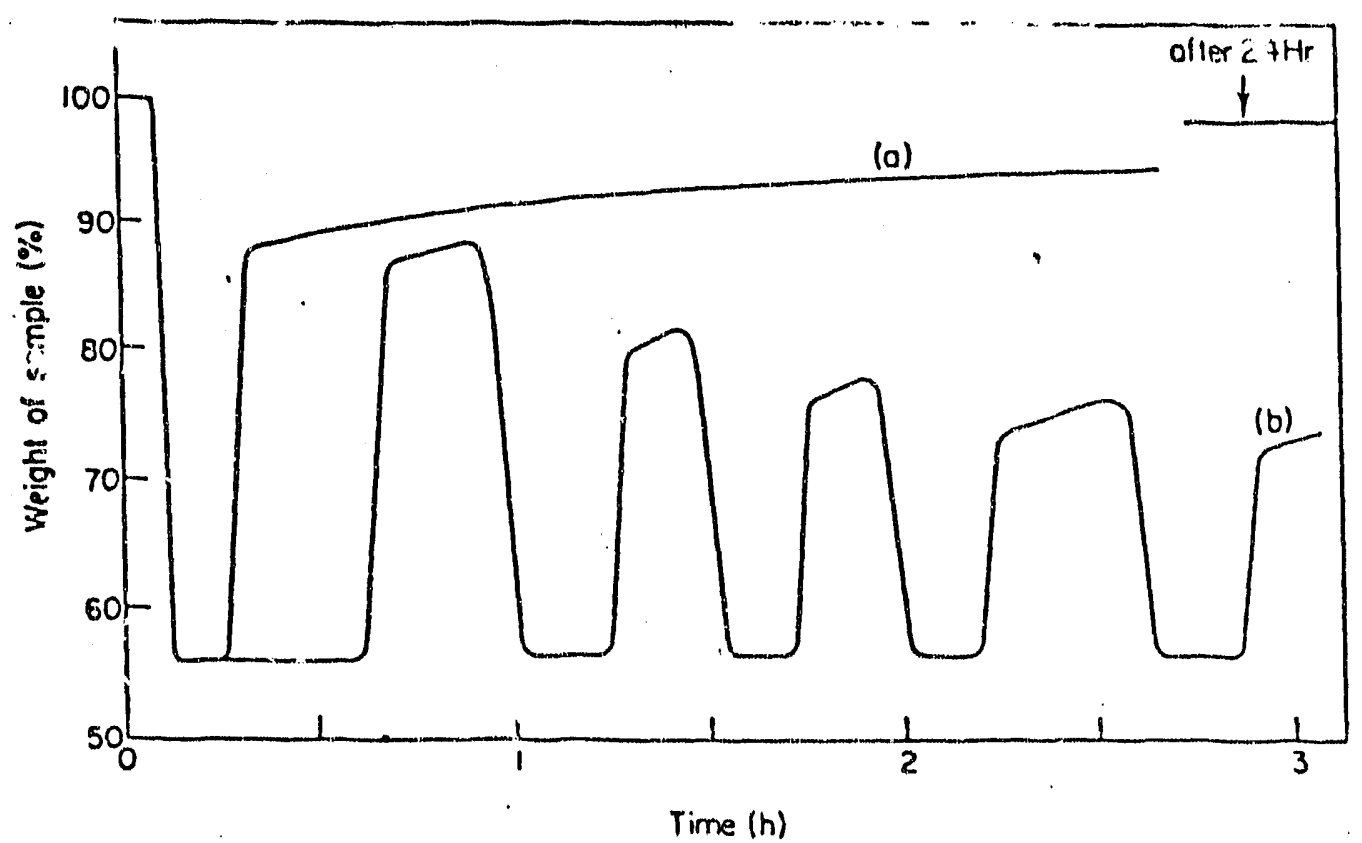

Figure 2, Calcination-Carbonation Test Results from Barker (1973). 
represented by the weight loss from $100 \%$ to $56 \%\left[\mathrm{M}\left(\mathrm{CaCO}_{3}\right)=100, \mathrm{M}(\mathrm{CaC})\right.$ $=56]$, was rapid and complete. Carbonation, represented by the weight gain, was initially rapid but the reaction rate dropped off to near zero well short of completion. Calcination was complete in each cycle but the transition from the rapid to the slow reaction rate occurred at progressively sma?ler values of fractional carhonation with increasing cycle number. The fact that the reaction does not completely stop after the initial rapid rate is shown by curve (a) in which a single carbonation test was extended for 24 hours, at the end of which time the sample weight had increased to approximataly $98 \%$.

Such reaction behavior can be explained on the basis of the varying structural characteristics of the reacting solid as the calcinationcarbonation reactions progress. Natural limestones comonly possess quite low porosity. However, the calcination reaction creates porosity as $\mathrm{CO}_{2}$ is driven off. During carbonation the pores are refilled. The refilling process occurs preferentially at the exterior of the particle, and the end of the rapid reaction period is presumed to correspond to total surface pore closure. The remaining unreacted cao within the particle is carbonated very slowly since $\mathrm{CO}_{2}$ must diffuse via a solid state or ionic mechanism through the nonporous carbonate layer. Similar probiems of pore closure are faced when calcium oxide is used for $\mathrm{SO}_{2}$ removal in flue gas desulfurization applications.

In his second paper, Barker (1974) used extremely small particles of approximately $20 \mathrm{~nm}$ diameter to minimize the quantity of CaO which could be isolated within the particles after pore closure. Calcination was carried out at $629^{\circ} \mathrm{C}$ and 1 atmosphere in $\mathrm{N}_{2}$, and carbonation at $577^{\circ} \mathrm{C}$ under 1 atmosphere of $\mathrm{CO}_{2}$. Approximately $93 \%$ carbonation was 
achieved during the rapid reaction phase and this value remained essentially constant through 30 complete cycles. While this latter study is of importance in understanding the mechanism of the carbonation reaction, the use of such small particles is not feasible in a commercial process.

Oakeson and cutler (1979) studied the CaO-CO 2 reaction using an electrobalance over a temperature range of 853 to $1044^{\circ} \mathrm{C}$ under $\mathrm{CO}_{2}$ pressures between 2.35 and 24.9 atmospheres. The rate of reaction was reported to follow a parabolic correlation with time, while the pressure dependerice was related to a Langmuir-type adsorption isotherm. The reaction was reported to be diffusion controlled with a diffusion activation energy of $29 \pm 6 \mathrm{kcal} / \mathrm{mol}$.

Bhatia and Perlmutter (1983) investigated the kinetics of the $\mathrm{CO}_{2}-\mathrm{CaO}$ reaction using a $\mathrm{CO}_{2}-\mathrm{N}_{2}$ mixture at one atmosphere over the temperature range of 400 to $725^{\circ} \mathrm{C}$. Their data were analyzed using a random pore model (Bhatia and Perlmutter, 1980 and 1981) and the average value of the rate constant during the initial rapid reaction period was found to be $0.0595 \pm 0.0018 \mathrm{~cm}^{4} / \mathrm{mol} \cdot \mathrm{s}$. The slow second phase was reported to be diffusion controlled with an activation energy of $88.9 \pm$ $3.6 \mathrm{~kJ} / \mathrm{mol}$ below $515^{\circ} \mathrm{C}$ and $179.2 \pm 7 \mathrm{~kJ} / \mathrm{mol}$ above $515^{\circ} \mathrm{C}$. $515^{\circ} \mathrm{C}$ was claimed to be near the ramman temperature of $\mathrm{CaCO}_{3}$ (about $533^{\circ} \mathrm{C}$ ), where a change in the solid state diffusion mechanism was said to occur.

Delucia (1985) studied the multicycle behavior of the calcinationcarbonation reactions using $\mathrm{CO}_{2}$ at atmospheric pressure over the temperature range of 50 to $800^{\circ} \mathrm{C}$. The carbonation reactivity decreased by 10 to $25 \%$ per cycle, which was attributed to continued particle shrinkage during calcination. 
Dhupe and Gokarn (1987 and 1990) mixed inert solid with calciumbased sorbent pellets and studied the reaction with $\mathrm{CO}_{2}$. Metallurgical grade silicon powders were used as the inert, while they reported a maximurn $\mathrm{CO}_{2}$ uptake capacity at a particular inert concentration, no clear explanation of the results was presented.

Finally, Mess (1989) studied the diffusion procass through the $\mathrm{CaCO}_{3}$ product layer using an electrobalance under $\mathrm{CO}_{2}$ pressures up to 12 atmospheres at temperatures from 550 to $1050^{\circ} \mathrm{C}$. At termperatures of $600^{\circ} \mathrm{C}$ and above, the product layer contained crystalline grains whose size varied from 1 to 20 microns. The $\mathrm{CaCO}_{3}$ grains grew laterally and were temperature dependent. Above $900^{\circ} \mathrm{C}$, the reaction was first-order in $\mathrm{CO}_{2}$ pressure and the activation energy in the diffusion controlled region was $56.9 \mathrm{kcal} / \mathrm{mol}$.

A closely related reaction, the sulfation of Cao,

$$
\mathrm{CaO}(\mathrm{s})+\mathrm{SO}_{2}(\mathrm{~g})+\frac{1}{2} \mathrm{O}_{2}(\mathrm{~g}) \rightarrow \mathrm{CaSO}_{4}(\mathrm{~g})
$$

has been the subject of a great deal of research as a potential method for $\mathrm{SO}_{2}$ control in flue gas desulfurization applications. One study in particular (Hartman et al., 1978) provides information which is directly applicable to the carbonation reaction. The effect of porosity of the calcium carbonate sorbent precursor on the sulfation reaction was esamined. While the initial pore volume of most limestones is low ( $\leq$ $\left.0.05 \mathrm{~cm}^{3} / \mathrm{g}\right)$, related natural carbonate products such as chalks and marls may have initial pore volumes in the range of 0.1 to $0.2 \mathrm{~cm}^{3} / \mathrm{g}$ and 0.25 to $0.9 \mathrm{~cm}^{3} / \mathrm{g}$, respectively (Boynton, 1980).

Hartman et al. (1978) showed that the porosity of the calcined product. ( $\mathrm{CaO}$ ) was a strong function of the porosity of the natural rock 
$\left(\mathrm{CaCO}_{3}\right)$. Figure 3 shows test results which include limestones, chalks, and marls as precursors. The straight lines in the figure are from the nquation

$$
\varepsilon_{C O}=1-\varepsilon_{C C}\left[y\left(\frac{V_{C O}}{V_{C C}}-1\right)+1\right]
$$

where $\varepsilon$ represents porosity, $V$ is the molar volume, and $y$ is the fractional purity. The subscript CC represents the original calcium carbonate starting material and the subscript co presents the calcined product, calcium oxide. Values of $\mathrm{V}_{\mathrm{CO}}=16.6 \mathrm{~cm}^{3} / \mathrm{mol}$ and $\mathrm{v}_{\mathrm{CC}}=36.9$ $\mathrm{cm}^{3} / \mathrm{mol}$ were assigned along with values of $\mathrm{y}=0.8,0.9$, and 1.0 to obtain the straight lines. The correlation between measured precursor and product porosities and the geometric arguments represented by the equation is quite good. Calcines from nonporous limestones had porosities in the range of 0.5 to 0.55 , while chalks and marls produced calcines having porosities as high as 0.69 and 0.85 , respectively.

Subsequent sulfation results shown in Figure 4 (Hartman et al., 1978) illustrate the importance of the calcine porosity on the progress of the sulfation reaction. Using nonporous limestone precursor $\left(\varepsilon_{\mathrm{LS}}=\right.$ $0)$, the fractional sulfation was less than 0.3 after 60 minutes. The moderate porosity chalk ( $\left.\varepsilon_{\text {LS }}=0.27\right)$ resulted in 0.6 to 0.7 fractional sulfation after 60 minutes (depending upon particle size), while the calcine from the high porosity marl $\left(\varepsilon_{\text {LS }}=0.71\right)$ was completely sulfated in approximately 20 minutes.

Finally, in any review of the use of calcium-based sorbents in noncatalytic gas-solid reactions, one would be remiss in not mentioning at least some of the work of Borgwardt. One paper (Borgwardt, 1989) 


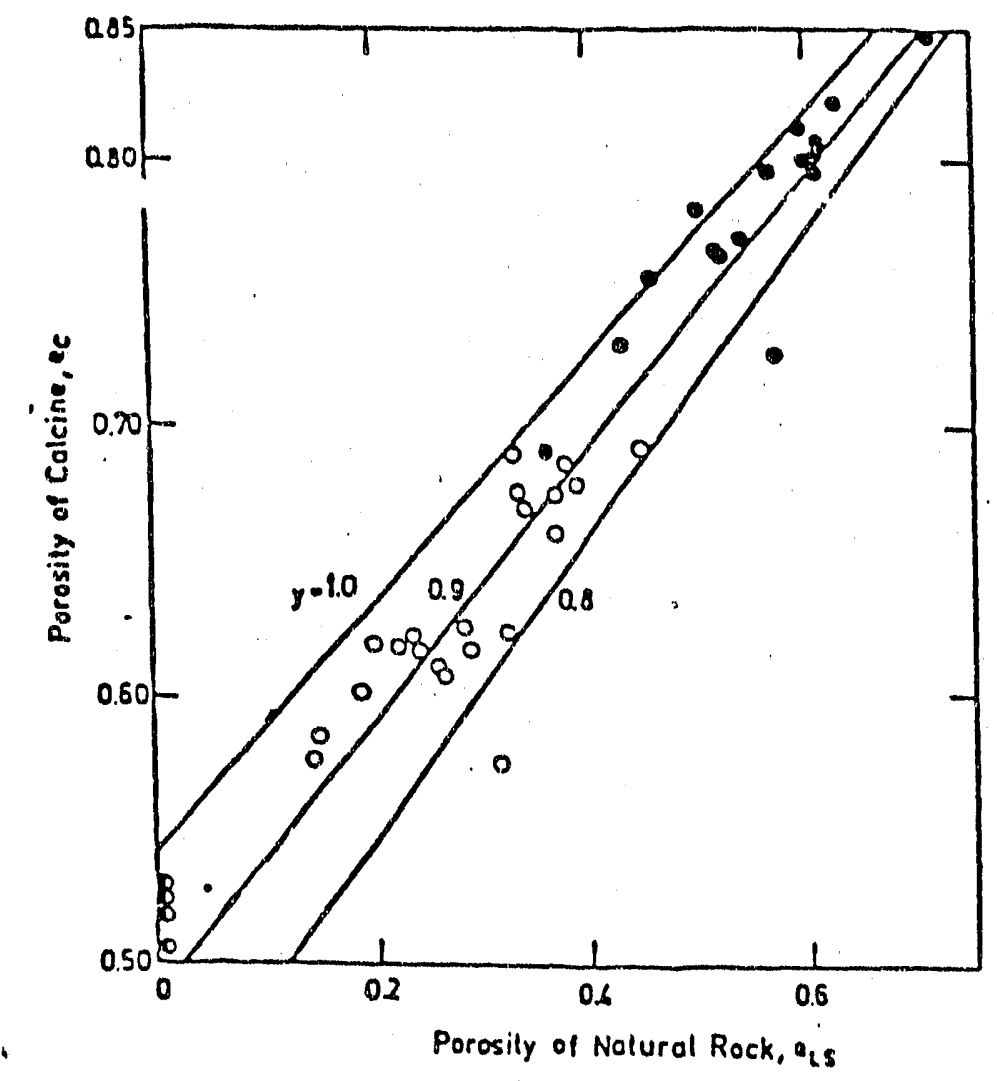

Figure 3. Porosity of the Calcine as a Function of the Porosity of the Precursor (Hartman et a1., 1978). 


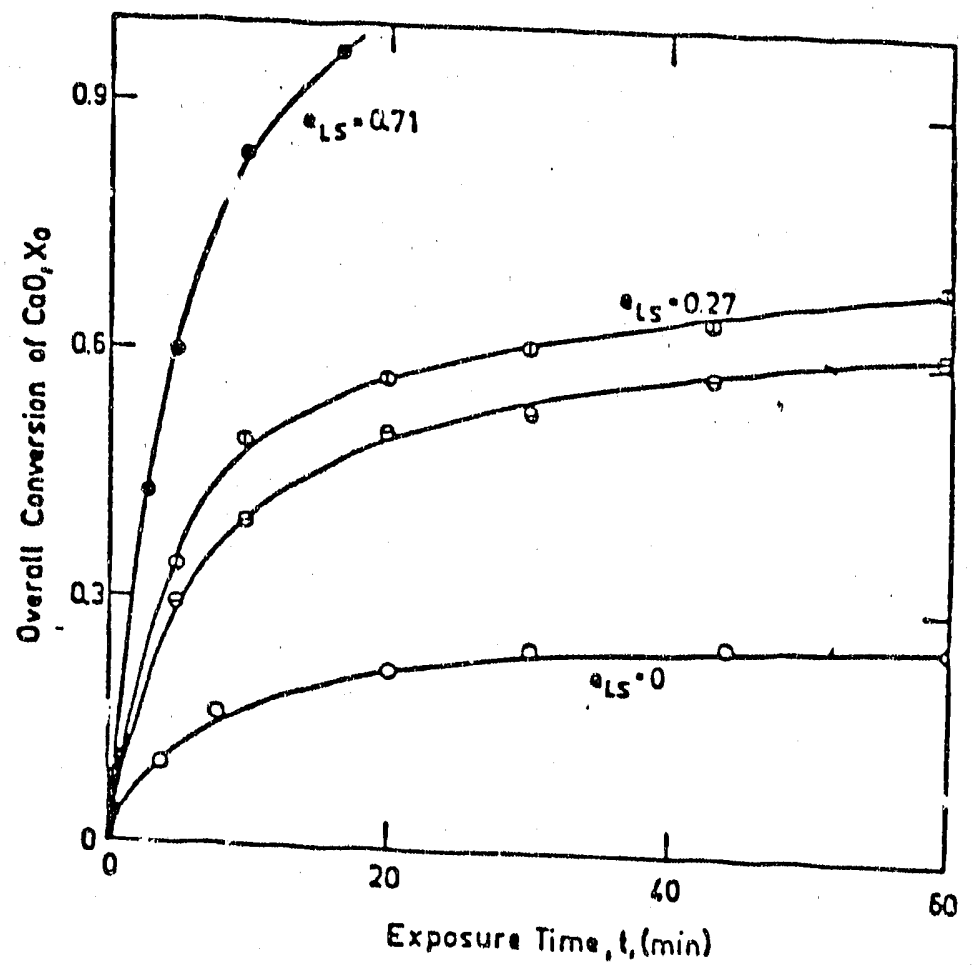

Figure 4. The Extent of Calcium Oxide Sulfation as a Function of the Porosity of the Precursor (Hartman et a1., 1978). 
will provide a point of entry which the reader can use to trace back the numerous contributions made by Borgwardt and associates.

The literature provides guidance into the expected behavior of the CaO- $\mathrm{CO}_{2}$ reaction in several areas. In general, the carbonation reaction is characterized by a rapid initial reaction period followed by an abrupt transition to a slow reaction phase well short of complete calcium conversion. This behavior seems to be related to pore closure at the exterior surface of the particle which prevents $\mathrm{CO}_{2}$ from reaching unreacted $\mathrm{CaO}$ at the interior of the particle. Multicycle tests generally show decreased reactivity with each carbonation cycle, a phenomenon consistent with particle shrinkage and associated reduction in porosity. At least one paper (Bhatia and Perlmutter, 1983) implies that exceeding the Tamman temperature of $\mathrm{CaCO}_{3}$ could be responsible for the skrinkage.

The literature also suggests possible ways of avoiding or at least delaying the transition from the rapid to the slow reaction phase to obtain increased fractional calcium utilization. Decreasing the sorbent particle size appears to be an effective, but commercially impractical, method. Nanometer diameter particles used by Barker (1974) require special preparation techniques and would be impossible to confine in a commercial process. Increasing the porosity of the sorbent by using a high-porosity precursor such as described by Hartman et al. (1978) seems to be a more promising option. other options of increasing and/or maintaining porosity during calcination and carbonation include the addition of inerts to the sorbent and using other sorbent precursors.

Although a number of previous studies on the behavior of the CaO- $\mathrm{CO}_{2}$ reaction have been cited, none provide the broad scope of work 
necessary to evaluate fully the feasibility of a CaO-based high-temperature $\mathrm{CO}_{2}$ removal process. The process patent of Gluud et al. (1971) does not contain any fundamental kinetic data. Similarly, squires (1967) paper presents a conceptual modification to Gluud's process but again without the necessary kinetic data. Many of the more fundamental studies have examined only a narrow range of conditions such as a single pressure, or a single sorbent, or only a single carbonation cycle. The objectives of the present study are to build upon this past work by studying a number of sorbents having a wide variation in structural properties, to determine the effects of the important reaction parameters over a range of conditions likely to be encountered in a commercial process, and to develop information on sorbent durability through multi-cycle testing. The kinetic data will be supplemented with key structural property measurements of the sorbents at various stages in the reaction cycles.

\section{SORBENT SELECTION}

A total of nine calcium-based sorbents have been acquired and subjected to preliminary screening tests (see Task 2). A general description of the sorbents is presented in Table I. Sorbent selection was based upon availability and also upon the desirable pronerties identified in the literature search. Sample 1, reagent-grade $\mathrm{CaCO}_{3}$ from Mallinckrodt was selected as the base sorbent against which others would be compared. Samples 2 through 6 were all commercial-grade $\mathrm{CaCO}_{3}$ obtained from producing quarries. Limestone, chalk, and marl were included in this group in the hopes of matching the type of results shown in Figure 4 by Hartman et al. (1978). Instead, as will be shown, 
Table I

Description of Calcium-Based sorbent Precursors.

\begin{tabular}{|c|c|c|}
\hline Sample No. & General Description & Source \\
\hline 1 & $\begin{array}{l}\text { Reagent grade calcium } \\
\text { carbonate, } \mathrm{CaCO}_{3}\end{array}$ & Mallinckrodt Chemicals \\
\hline 2 & Marl from producing quarry & $\begin{array}{l}\text { Gifford-Hill Co. } \\
\text { Harleyville, SC }\end{array}$ \\
\hline 3 & Chalk from producing quarry & $\begin{array}{l}\text { United Cement Co. } \\
\text { Artesia, MS }\end{array}$ \\
\hline 4 & Chalk from producing quarry & $\begin{array}{l}\text { Texas Crushed Stone Co. } \\
\text { Georgetown, IX }\end{array}$ \\
\hline 5 & $\begin{array}{l}\text { timestone from newly } \\
\text { developed quarry in } \\
\text { Yucatan, Mexico }\end{array}$ & $\begin{array}{l}\text { Vulcan Materials Co. } \\
\text { Houston, TX }\end{array}$ \\
\hline 6 & Chalk from producing quarry & $\begin{array}{l}\text { Gifford-Hill Co. } \\
\text { Midlothian, TX }\end{array}$ \\
\hline 7 & $\begin{array}{l}\text { Reagent grade calcium } \\
\text { acetate, } \mathrm{Ca}\left(\mathrm{C}_{2} \mathrm{H}_{3} \mathrm{O}_{2}\right)_{2} \cdot \mathrm{x} \\
\mathrm{H}_{2} \mathrm{O}\end{array}$ & Mallinckrodt Chemicals \\
\hline 8 & $\begin{array}{l}\text { Reagent grade calcium } \\
\text { sulfate, } \mathrm{CaSO}_{4} \cdot 2 \mathrm{H}_{2} \mathrm{O}\end{array}$ & Mallinckrodt Chemicals \\
\hline 9 & Dolomite, $\mathrm{CaCO}_{3} \cdot \mathrm{MgCO}_{3}$ & $\begin{array}{l}\text { National Lime Co. } \\
\text { Findley, OH }\end{array}$ \\
\hline
\end{tabular}


Table II Chemical Analysis of Mallinckrodt Analytical Reagent $\mathrm{CaCO}_{3}$ (Sample 1), Chelometric Standard (as reported by Mallinckrodt)

\begin{tabular}{|c|c|}
\hline $\mathrm{CaCO}_{3}$ & $99.97 \%$ (after 2 hours at $285^{\circ} \mathrm{C}$ ) \\
\hline Alkalinity & Passes Test \\
\hline Ammonium $\left(\mathrm{NH}_{4}\right)$ & $0.002 \%$ \\
\hline Barium ( $\mathrm{Ba}$ ) & $0.002 \%$ \\
\hline Chloride ( $\mathrm{Cl})$ & $0.001 \%$ \\
\hline F'lucride $(F)$ & $0.0009 \%$ \\
\hline Heavy Metals (as Pb) & $0.0005 \%$ \\
\hline Insoluble in $\mathrm{HCl}$ and $\mathrm{NH}_{4} \mathrm{OH}$ ppt & $0.00025 \%$ \\
\hline Iron $(\mathrm{Fe})$ & $<0.0002 \%$ \\
\hline Magnesium (Mg) & $0.0006 \%$ \\
\hline other Alkaljs & Passes Test \\
\hline Oxidizing substances (as $\mathrm{NO}_{3}$ ) & $<0.005 \%$ \\
\hline Potassium (K) & $0.0006 \%$ \\
\hline Silica $\left(\mathrm{SiO}_{2}\right)$ & $<0.0006 \%$ \\
\hline Silicon (Si) & $0.0003 \%$ \\
\hline Sodium (Na) & $0.002 \%$ \\
\hline Strontum (Sr) & $0.006 \%$ \\
\hline Sulfate $\left(\mathrm{SO}_{4}\right)$ & $<0.0025 \%$ \\
\hline
\end{tabular}


Table III. Chemical Analysis of Mallinckrodt Analytical. Reagent Calcium Acetate (Sample 7) (as reported by Mallinckrodt)

$\begin{array}{lc}\mathrm{Ca}\left(\mathrm{C}_{2} \mathrm{H}_{3} \mathrm{O}_{2}\right)_{2} & >91.47 \% \\ \text { Barium ( } \mathrm{Ba}) & <0.005 \% \\ \text { Chloride }(\mathrm{Cl}) & <0.001 \% \\ \text { Heavy Metals (as Pb) } & <0.001 \% \\ \text { Iron (Fe) } & <0.001 \% \\ \text { Magnesium and Alkali Salts } & <0.2 \% \\ \left.\text { Sulfate ( } \mathrm{SO}_{4}\right) & <0.01 \% \\ \text { Water } & 8.3 \%\end{array}$


the calcination-carbonation behavior of samples 1 through 6 was qualitatively similar.

Sorbents 7 and 8 , reagent-grade calcium acetate and reagent-grade calcium sulfate, respectively, were selected in the hope that their decomposition would yield a higher porosity $\mathrm{CaO}$ in which the rapid reaction phase would be extended to higher fractional calcium utilization. Finally, sorbent 9 , which is a commercial dolomite containing approximately equal molar quantities of $\mathrm{MgCO}_{3}$ and $\mathrm{CaCO}_{3}$, was tested to evaluate the effect of an inert on the carbonation reaction. At reaction conditions, both $\mathrm{MgCO}_{3}$ and $\mathrm{CaCO}_{3}$ are calcined to their respective oxides; both components, therefore, are effective in creating porosity during calcination. At carbonation conditions $\mathrm{Mgo}$ is inert so that pore closure due to $\mathrm{CaCO}_{3}$ formation should be moderated, and open pores for $\mathrm{CO}_{2}$ diffusion should remain.

On the basis of the screening tests, three sorbents - samples 1,7 , and 9 - were selected for more detailed testing in Task 3 . Chemical analyses of the three selected sorbents are presented in Tables II, III, and IV. More detailed structural property results for these samples are reported subsequently in this report.

\section{HJGH-TEMPERATURE HIGH-PRESSURE ELECTROBALANCE REACTOR}

The high-pressure electrobalance reactor system shown schematically in Figure 5 has been constructed and is now being used in the Task 3 test program. The key component of this reactor is a Cahn Model $\mathrm{C}-100$ pressure balance having $100 \mathrm{~g}$ capacity and $10 \mathrm{\mu g}$ sensitivity. The housing and hang-down tube are constructed of 316 stainless steel and the unit is rated for $1500 \mathrm{psig}$ at $600^{\circ} \mathrm{C}$. Gases from high-pressure 


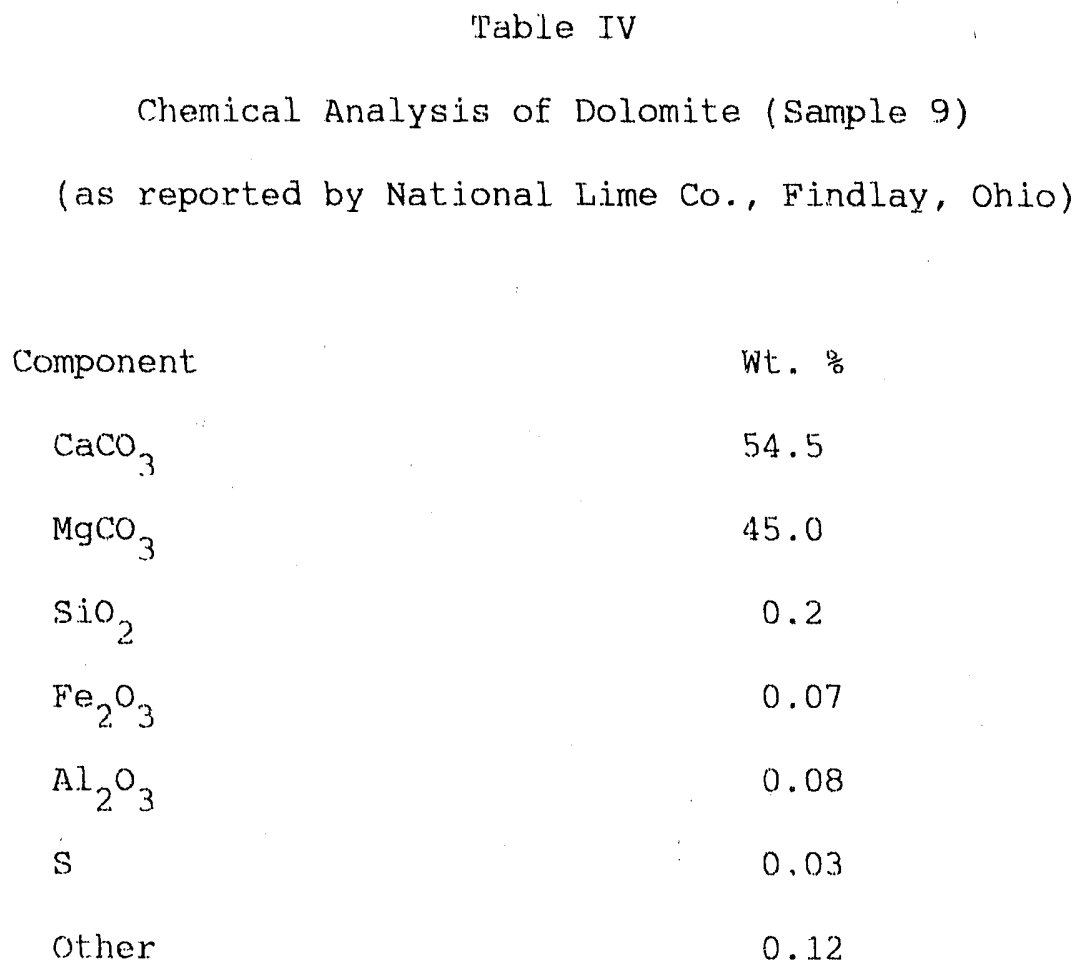

Loss on ignition after calcination

at $1800^{\circ} \mathrm{F}-47.4 \%$ 


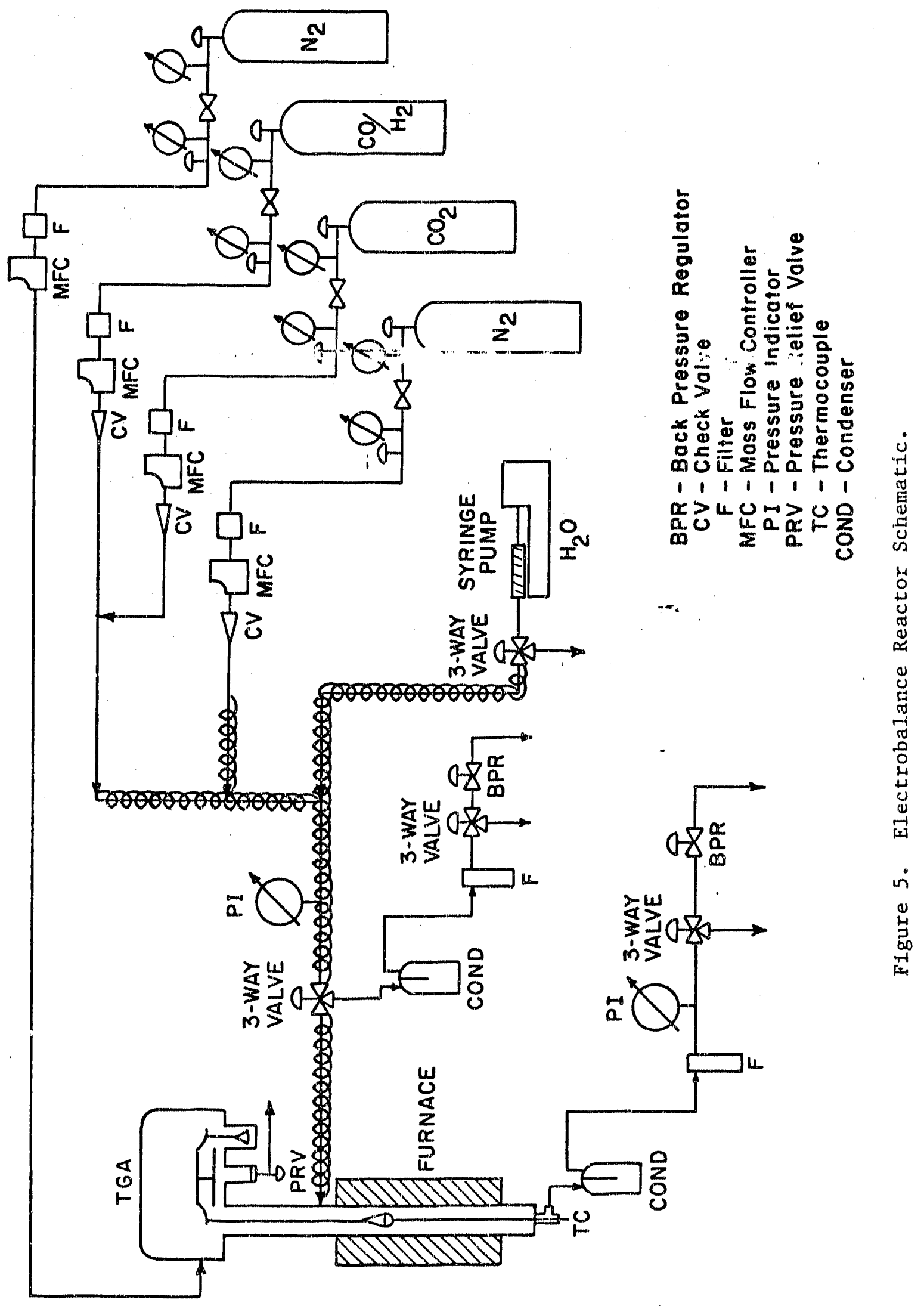


cylinders are fed to the reactor using high pressure mass flow controllers (Porter Instruments Model 201). Water may be added to the feed mixture using a high-pressure syringe pump (Harvard Apparatus Model 909). The gas feed line leading to the side-arm of the hang-down tube is heat traced to induce water vaporization. Inert gas $\left(\mathrm{N}_{2}\right)$ which is fed 'O the balance housing joins with reactive gases $\left(\mathrm{N}_{2}, \mathrm{CO}, \mathrm{CO}_{2}, \mathrm{H}_{2}\right.$ ' and $\mathrm{H}_{2} \mathrm{O}$ ) which enter through the side-arm and the combined gases flow downward over the solid reactant. At typical tests conditions the volumetric flow rate of inert through the balance housirg was 300 $\mathrm{cm}^{3} / \min$ (STP) while the total flow of reactive gases through the reactor side-arm was $200 \mathrm{~cm}^{3} / \mathrm{min}$ (STP). Exit gases pass first through a condenser and are venteà either through a three-way valve for atmospheric pressure tests or through a back-pressure regulator (Tescom Model 26-232-24-0301) for high pressure tests. A similar condenser, three-way valve, back-pressure regulator arrangement is provided in the side-arm gas feed line. Reactive gas flow rate and pressure adjustments are made while directing the gases to vent. Subsequently switching the three-way valve in the side-arm feed line permits reactive gases to be introduced to the reactor with minimum system upset and time delay.

Reactor temperature is maintained using a single-zone split-tube furnace (Applied Test Systems Series 3210) equipped with a single-zone temperature controller which is microprocessor programable for up to eight ramp and soak intervals. An over-temperature controller provides protection against temperature run-away.

An IBM PS/2 Model 30/286 computer is provided to acquire, store, and process sampie weight, reactor cemperature, and mass flow controller readings. A data interface package and software supplied by Cahn 


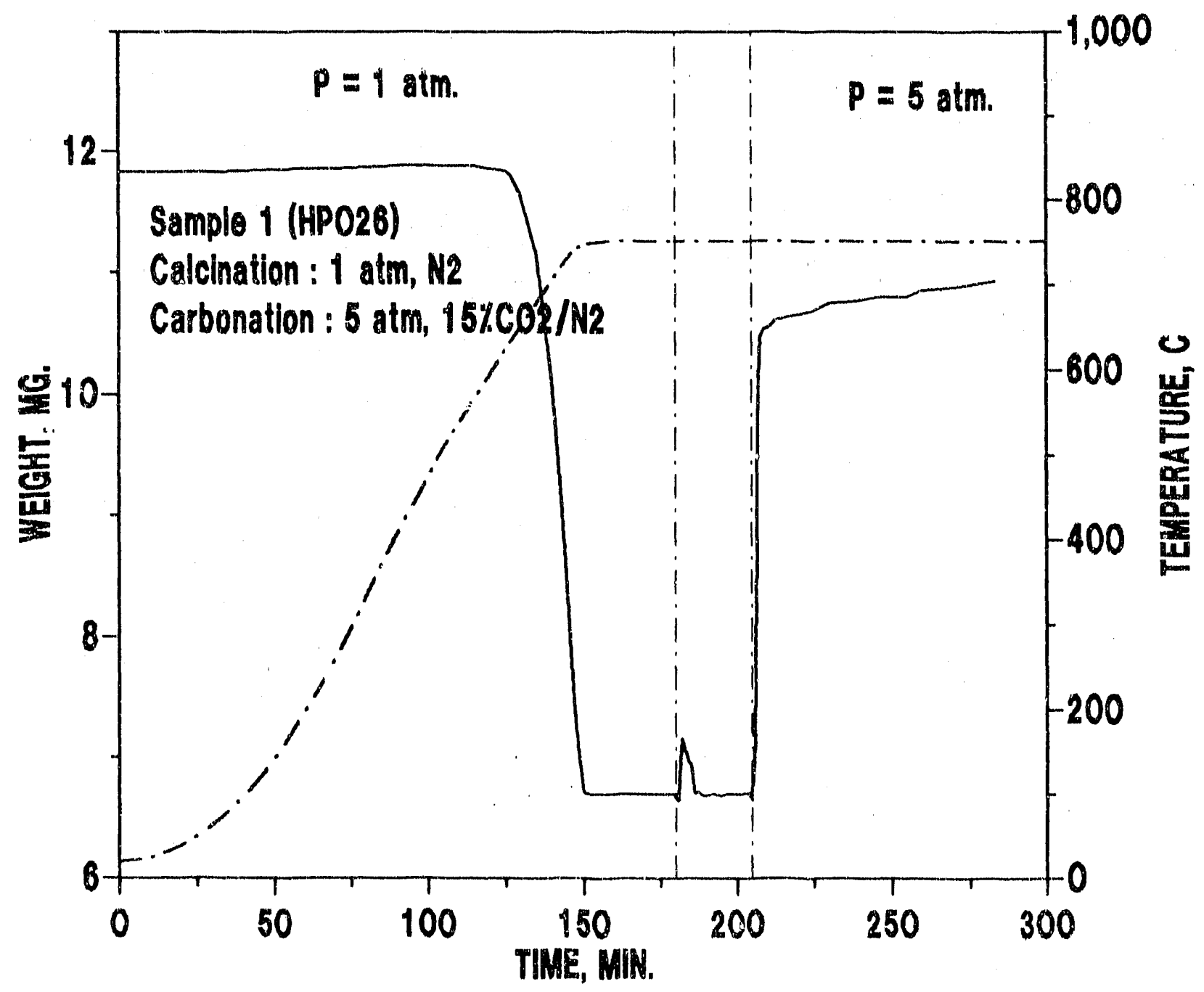

Figure 6. Typical Electrobalance Response: One Complete Calcination-Carbonation Cycle. 
Instruments are used for data acquisition and processing. Both a printer (Epson RX-100) and plotte (IBM 6/80/001) are provided for hard-copy data output.

A typical electrobalance response curve through one complete Calcination-carbonation cycle using reagent grade $\mathrm{CaCO}_{3}$ (sample 1 ) is shown in Figure $6.11 .8 \mathrm{mg}$ of $\mathrm{CaCO}_{3}$, were heated at a rate of approximately $5^{\circ} \mathrm{C} / \mathrm{min}$ to $750^{\circ} \mathrm{C}$ under one atmosphere of nitrogen. The high reactor mass produced a ronlinear response during the first 50 minutes of the heating cycle. However, the heating rate approched linearity well brffore the active reaction temperature was reached.

The sample weight showed a small apparent increase during the early heat-up period prior to the beginning of active calcination. This apparent weight increase was due to increased aerodynamic drag exerted by the flowing nitrogen. Calcination began after 125 minutes at a temperature of approximately $625^{\circ} \mathrm{C}$ and was complete after 150 minutes, coinciding approximately with the time that the temperature reached the final $750^{\circ} \mathrm{C}$ set-point. The sample weight of $6.6 \mathrm{mg}$ at the end of calcination corresponds to the theoretical weight associated with the complete decomposition of pure $\mathrm{CaCO}_{3}$ to CaO. After 160 minutes, the reactor pressure was increased to 5 atmospheres of nitrogen. At the same time, the pressure and flow rate of $\mathrm{N}_{2}$ and $\mathrm{CO}_{2}$ in the side-arm were adjusted and directed to vent. No $\mathrm{CO}, \mathrm{H}_{2}$, or $\mathrm{H}_{2} \mathrm{O}$ was present in the feed gas for this run.

As shown in Figure 6, system pressurization produced a great deal of temporary upset in the sample weight reading. Once the final pressure of 5 atmospheres was reached, the sample weight also stabilized. After 210 minutes, the three-way valve in the side-arm was 
switched and reactive gas composed of $15 \% \mathrm{CO}_{2}$, balance $\mathrm{N}_{2}$ was directed over the sample. The carbonation reaction began irmediately as evidenced by the solid weight increase to approximately $10.3 \mathrm{mg}$ within two minutes. Thereafter, the rate was quite slow and a maximum weight of $10.9 \mathrm{mg}$ was reached when the run was terminated after 280 minutes. The 10.3 and $10.9 \mathrm{mg}$ weights correspond to fractional carbonations of 0.71 and 0.83 , respectively. These typical results are, therefore, consistent with previous results reported in the literature. 
TASK 2: REACTION SCREENING TESTS

A number of calcination-carbonation screening tests were carried out as part of Task 2 activities in order to determine the general characteristics of the reactions as a function of temperature, pressure, and gas composition as well as to compare the reactivity of the various sorbents (see Table I). As a result of these screening tests, three sorbents have been selected for more detailed kinetic testing under l'ask 3 , and the ranges of parameters to be studied in rask 3 have been defined.

Most of the tests were conducted using can existing atmospheric pressure electrobalance reactor system while the high pressure reactor was being constructed. The principle behind the two reactors is identical. Important practical differences between the two, in addition to the pressure limit, are as follows. Gas flow rates in the atmospheric pressure reactor were controlled manually using rotameters and needle valves instead of mass flow controllers. The reduced thermal mass of the atmospheric pressure reactor permitted much faster temperature response. For example, rates of temperature change of $50^{\circ} \mathrm{C} / \mathrm{min}$ were easily achieved in the low pressure reactor while approximately $5^{\circ} \mathrm{C} / \mathrm{min}$ has been found to be the maximum practical value in the high pressure unit. In the low pressure unit, the experimental data (sample weight and temperature as a function of time) were acquired and stored using an electronic recorder (Bascom-Turner) rather than the PS-2 computer system used in the high pressure unit. In addition, it appears that, at approximately $750^{\circ} \mathrm{C}$, the temperature in the low pressure reactor was 20 to $30^{\circ} \mathrm{C}$ lower than the set-point. This caused no problems in comparing results between low pressure reactor runs, but 
caution must be exercised in comparing runs at "identical" conditions from the low and high pressure reactors.

CHARACTERISTICS OF' THE CALCINATION-CARBONATION REACIIONS

A number of tests in Task 2 were carried out to learn more about the general characteristics of the calcination-carbonation reaction. Most of the tests used sample' 1 (reagent calcium carbonate) and most were performed using the atmospheric pressure reactor. The results of these tests were used to establish the ranges of the reaction parameters to be studied in Task 3 .

THE EFFECT OF TEMPERATURE

Figure 7 shows the effect of temperature on the calcination rate. Calcination was carried out in nitrogen at 1 atmosphere using a heating rate of $50^{\circ} \mathrm{C} / \mathrm{min}$ to the indicated temperature, with isothermal operation thereafter. Calcination began at a very low rate at approximately $600^{\circ} \mathrm{C}$, and the rate increased rapidly with temperature to $845^{\circ} \mathrm{C}$. Calcination was complete within the 50 minute time frame shown in the figure at both 745 and $845^{\circ} \mathrm{C}$. Longer time data (not shown) suggests that calcination would be complete at $660^{\circ} \mathrm{C}$ after approximately 200 minutes and after about 65 minutes at $710^{\circ} \mathrm{C}$.

The effect of carbonation temperature is shown in Figure 8 using a calcination temperature of $750^{\circ} \mathrm{C}$. Carbonation was carried out at 1 atmosphere in $5.6 \% \mathrm{CO}_{2}$, balance $\mathrm{N}_{2}$. Each test resulted in an initial rapid reaction period followed by an abrupt change to a slow reaction phase. This behavior is in general agreement with previous results reported in the literature. Both the time and extent of carbonation at the end of the rapid phase are strong functions of temperature. The 


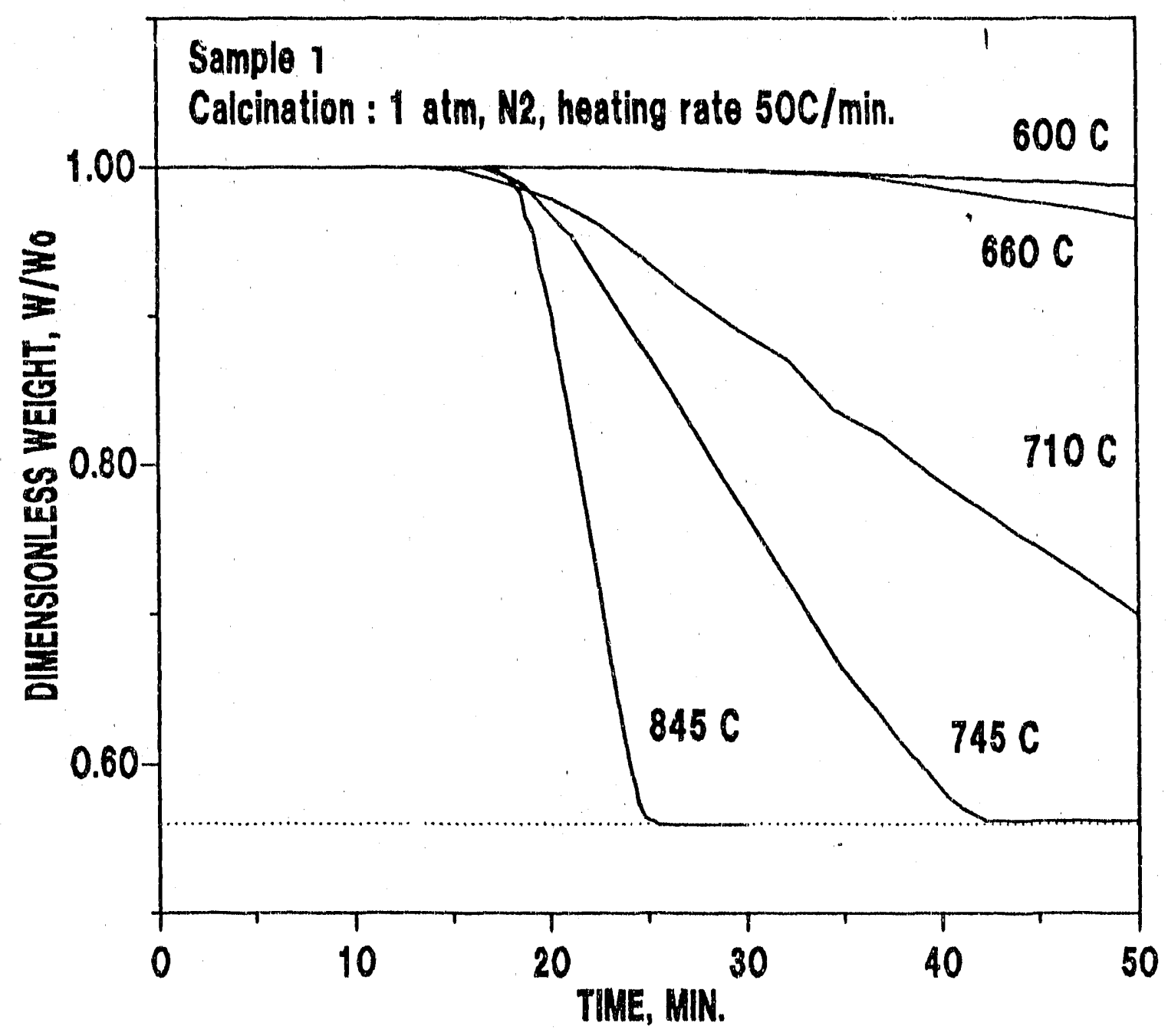

Figure 7. The Effect of Temperature on Calcination Kinetics: Sample 1 . 


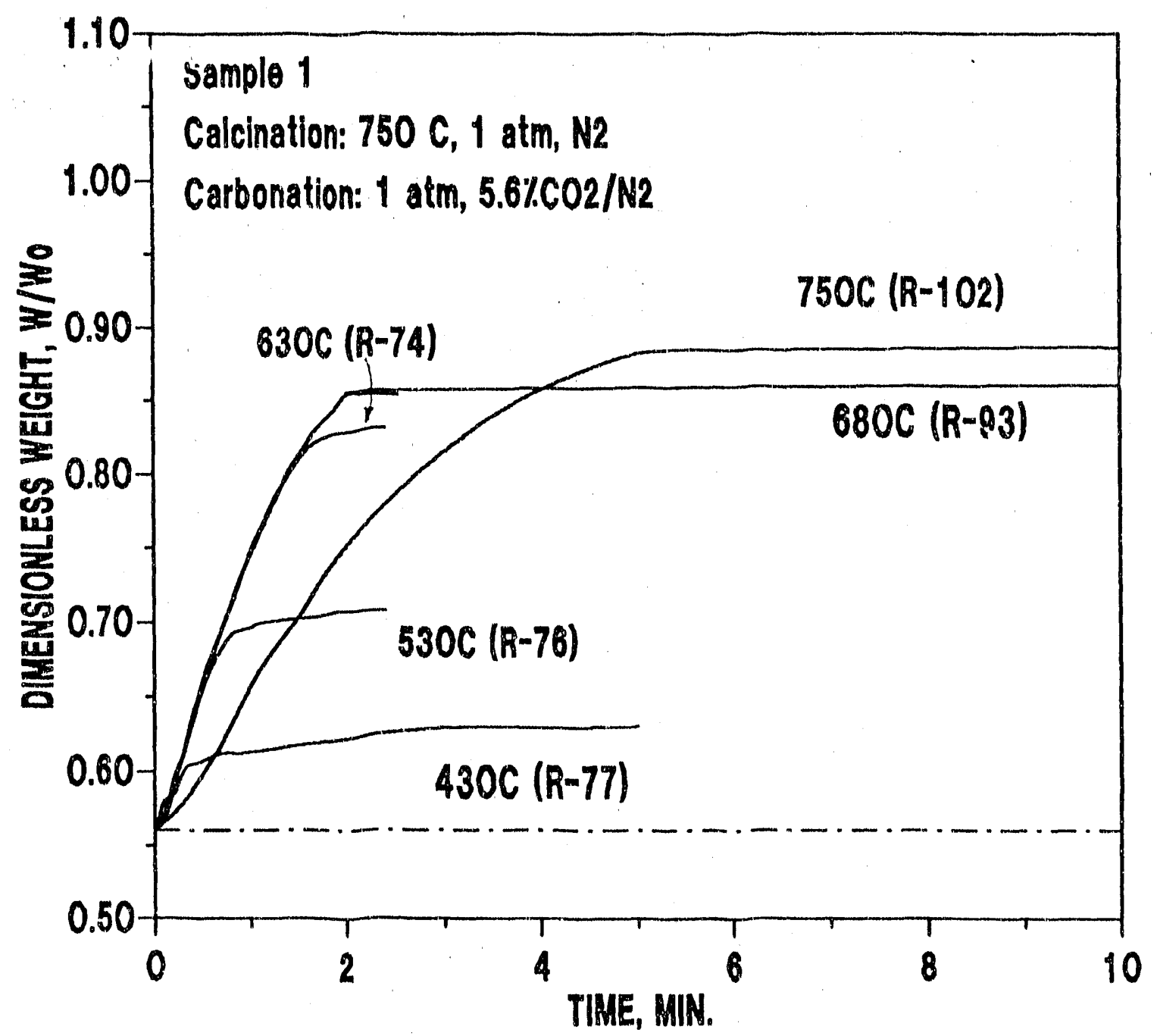

Figure 8. The Effect of Temperature on Carbonation Kinetics: Sample 1 . 
final values of $W / w_{0}$, which ranged from approximately 0.63 at $430^{\circ} \mathrm{C}$ to 0.89 at $750^{\circ} \mathrm{C}$, correspond to fractional carbonations of approximately 0.16 to 0.75 , respectively. The global rate during the rapid reaction phase was approximately equal in the temperature range from 430 to $680^{\circ} \mathrm{C}$; the decrease in the global reaction rate at $750^{\circ} \mathrm{C}$ is attributed to the fact that the actual partial pressure of $\mathrm{CO}_{2}$ was only slightly greater than the equilibrium partial pressure at this temperature.

Although each test exhibited a similar sharp decrease in global rate after a certain time, the carbonation reaction never stopped completely as shown in Figure 9. In this test, calcination at $895^{\circ} \mathrm{C}$ in $\mathrm{N}_{2}$ at 1 atmosphere was followed by carbonation at $710^{\circ} \mathrm{C}$ in $15 \% \mathrm{CO}_{2}$, balance $\mathrm{N}_{2}$, with the carbonation cycle extended to 24 hours. The rapid reaction period, which lasted for approximately 5 minutes, appears to end instantaneously at $w / w_{0}=0.85$, corresponding to $x$ (fractional carbonation) $\sim 0.66$. Over the next 24 hours, $W / w_{0}$ gradually increased to 0.93 , corresponding to $x \sim 0.84$.

\section{THE EFFECT OF GAS COMPOSITION}

The most interesting and unexpected result from the reaction screening tests concerned the effect of gas composition on carbonation kinetics. The carbonation rate should certainly be dependent upon the $\mathrm{CO}_{2}$ concentration. This is confirmed by the results in Figure 10. The time scale in this figure is enlarged to emphasize the early reaction period. All calcination conditions and carbonation temperature were equal in each run. While higher $\mathrm{CO}_{2}$ concentration produced a marked increase in rate during the rapid reaction period, there was relatively little difference in the carbonation level at the end of the test. 


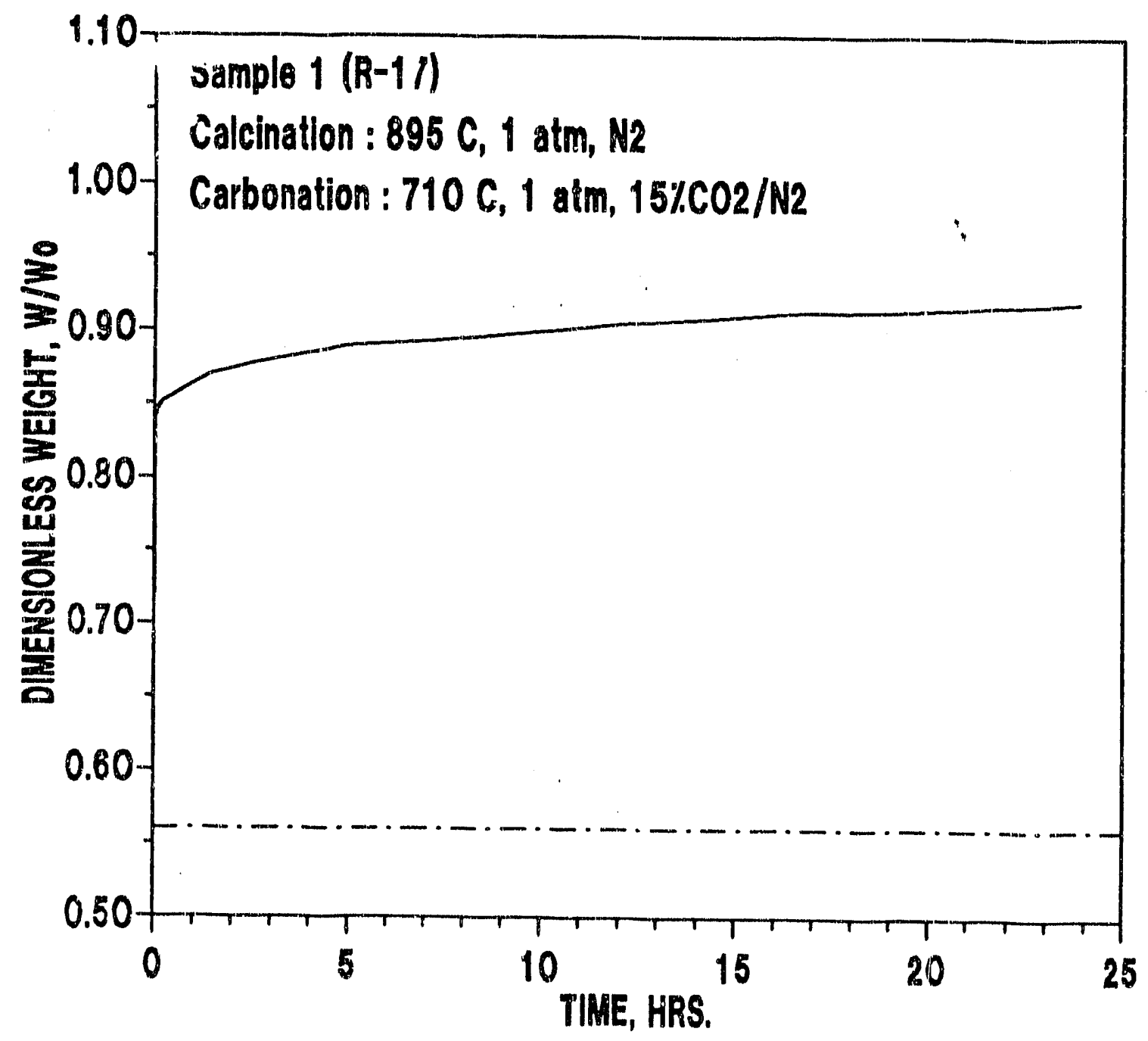

Figure 9. Long-Term Carbonation Results: Sample 1. 


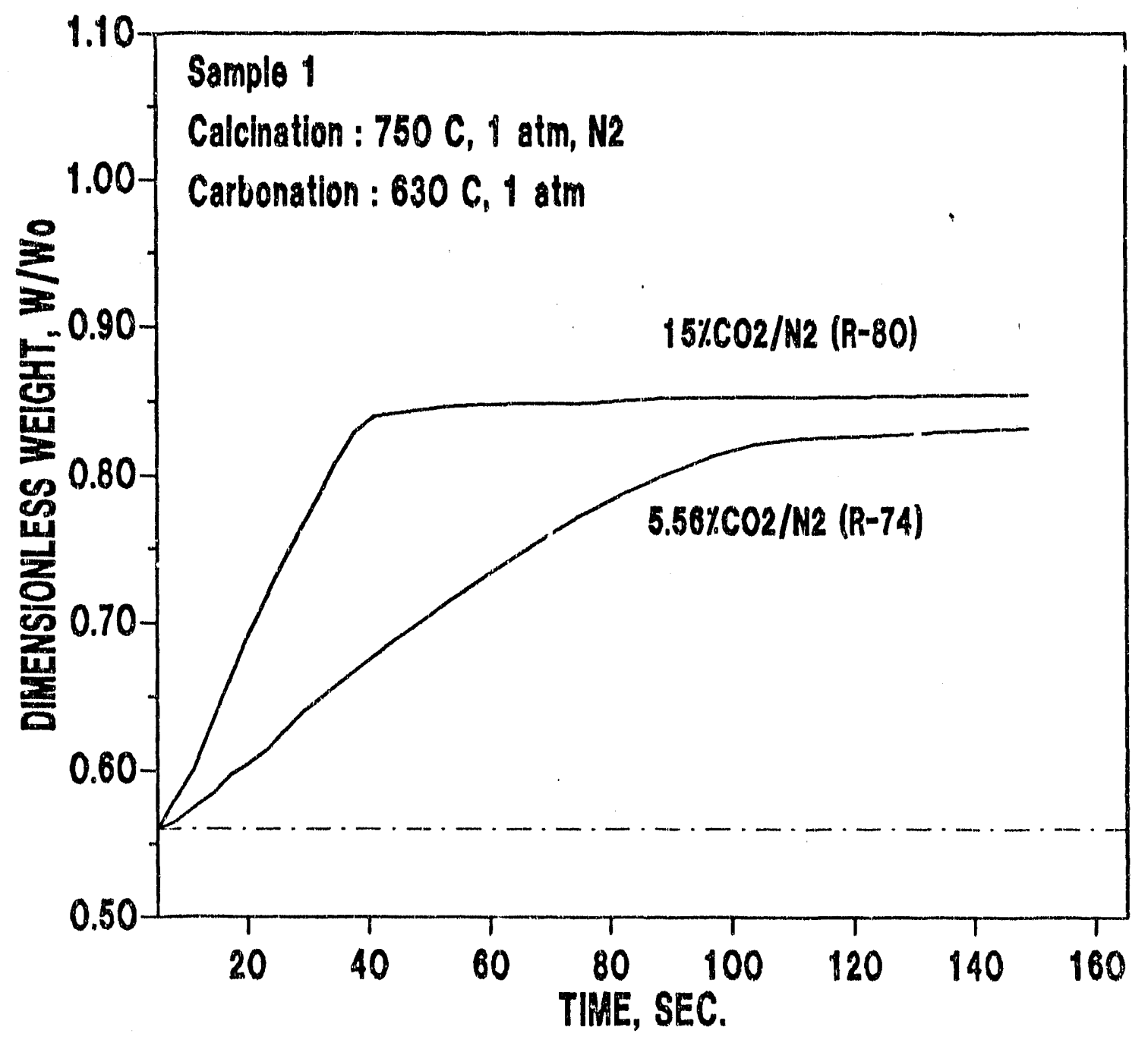

Figure 10. The Effect of $\mathrm{CO}_{2}$ Composition on Carbonation Kinetics: Sample 1. 
In all carbonation tests discussed to this point, the reactive atmosphere consisted of $\mathrm{CO}_{2}$ and $\mathrm{N}_{2}$ only. The following discussion reports the results of tests in which other components were added, in a stepwise manner, to produce a simulated coal gas containing $\mathrm{CO}, \mathrm{CO}_{2}, \mathrm{H}_{2}$ ' $\mathrm{H}_{2} \mathrm{O}$ and $\mathrm{N}_{2}$. Sample 1 (reagent calcium carbonate) was the sorbent in. each case.

Figure 11 compares carbonation results from the $\mathrm{CO}_{2} / \mathrm{N}_{2}$ atmosphere to results obtained in an atmosphere containing $\mathrm{CO}_{2} / \mathrm{CO} / \mathrm{H}_{2} / \mathrm{N}_{2}$ (at the same $\mathrm{CO}_{2}$ concentration). The latter atmosphere contains all of the major components present in coal-gas except steam. Addition of $\mathrm{CO}$ and $\mathrm{H}_{2}$ appears to result in a decrease in rate during the rapid reaction period; however, the decrease is slight and could be the result of normal data scatter. In each case the rapid reaction period ends at essentially the same level of $\mathrm{w} / \mathrm{w}_{0}$.

The more complex gas composition lies in the equilibrium carbon deposition region (Lamoreaux et al., 1986), and, after the test, carbon deposits were noted on the walls of the hang-down tube downstream of the sorbent. Carbon deposition on either the sorbent or the hang-down wire or pan would produce a weight gain, thereby confounding the carbonation kinetics. In order to check for carbon deposition, two blank runs were made in which inert $\mathrm{Al}_{2} \mathrm{O}_{3}$ was substituted for reactive $\mathrm{CaO}$. Two gas atmospheres, that shown in Figure 11, and a similar gas with $\mathrm{H}_{2} \mathrm{O}$ added, were tested. Addition of $\mathrm{H}_{2} \mathrm{O}$ left the gas composition within the carbon deposition region, but nearer the boundary, thereby reducing somewhat the carbon deposition tendency. However, no weight gain was observed with either test showing that carbon deposition does not occur on the critical components to an extent sufficient to confound the carbonation results. 


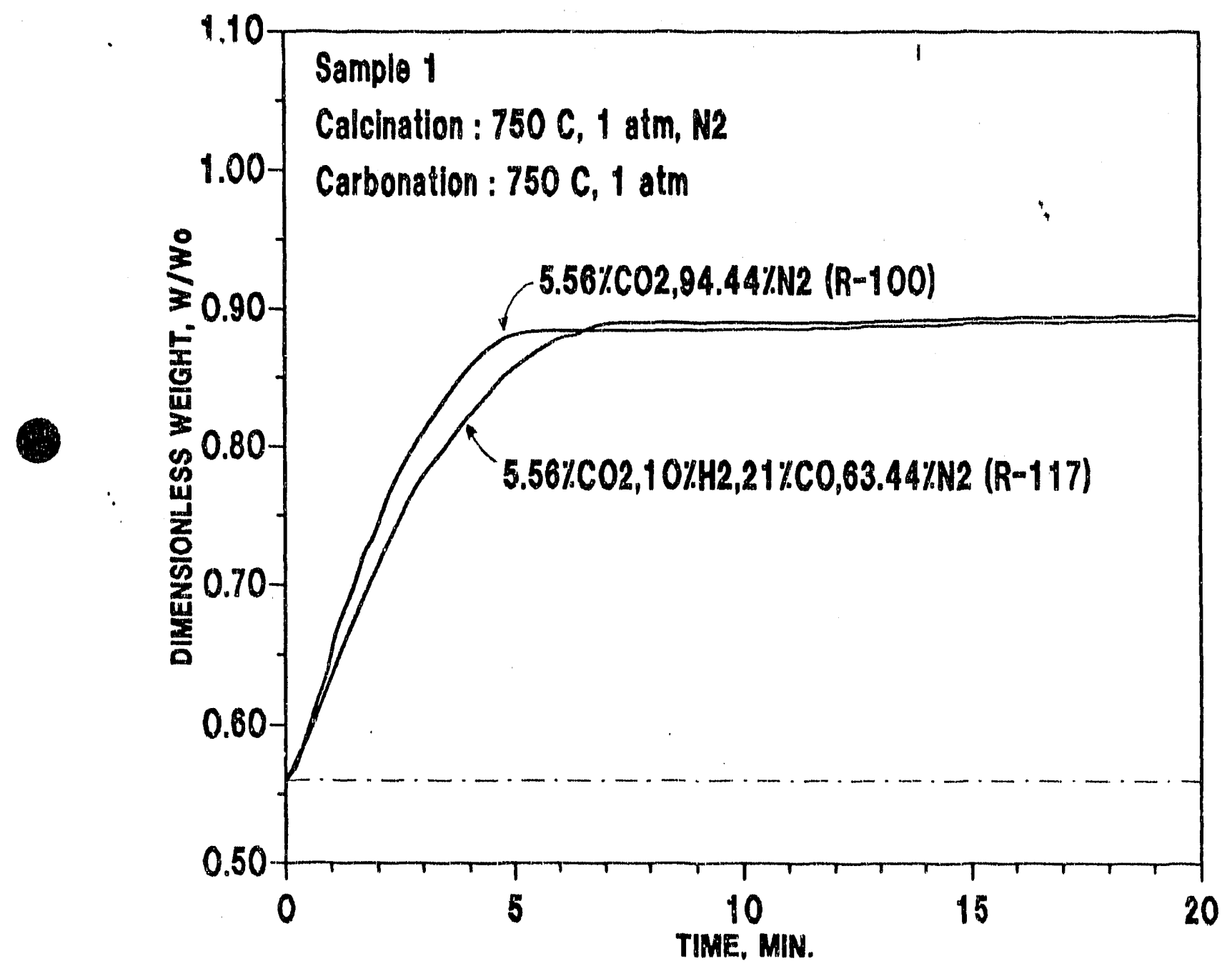

Figure 11. The Effect of Gas Composition on Carbonation Kinetics, The Addition of $\mathrm{CO}$ and $\mathrm{H}_{2}$ : Sample 1 . 
The addition of steam to complete the simulated coal-gas atmosphere produced a dramatic increase in the carbonation rate during the rapid reaction phase as shown in Figure 12 . Once again there was no apparent change in the final fractional carbonation. Two possible reasons for the rate increase were considered. Since all components involved in the water-gas shift reaction were present, the occurrence of this reaction would increase the $\mathrm{CO}_{2}$ concentration above that of the feed gas, and cause the rate in the rapid reaction phase to increase. Secondly, it was considered possible that $\mathrm{H}_{2} \mathrm{O}$ simply served as a rate enhancer.

Results of an additional test tests designed to evaluate the possible importance of the shift reaction are shown in Figure 13. In one test, the "simple" gas composed of $5 \% \mathrm{CO}_{2}$ in $\mathrm{N}_{2}$ was used. In the second, a simulated coal gas containing $5 \% \mathrm{CO}_{2}$ and the indicated amounts of $\mathrm{CO}, \mathrm{H}_{2}, \mathrm{H}_{2} \mathrm{O}$ and $\mathrm{N}_{2}$ was fed. A marked increase in rate during the rapid reaction period with no change in the final value of $\mathrm{w} / \mathrm{w}_{0}$ was observed. The third test gas was composed of $8.9 \% \mathrm{CO}_{2}$ in $\mathrm{N}_{2}$, and the rate was similar to that observed in the simulated coal gas. Shift equilibrium calculations showed that if the simulated coal gas feed was allowed to equilibrate, the $\mathrm{CO}_{2}$ composition would be increased to approximately $9 \%$. While the evidence is indirect, the similarity in the two rate curves suggests that the carbonation and water-gas shift reactions may occur simultaneously when the necessary shift components are present.

Other evidence of the probable importance of the shift reaction is shown in Figure 14. In this test, the $\mathrm{CO}_{2}$ feed concentration was held constant while the background gas composition was changed ten minutes into the run. During the early stages when the feed gas consisted of $5 \%$ $\mathrm{CO}_{2} / 27 \% \mathrm{H}_{2} / 68 \% \mathrm{~N}_{2}$, no carbonation cccurred. Reverse shift equilibrium under these feed conditions would leave approximately $1 \% \mathrm{CO}_{2}$ in the gas, 


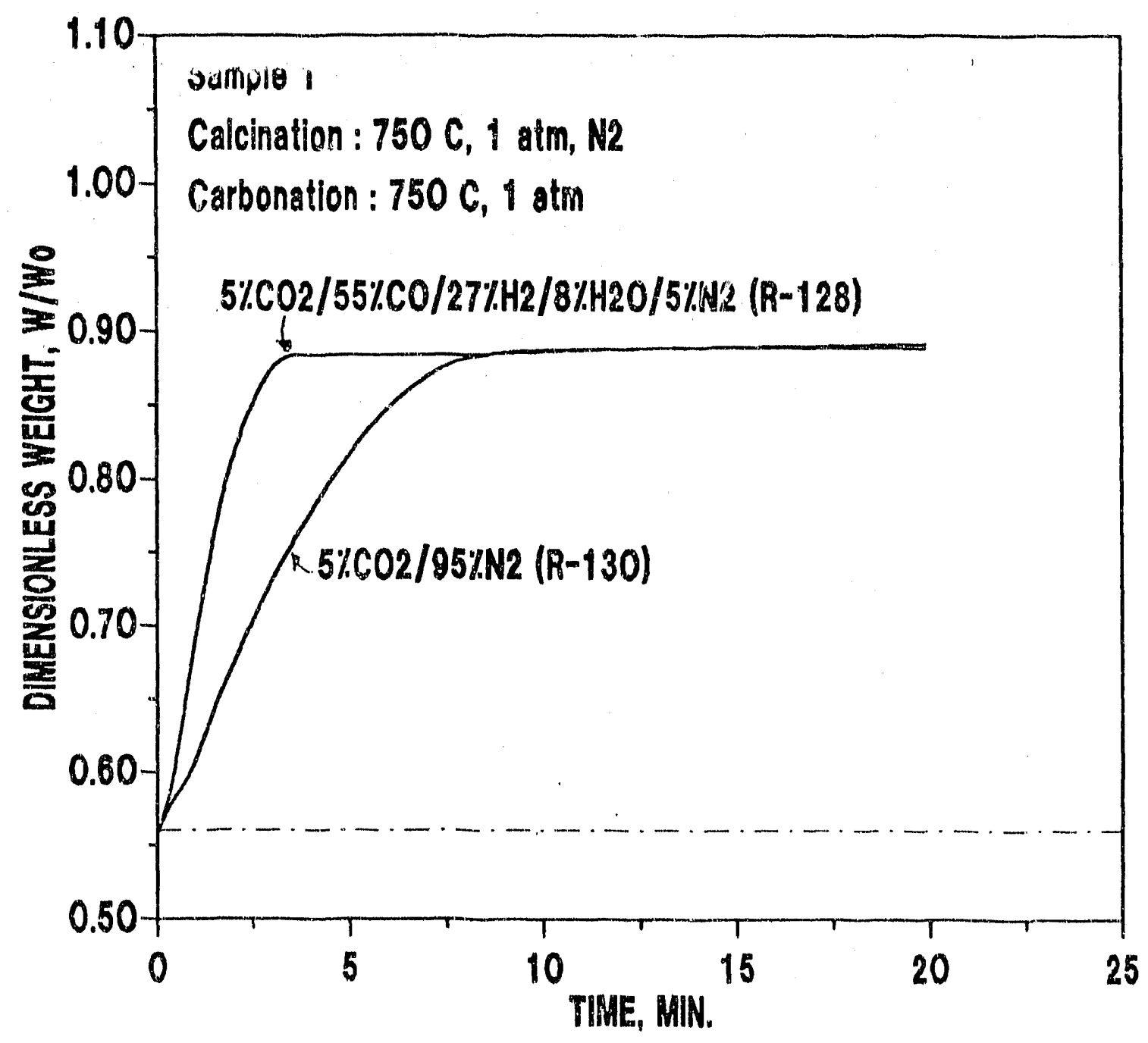

Figure 12. The Effect of Gas Composition on Carbonation Kinetics, The Addition of $\mathrm{CO}, \mathrm{H}_{2} \mathrm{O}$, and $\mathrm{H}_{2}$ : Sample 1 . 


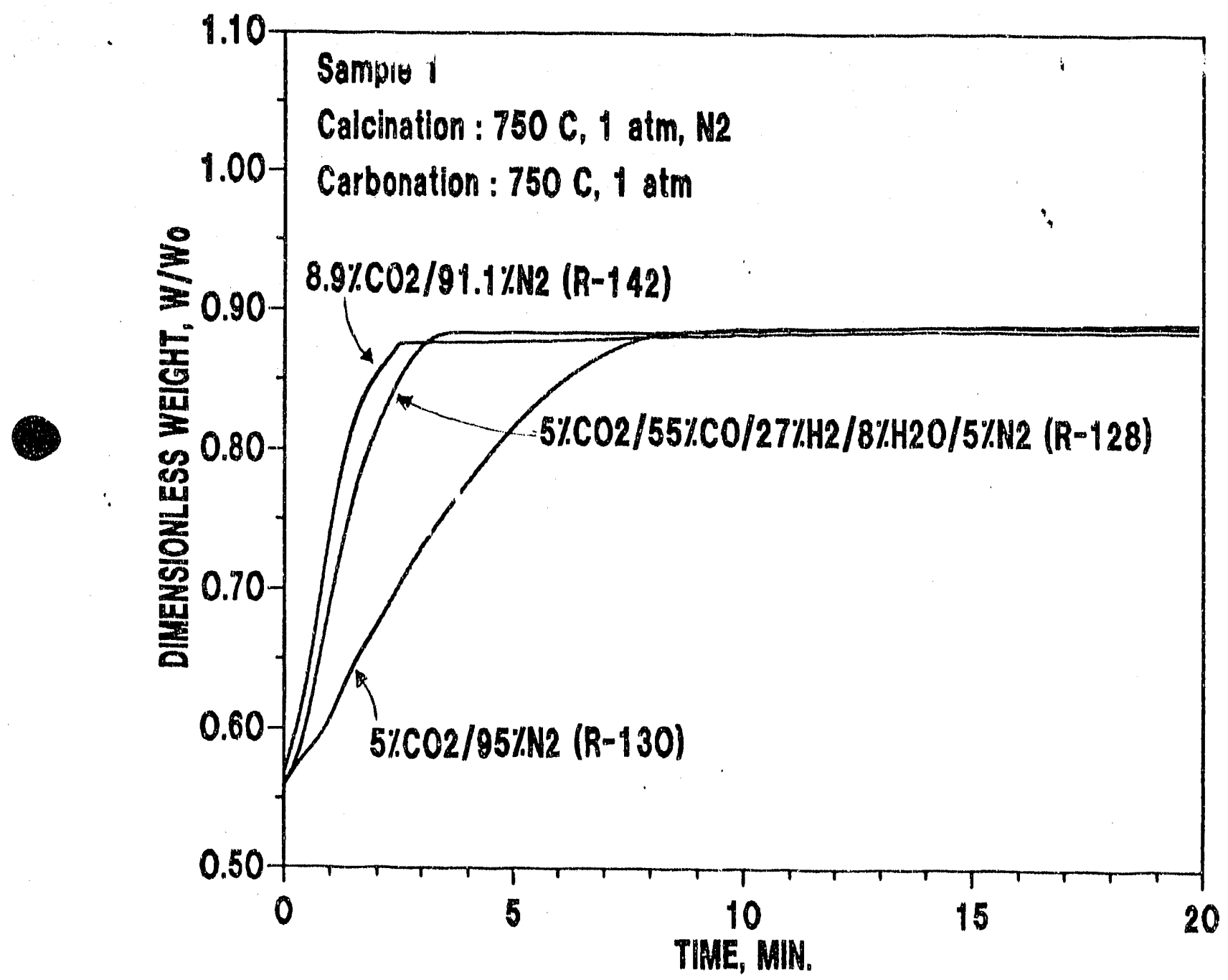

Figure 13. Testing for the Presence of the Shift Reaction: Sample 1 . 


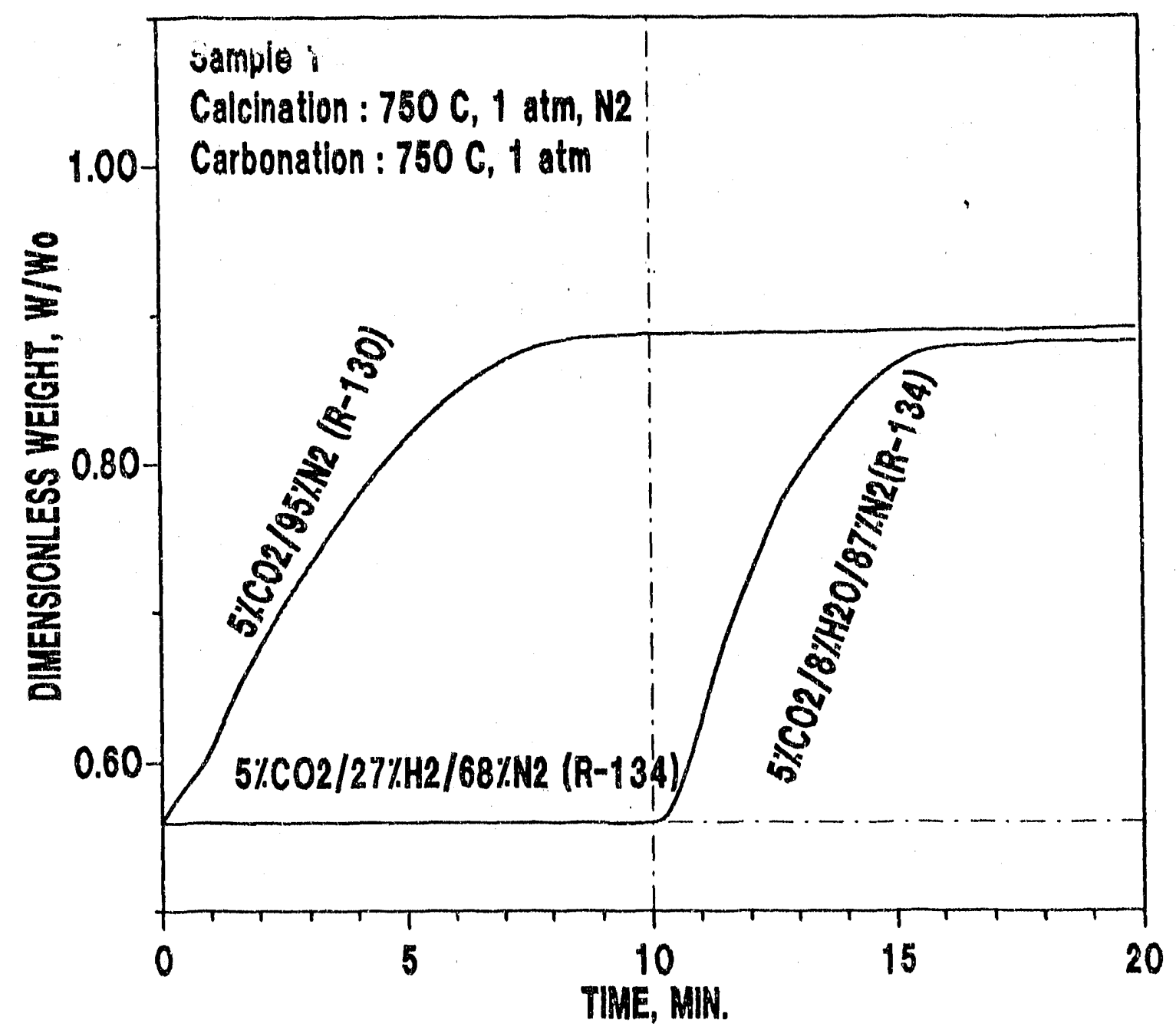

Figure 14. Carbonation Kinetics With Constant $\mathrm{CO}_{2}$ Concentration and Varying Background Gas Composition: Sample 1. 
which, at 1 atmosphere and $750^{\circ} \mathrm{C}$ is below the equilibrium $\mathrm{CO}_{2}$ pressure for the carbonation reaction. After 10 minutes, $\mathrm{H}_{2}$ feed was stopped and $\mathrm{H}_{2} \mathrm{O}$ was added to stop the shift reaction from occurring. As indicated in the figure, carbonation began immediately, and proceeded to a $\mathrm{w} / \mathrm{w}_{\mathrm{O}}$ value approximately equal to that observed in the simple $\mathrm{CO}_{2} / \mathrm{N}_{2}$ composition.

Results of one final test showing the importance of background gas compusition are shown in Figure 15. In this test, the feed gas contained no $\mathrm{CO}_{2}$ but did contain the shift reactants $\mathrm{CO}$ and $\mathrm{H}_{2} \mathrm{O}$. The observed weight increases proves that carbonation did occur, and the only reasonable source of $\mathrm{CO}_{2}$ was the shift reaction. The fact that the $\mathrm{W} / \mathrm{w}_{\mathrm{O}}$ value reached a maximum of approximately 0.68 after 10 minutes and declined thereafter suggests that $\mathrm{CO}_{2}$ formation was transitory. This behavior would be consistent with CaO serving as a shift catalyst. Early in the test when most of the sorbent was in the oxide form, the shift reaction produced $\mathrm{CO}_{2}$ which subsequently reacted to form $\mathrm{CaCO}_{3}$. once an appreciable quantity of $\mathrm{CaCO}_{3}$ was formed, the catalytic effect diminished, less $\mathrm{CO}_{2}$ was formed, and a portion of the $\mathrm{CaCO}_{3}$ decomposed.

The possibility of simultaneous shift reaction $-\mathrm{CO}_{2}$ removal provides a number of interesting options in so far as a one-step process for the production of hydrogen is concerned. While such options should be pursued, they are beyond the scope of the present study. The combined reactions create problems for the current study in that the $\mathrm{CO}_{2}$ concentration in contact with the CaO sorbent is no longer determined by the feed gas composition whenever shift reaction components are present. For this reason, a decision was made to concentrate in the Task 3 kinetic studies on the "simple" reactive gas containing onl.y $\mathrm{CO}_{2}$ and $\mathrm{N}_{2}$ " 


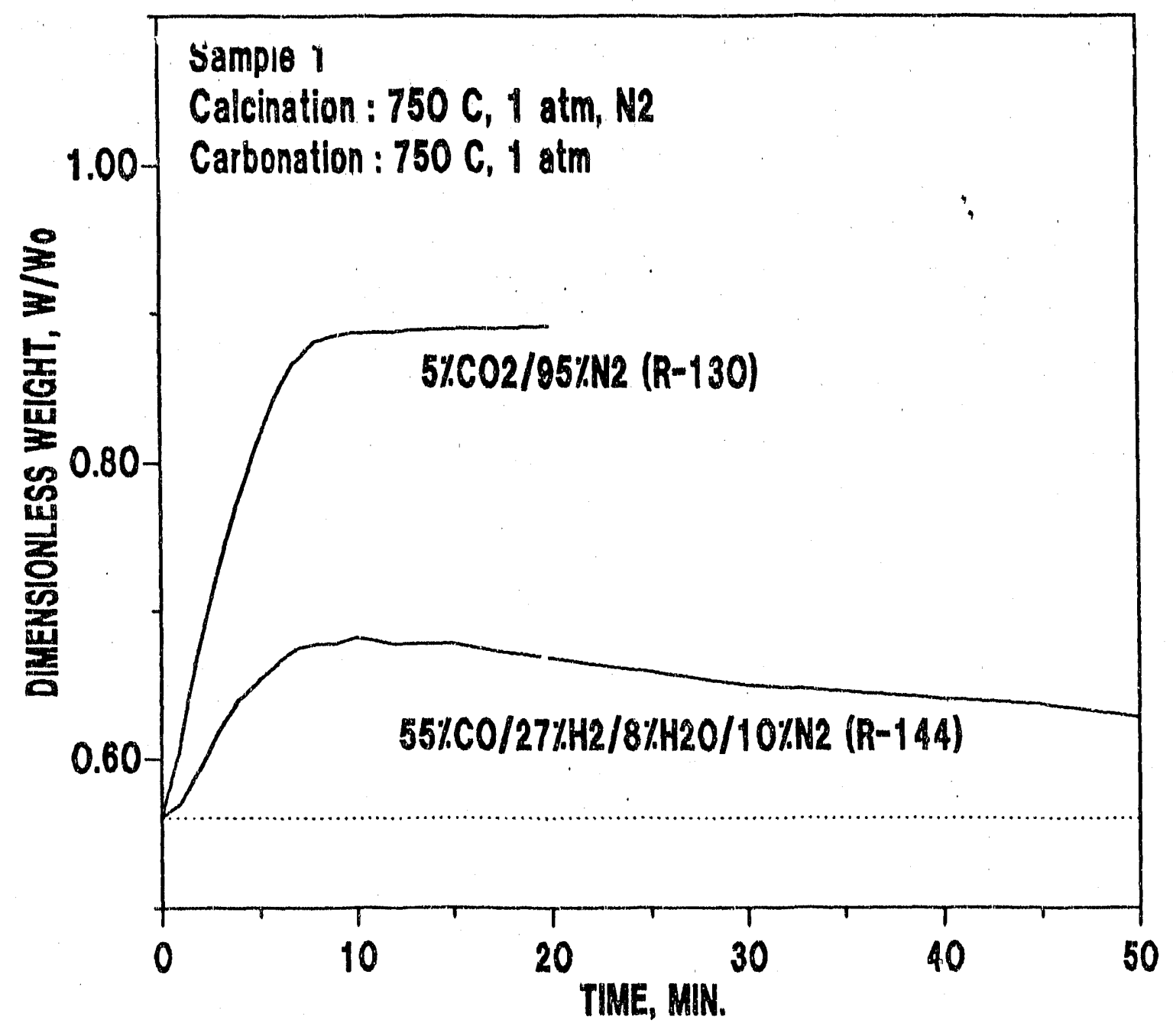

Figure 15. Carbonation With No $\mathrm{CO}_{2}$ in the Feed Gas: Sample 1. 
with a few tests added to provide further information of the effect of background gas composition.

COMPARISON OF SORBENT REACTIVITY

Calcination results for the six calcium carbonate test sorbents (samples 1-6) are compared in Figures 16 and 17. Callcination conditions were equivalent in each test and results from sample 1 are included in both figures for references purposes. All calcination results were qualitatively similar. The calcination rate became appreciable after about 12 minutes with $T \sim 625^{\circ} \mathrm{C}$. Complete calcination, as evidenced by the constant values of $\mathrm{W} / \mathrm{w}_{0}$ occurred in the range of 43 to 75 minutes. We attribute the differences in time for complete calcination primarily to particle size effects among the samples. Differences in the values of $\mathrm{W} / \mathrm{w}_{0}$ at complete calcination were due to differences in impurity levels. The final weight of sample 1, which was pure $\mathrm{CaCO}_{3}$, was quite close to the theoretical value of 0.56 . The final value of $\mathrm{w} / \mathrm{w}_{0}$ for the other samples, all of which were obtained from commercial quarries, ranged from 0.56 to 0.64 .

Comparable carbonation curves for these samples are shown in Figures 18 and 19. Again, data for sample 1 is included in both figures for reference purposes. In Figure 18 carbonation was carried out isothermally at $630^{\circ} \mathrm{C}$ while $750^{\circ} \mathrm{C}$ carbonation temperature was used in the Figure 19 tests. The carbonation gas in all tests consisted of $5.6 \%$ $\mathrm{CO}_{2}$ in $\mathrm{N}_{2}$. Differences in the initial values of $\mathrm{w} / \mathrm{w}_{0}$ reflect the differences in the final $w / w_{0}$ values from the calcination cycle. Within limits, each of the carbonation curves are similar. In particular, the final values of $w / w_{0}$ at the end of the test ranged from 0.82 to 0.85 at $630^{\circ} \mathrm{C}$ (Figure 18), while the final $W / w_{0}$ values from the three $750^{\circ} \mathrm{C}$ 


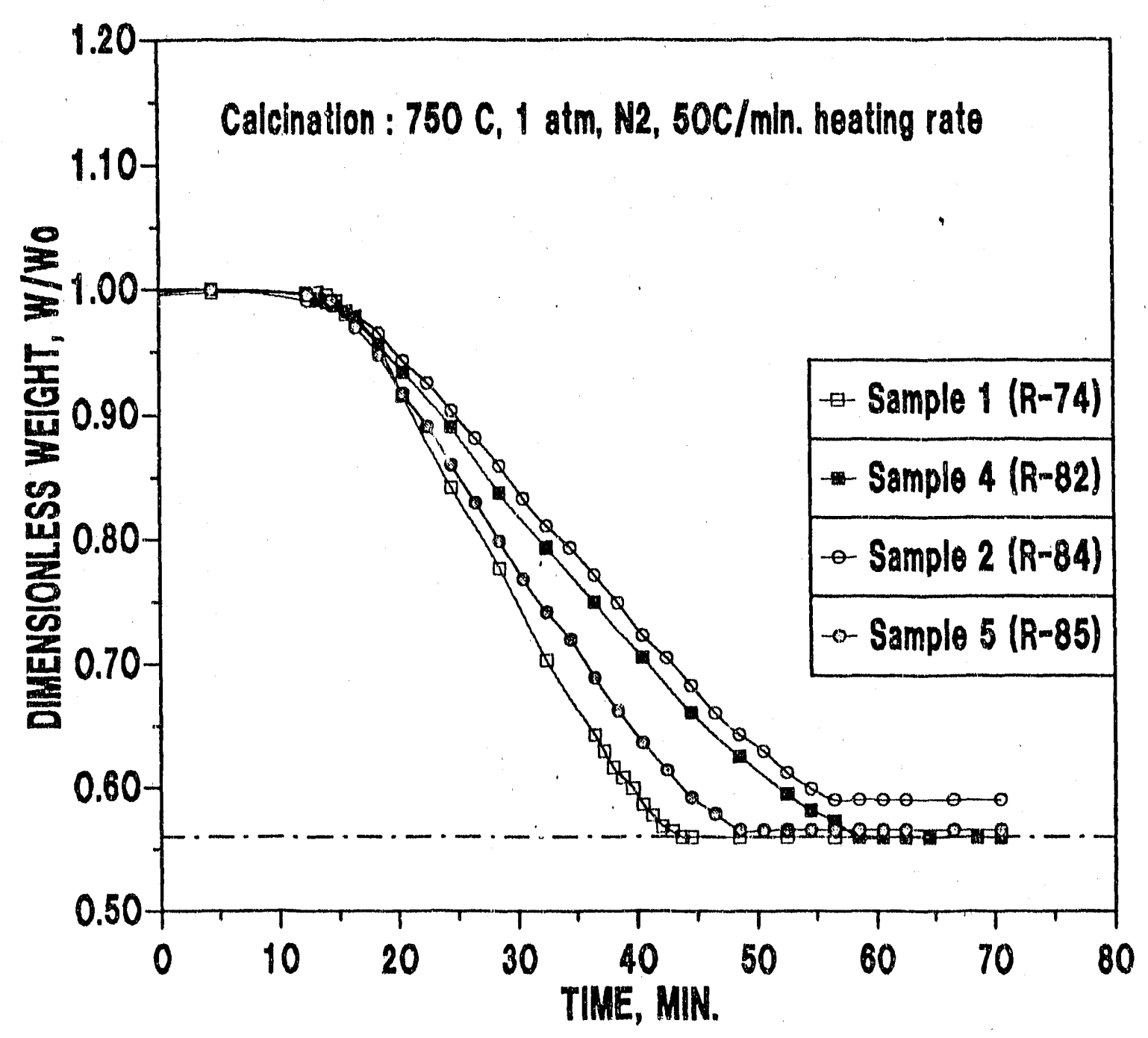

Figure 16. Comparison of Calcination Kinetics: Samples 1, 2,4 and 5 . 


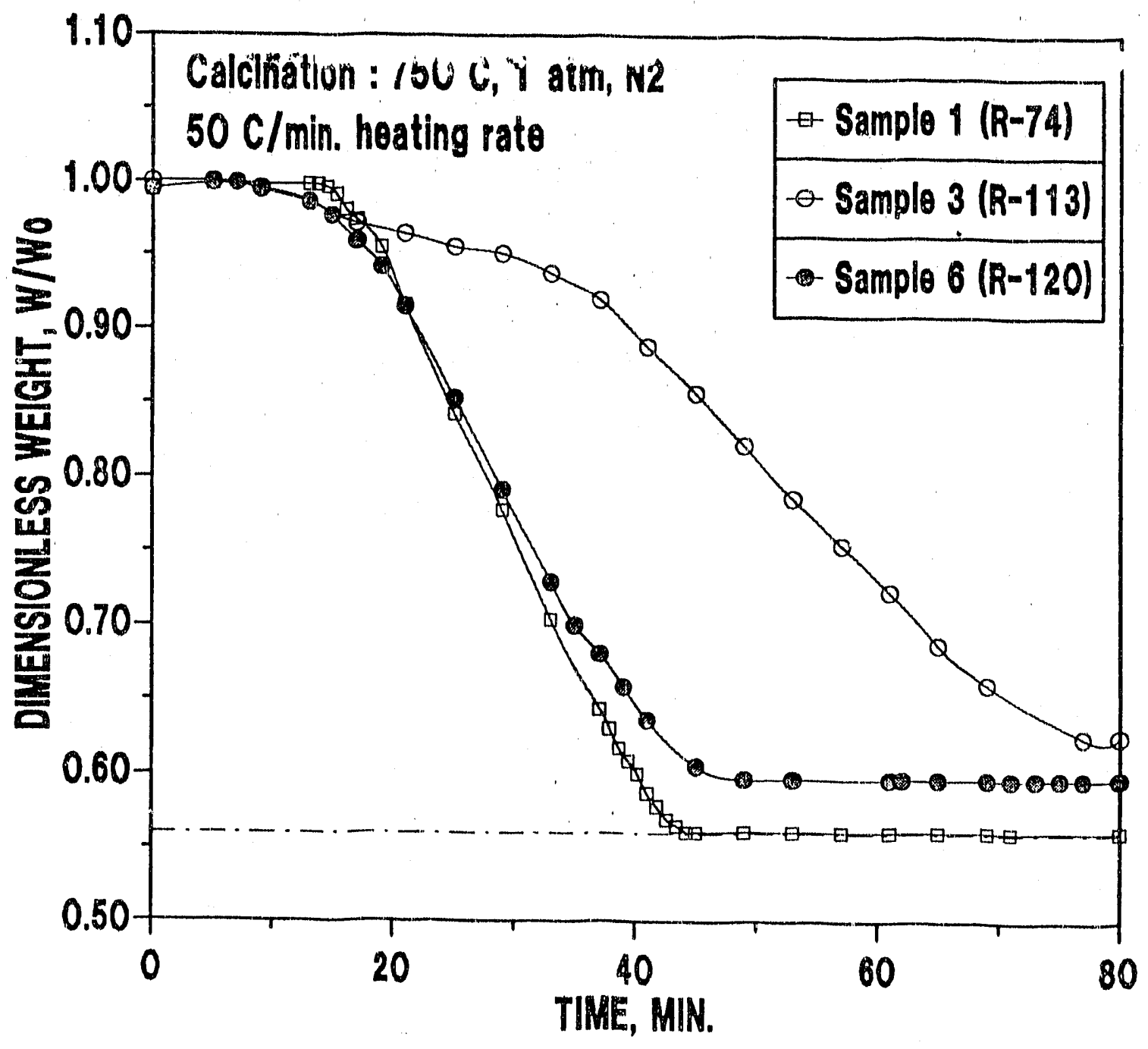

Figure 17. Comparison of Calcination Kinetics: Samples 1 ,
3, and 6 . 


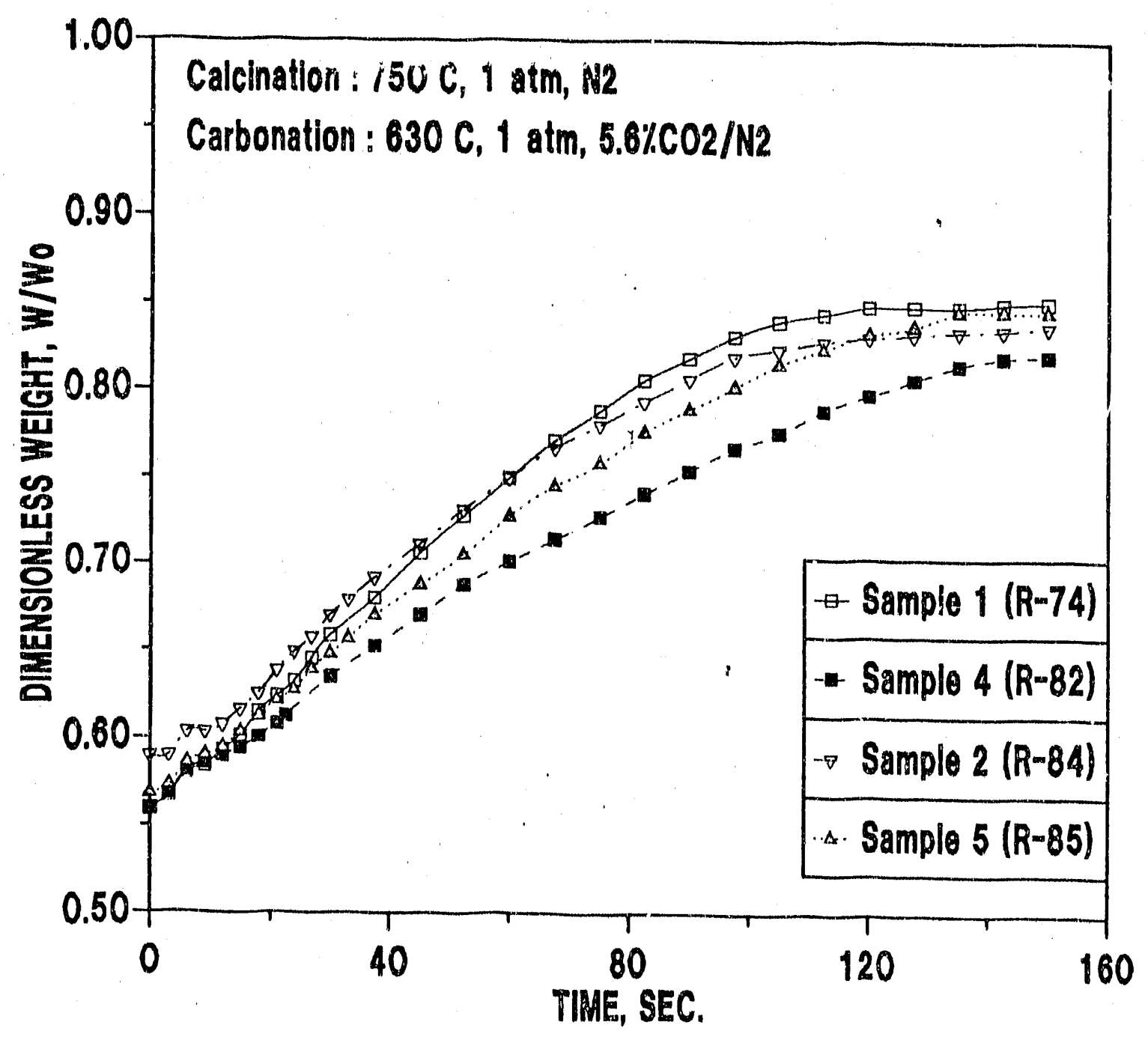

Figure 18. Comparison of Carbonation Kinetics: Samples 1, 2,4 , and 5 . 


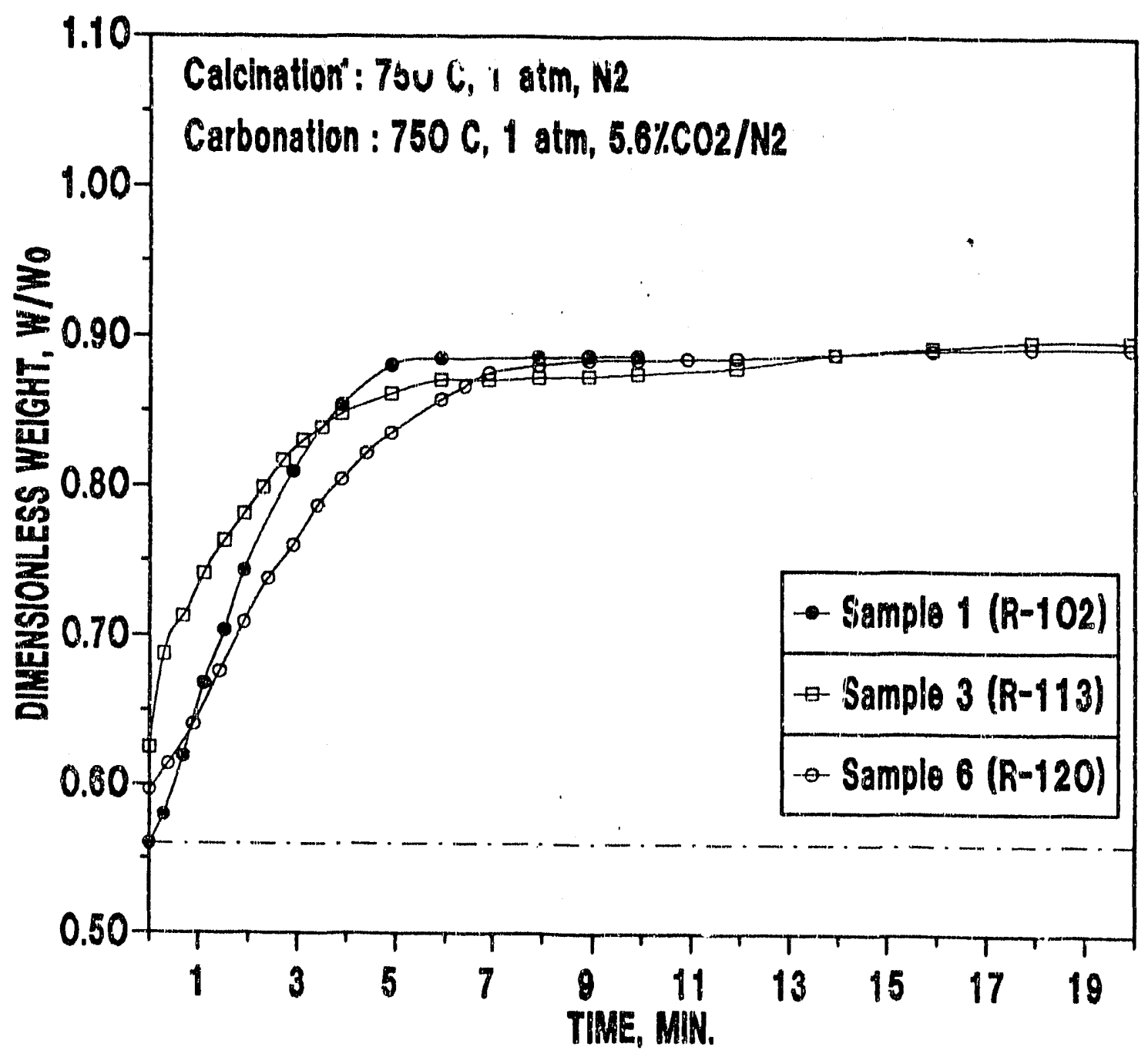

Figure 19. Comparison of Carbonation Kinetics: Samples 1, 3 , and 6 . 
tests (Figure 19) were all approximately 0.89 . These results were somewhat disappointing. Instead of chalks and marls providing significantly increased reactivity as reported by Hartman et al. (1978) in their sulfation studies, the carbonation behavior of all samples was similar to that of the reagent grade $\mathrm{CaCO}_{3}$.

An al.ternate approach to increasing sorbent reactivity was then pursued. Samples 7 and 8 , consisting of reagent grades of calcium acetate and calcium sulfate, respectively, were chosen as test sorbent precursors. The rationale in these selections was that decomposition of either precursor wolld involve driving off a significantly increased quantity of volatile material leaving $\mathrm{CaO}$ with increased pore volume and, presumably, greater carbonation reactivity.

Figure 20 shows decomposition-carbonation results for one complete cycle using sample 7 (calcium acetate). The precursor, $\mathrm{Ca}\left(\mathrm{C}_{2} \mathrm{H}_{3} \mathrm{O}_{2}\right)_{2} \cdot \mathrm{xH}_{2} \mathrm{O}$ containing $8.3 \% \mathrm{H}_{2} \mathrm{O}$, was heated in $\mathrm{N}_{2}$ as shown. Water of hydration was driven of $f$ in two increments in the temperature range $100-300^{\circ} \mathrm{C}$, leaving $\mathrm{Ca}\left(\mathrm{C}_{2} \mathrm{H}_{3} \mathrm{O}_{2}\right)_{2}$ with $\mathrm{W} / \mathrm{w}_{0} \sim 0.92$. Acetate decomposition began at about $450^{\circ} \mathrm{C}$ and a constant weight plateau was reached at $600^{\circ} \mathrm{C}$ with $\mathrm{w} / \mathrm{w}_{0}$ 0.58. This value of $\mathrm{w} / \mathrm{w}_{0}$ corresponds to that expected for $\mathrm{CaCO}_{3}$ formed from the original acetate. Additional weight loss to $\mathrm{W} / \mathrm{w}_{0}=0.314$ occurred in the vicinity of $750^{\circ} \mathrm{C}$. No further weight loss occurred during 45 minutes in $\mathrm{N}_{2}$ at $750^{\circ} \mathrm{C}$, and the final weight corresponded closely to the theoretical value of $w / w_{0}=0.325$ for the production of Cal from calcium acetate containing $8.3 \% \mathrm{H}_{2} \mathrm{O}$. Carbonation was initiated after 105 minutes by exposing the sorbent to $5.6 \% \mathrm{CO}_{2}$ in $\mathrm{N}_{2}$. Weight gain was rapid and the $f$ inal value of $\mathrm{w}_{0} \mathrm{w}_{0}=0.57$ corresponded closely to the value expected for total conversion of $\mathrm{CaO}$ to $\mathrm{CaCO}_{3}(\mathrm{~W} / \mathrm{W}$ $0.58)$ 


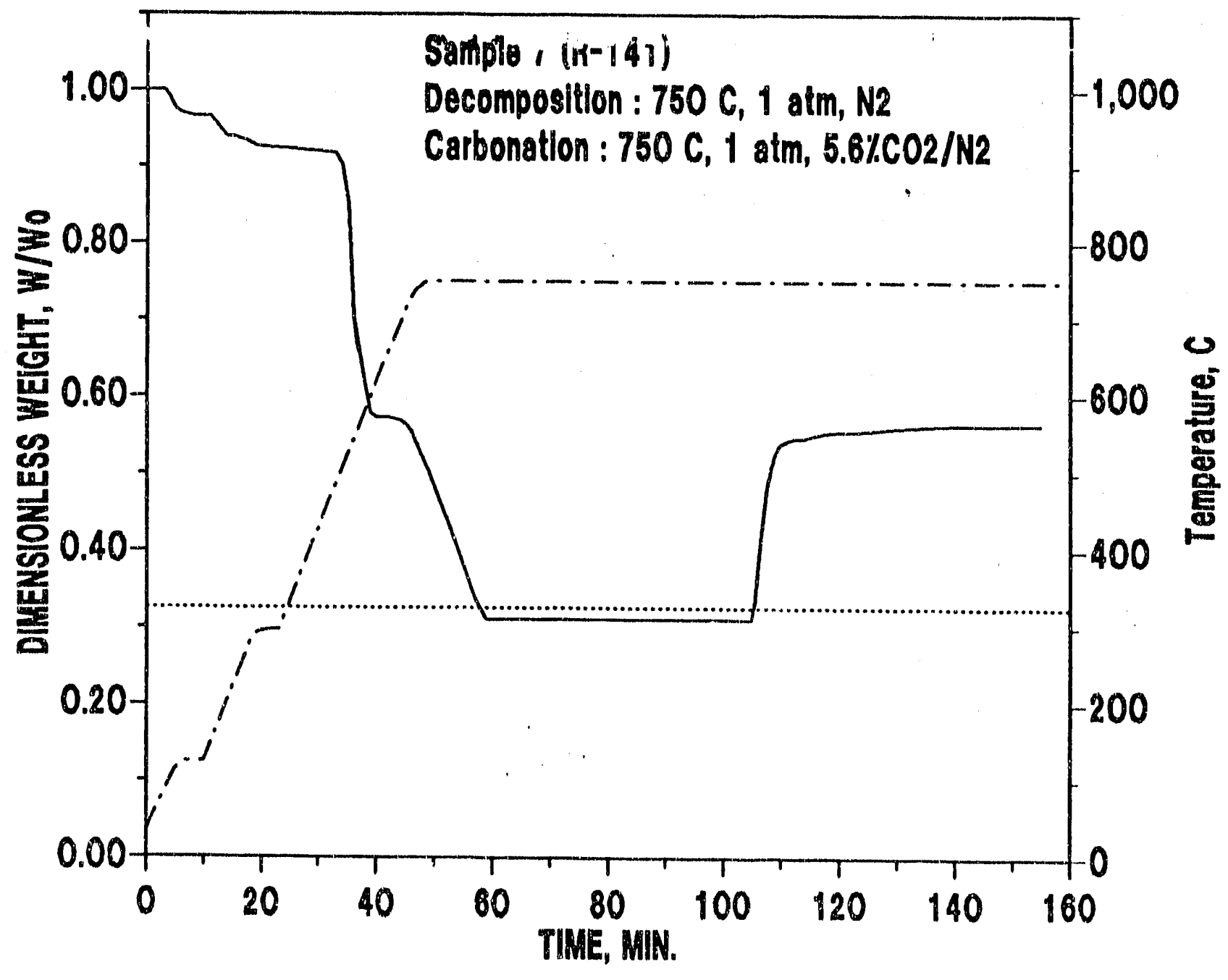

Figure 20. Decomposition-Carbonation Kinetics: Sample 7. 
Hydrated calcium sulfate, $\mathrm{CaSO}_{4} \cdot 2 \mathrm{H}_{2} \mathrm{O}$ (sample 8) was also examined as a possible precursor with results shown in Figure 21. The atmosphere during $\mathrm{CaSO}_{4}$ decomposition was $50 \% \mathrm{~N}_{2}-50 \% \mathrm{H}_{2}$, with the hydrogen added to promote the removal of sulfur as $\mathrm{H}_{2} \mathrm{~S}$. Past work in this laboratory (Focht et al., 1989) showed that when $\mathrm{ZnSO}_{4}$ was exposed to a reducing atmosphere at high temperature, Zno was produced as the solid product. Water of hydration was lost in the temperature range of $150-350^{\circ} \mathrm{C}$ to produce anhydrous $\mathrm{CaSO}_{4}$ with $\mathrm{w} / \mathrm{w}_{0}=0.79$. Further weight loss to $\mathrm{w} / \mathrm{w}_{0}=$ 0.42 occurred in the temperature range 800 to $1000^{\circ} \mathrm{C}$. However, this final $\mathrm{w} / \mathrm{w}_{0}=0.42$ corresponded to Cas formation instead of $\mathrm{CaO}\left(\mathrm{w} / \mathrm{w}_{0}=\right.$ 0.33). At 110 minutes hydrogen was purged from the system and the temperature was decreased to $750^{\circ} \mathrm{C}$; when $5.6 \% \mathrm{CO}_{2}$ was added at 130 minutes, essentially no weight gain occurred, thus, roviding additional evidence that the decomposition product was Cas instead of CaO. Overall, the attempt to increase the carbonation reactivity by decomposing calcium compounds to produce CaO having greater porosity was half successful and half a total failure. As a result, calcium acetate (sample 7) was selected as the second base sorbent to be tested in Task 3.

Sample 9 was a commercial dolomite containing approximately equal molar quantities of $\mathrm{CaCO}_{3}$ and $\mathrm{MgCO}_{3}$ obtained from National Lime Co. Dolomite was chosen in order to test the possible diluent effect of magnesium. Calcination of both calcium and magnesium carbonates should be effective in producing porosity in the product mixed oxides. Subsequent carbonation of $\mathrm{CaO}$ would reduce porosity as before. However, at carbonation conditions of interest, Mgo does not carbonate, but should act as a diluent to modify the degree of pore closure experienced by pure CaO. Results for one complete calcination-carbonation cycle 


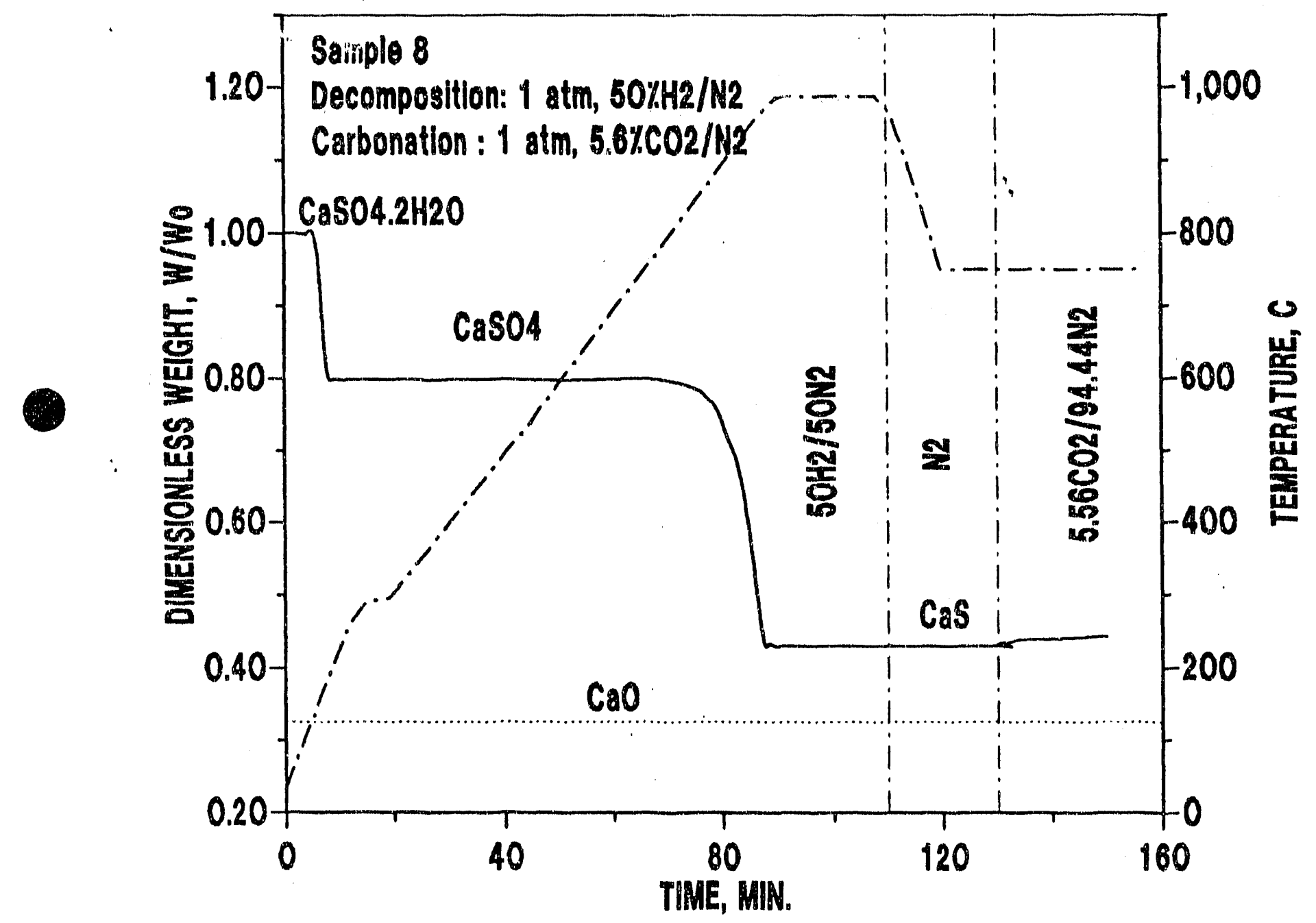

Figure 21. Decomposition-Carbonation Kinetics: Sample 8. 
using the high pressure reactor are shown in Figure 22. Calcination began at approximately $450^{\circ} \mathrm{C}$ and was complete at about the time the sample reached the desired final temperature of $750^{\circ} \mathrm{C}$. Calcination of $\mathrm{MgCO}_{3}$ should occur at lower temperature, followed by calcination of $\mathrm{CaCO}_{3} \cdot$ Experimentally, however, calcination began at a lower temperature compared to pure $\mathrm{CaCO}_{3}$, but there was no clearcut distinction in the weight loss curve between $\mathrm{MgCO}_{3}$ and $\mathrm{CaCO}_{3}$. The final value of $\mathrm{w} / \mathrm{w}_{0}$ corresponded closely to the loss on ignition value reported by National Lime, and represented complete conversion of $\mathrm{CaCO}_{3}$ and $\mathrm{MgCO}_{3}$ to the respective oxides.

Carbonation was carried out at $750^{\circ} \mathrm{C}, 1 \mathrm{~atm}$, in $15 \% \mathrm{CO}_{2}$ (balance $\mathrm{N}_{2}$ ), conditions where CaO can be carbonated but not Mgo. Carbonation behavior was qualitatively similar to that exhibited by other sorbents. A rapid initial reaction period lasting less than 5 minutes was followed by an abrupt transition to a slow reaction phase. The transition, however, occurred at $\mathrm{w} / \mathrm{w}_{\mathrm{O}} \sim 0.73$, which corresponds to a fractional calcium carbonation of 0.85 , significantly higher than observed using pure $\mathrm{CaCO}_{3}$. 60 minutes after the beginning of carbonation the value of $\mathrm{W} / \mathrm{w}_{\mathrm{O}}$ was 0.75 , which corresponds to 0.93 fractional calcium carbonation. Because of the favorable results, dolomite (sample 9) was chosen as the third base sorbent for Task 3 testing.

Figure 23 provides a direct comparison of first-cycle carbonation behavior for the three base sorbents at equivalent carbonation conditions. Fractional carbonation, $x$, is reported on the $y$-axis instead of $\mathrm{W} / \mathrm{w}_{\mathrm{o}}$ as used previously to facilitate the direct comparison between different samples. While each sample exhibits qualitatively similar behavior, it is clear that, at these conditions, greater than $90 \%$ carbonation can be achieved using samples 7 and 9 , compared to only about $80 \%$ carbonation for sample 1 . 


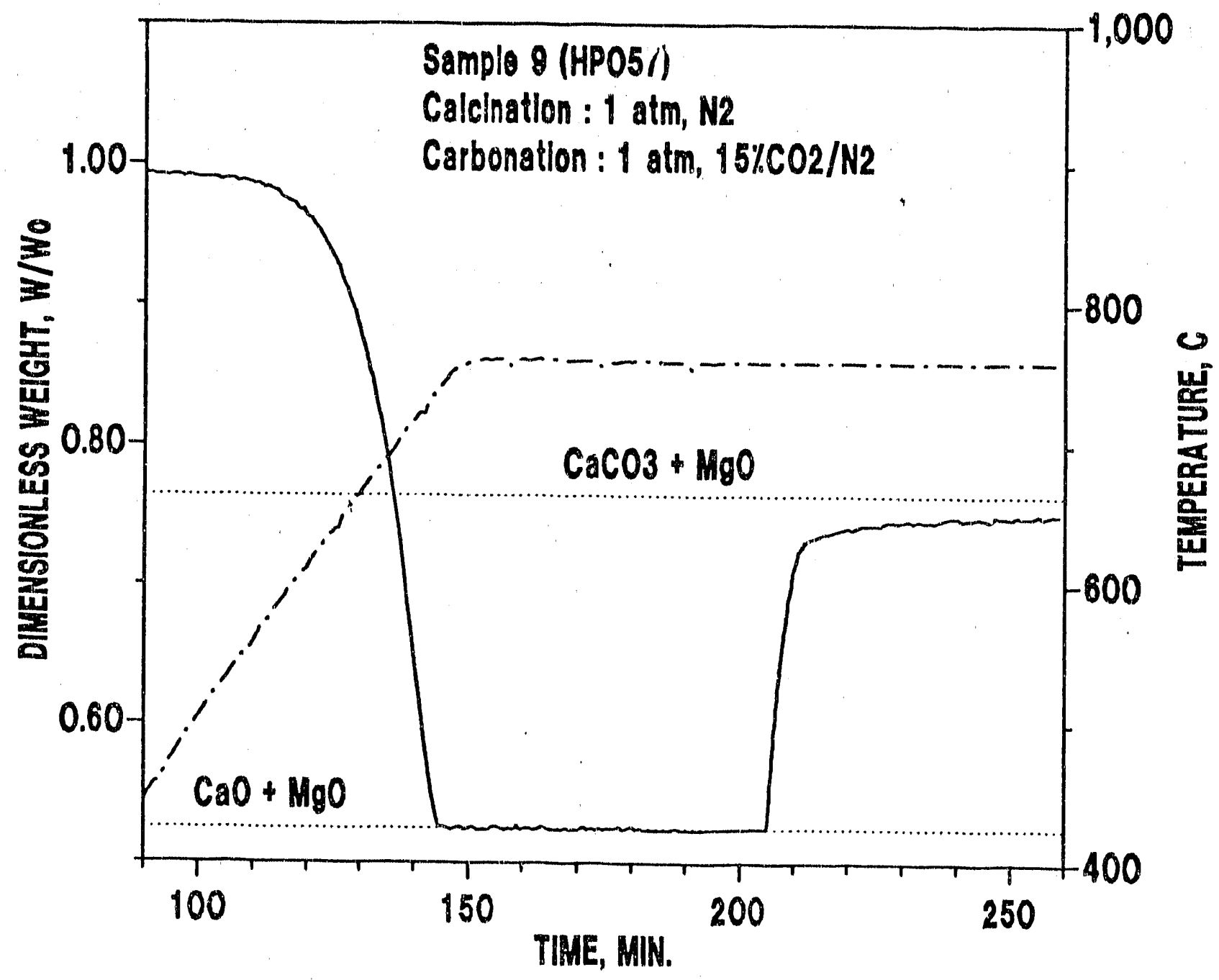

Figure 22. Calcination-Carbonation Kinetics: Sample 9. 


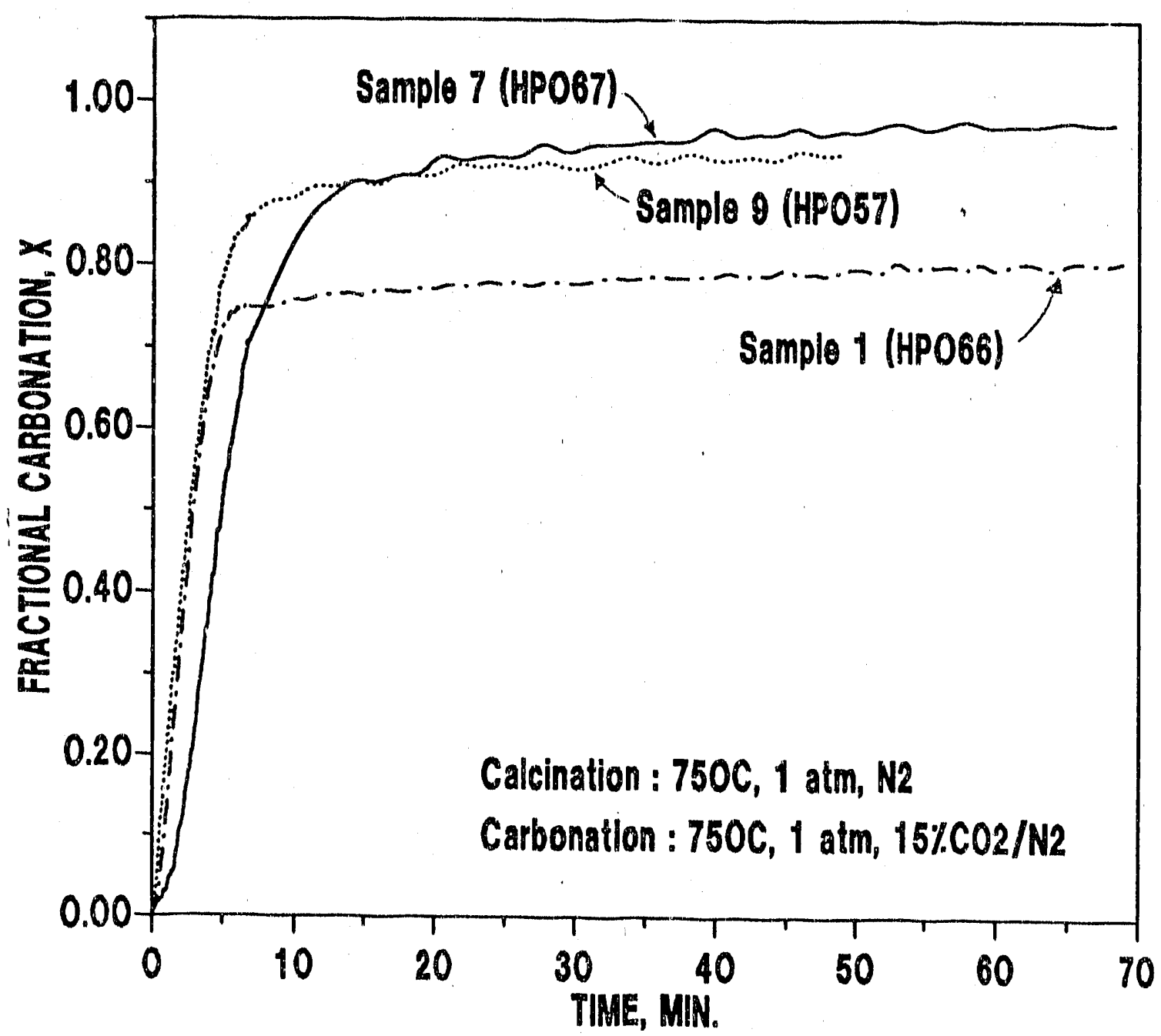

Figure 23. Comparison of First Cycle Carbonation Kinetics: Samples 1, 7, and 9. 
TASK 3: TWO-CYCLE TEST SERIES

The objective of Task 3 was to test the calcination-carbonation kinetics of the three base sorbents as a function of temperature, pressure, and gas composition. Each test consisted of two complete calcination-carbonation cycles so that preliminary information on sorbent durability would also be obtained. Reaction conditions were chosen on the basis of results from the screening program in Task 2. The primary parameters to be tested and their values are:
a. Calcination Temperature (3): $750,825,900^{\circ} \mathrm{C}$
b. Carbonation Temperature (3): $550,650,750^{\circ} \mathrm{C}$
c. Carbonation Pressure (3): 1, 5, $15 \mathrm{~atm}$
d. $\mathrm{CO}_{2}$ Mol Fraction (3): $0.01,0.05,0.15$

The complete matrix defined above consists of 243 tests $(3$ sorbents $\times 3$ calcination temperatures $\times 3$ carbonation temperatures $\mathrm{x} 3$ carbonation pressures $\times \quad 3 \mathrm{CO}_{2}$ mol fractions). Because this number of tests is unrealistic, deletions from the test matrix are being made as results are generated. Additional "off-matrix" tests involving secondary variables such as calcination gas composition, calcination pressure, and carbonation background gas composition will be carried out as need arises and as time permits.

The status of the Task 3 test matrix through August 1990 is shown in Tables V, VI, and VII for samples 1,7 , and 9, respectively. Completed tests are designated by the run number, HPXXx, in the appropriate row and colurn. As a normal rule only a single test has been carried out at a given set of test conditions. Reproducibility tests have been and will continue to be made periodically; tests which have been reproduced are designated by the multiple run number entries in a single position. 
Table V

Task 3 Test Matrix for Calcium Carbonate (Sample 1)

\begin{tabular}{|c|c|c|c|c|c|}
\hline $\begin{array}{l}\text { CALCIN- } \\
\text { ATION } \\
\text { TEMP C }\end{array}$ & $\begin{array}{l}\text { CARBON- } \\
\text { ATION } \\
\text { TEMP C }\end{array}$ & $\begin{array}{l}\text { CARBON- } \\
\text { ATTON } \\
\text { ATM\% } \mathrm{CO}_{2}\end{array}$ & $\begin{array}{l}\text { CARBONATION } \\
\text { PRESSURE } \\
1 \text { ATM }\end{array}$ & $\begin{array}{l}\text { CARBONATION } \\
\text { PRESSURE } \\
5 \text { ATM }\end{array}$ & $\begin{array}{l}\text { CARBONATION } \\
\text { PRESSURE } \\
15 \text { ATM }\end{array}$ \\
\hline 900 & 750 & 1.5 & HPO 48 & & HPO 40 \\
\hline 900 & 750 & 5 & & & 1111111111 \\
\hline 900 & 750 & 1 & & & 1111111111 \\
\hline 900 & 650 & 15 & & & 111111111 \\
\hline 900 & 650 & 5 & & & 111111111 \\
\hline 900 & 650 & 1 & & & 111111111 \\
\hline 900 & 550 & 15 & & & 111111111 \\
\hline 900 & 550 & 5 & & & 1111111111 \\
\hline 900 & 550 & 1 & & & 1111\|\|$\|$ \\
\hline 825 & 750 & 15 & & & HP039 \\
\hline 825 & 750 & 5 & & & \\
\hline 825 & 750 & 1 & & & \\
\hline 825 & 650 & 15 & $\mathrm{HPO} 45$ & & \\
\hline 825 & 650 & 5 & HPO51 & & \\
\hline 825 & 650 & 1 & & & \\
\hline 825 & 550 & 15 & & & \\
\hline 825 & 550 & 5 & & & \\
\hline 825 & 550 & 1 & & & \\
\hline 750 & 750 & 15 & HPO21;023 & HP063 & $\mathrm{HPO} 32$ \\
\hline 750 & 750 & 5 & & & $\mathrm{HPO} 34$ \\
\hline 750 & 750 & 1 & & & HP033 \\
\hline 750 & 650 & 15 & $\mathrm{HPO46}$ & & \\
\hline 750 & 650 & 5 & $\mathrm{HPO} 43$ & & \\
\hline 750 & 650 & 1 & DIIIII & & \\
\hline 750 & 550 & 15 & HPO49 & & \\
\hline 750 & 550 & 5 & & & \\
\hline 750 & 550 & 1 & HPO50;059 & & \\
\hline
\end{tabular}


Table VI

Task 3 Text Matrix For Calcium Acetate (Sample 7)

\begin{tabular}{|c|c|c|c|c|c|}
\hline $\begin{array}{l}\text { CALCIN- } \\
\text { ATION } \\
\text { 'TEMP C }\end{array}$ & $\begin{array}{l}\text { CARBON- } \\
\text { ATION } \\
\text { TEMP C }\end{array}$ & $\begin{array}{l}\text { CARBON- } \\
\text { AT'ION } \\
\text { A'TM\% } \mathrm{CO}_{2}\end{array}$ & $\begin{array}{c}\text { CARBONATION } \\
\text { PRESSURE } \\
1 \text { ATM }\end{array}$ & $\begin{array}{l}\text { CARBONATION } \\
\text { PRESSURE } \\
5 \text { ATM }\end{array}$ & $\begin{array}{l}\text { CARBONATION } \\
\text { PRESSURE } \\
15 \text { ATM }\end{array}$ \\
\hline 900 & 750 & 15 & HPO 55 & & HP076 \\
\hline 900 & 750 & 5 & & & \\
\hline 900 & 750 & 1 & ttI & & \\
\hline 900 & 650 & 15 & 111\|\|\|\|\|\| & & \\
\hline 900 & 650 & 5 & 1111111 & & \\
\hline 900 & 650 & 1 & & & \\
\hline 900 & 550 & 15 & \|\|\|\|\|\|$U \|$ & & \\
\hline 900 & 550 & 5 & 1111111111111 & & \\
\hline 900 & 550 & 1 & 11111111111 & & \\
\hline 825 & 750 & 15 & 053 & & \\
\hline 825 & 750 & 5 & & & \\
\hline 825 & 750 & 1 & & & \\
\hline 825 & 650 & 15 & HPO54 & & \\
\hline 825 & 650 & 5 & HP052 & & \\
\hline 825 & 650 & 1 & & & \\
\hline 825 & 550 & 15 & & & \\
\hline 825 & 550 & 5 & & & \\
\hline 825 & 550 & 1 & & & \\
\hline 750 & 750 & 15 & $\begin{array}{l}\text { HP022;025;067; } \\
068\end{array}$ & HPO64 & HPO 36 \\
\hline 750 & 750 & 5 & & & HPO37 \\
\hline 750 & 750 & 1 & & 17177 & HPO 38 \\
\hline 750 & 650 & 15 & HP0 56 & & \\
\hline 750 & 650 & 5 & & & \\
\hline 750 & 650 & 1 & MIIIDIIIIIIII & & \\
\hline 750 & 550 & 15 & HPO61 & & \\
\hline 750 & 550 & 5 & & & \\
\hline 750 & 550 & 1 & HPO60 & & \\
\hline
\end{tabular}


Table VII

Task 3 Test Matrix for Dolomite (Sample 9)

\begin{tabular}{|c|c|c|c|c|c|}
\hline $\begin{array}{l}\text { CALCIN- } \\
\text { ATION } \\
\text { TEMP C }\end{array}$ & $\begin{array}{l}\text { CARBON- } \\
\text { ATION } \\
\text { TEMP C }\end{array}$ & $\begin{array}{c}\text { CARBON- } \\
\text { ATION } \\
\text { ATM: } \mathrm{CO}_{2} \\
\end{array}$ & $\begin{array}{l}\text { CARBONATION } \\
\text { PRESSURE } \\
1 \text { ATM }\end{array}$ & $\begin{array}{l}\text { CARBONATTON } \\
\text { PRESSURE } \\
5 \text { ATM }\end{array}$ & $\begin{array}{l}\text { CARBONATION } \\
\text { PRFGSURE } \\
15 \text { ATM }\end{array}$ \\
\hline 900 & 750 & 15 & HPOE2 & 11111111111 & HP077 \\
\hline 900 & 750 & 5 & & 1111111111 & \\
\hline 900 & 750 & 1 & & & \\
\hline 900 & 650 & 15 & & 1111111111 & \\
\hline 900 & 650 & 5 & & 11111111111 & \\
\hline 900 & 650 & 1 & & 11111111111 & \\
\hline 900 & 550 & 15 & & 1111111111 & \\
\hline 900 & 550 & 5 & & 1111111111 & \\
\hline 900 & 550 & 1 & & 1111111111 & \\
\hline 82.5 & 750 & 15 & & & \\
\hline 825 & 750 & 5 & & & \\
\hline 825 & 750 & 1 & & & \\
\hline 825 & 650 & 15 & & & \\
\hline 825 & 650 & 5 & & & \\
\hline 825 & 650 & 1 & & & \\
\hline 825 & 550 & 15 & & & \\
\hline 825 & 550 & 5 & & & \\
\hline 82.5 & 550 & 1 & & & \\
\hline 750 & 750 & .15 & 057 & HP069 & HP075 \\
\hline 750 & 750 & 5 & & & \\
\hline 750 & 750 & 1 & & & HPO8O \\
\hline 750 & 650 & 15 & HP071 & & \\
\hline 750 & 650 & 5 & $\mathrm{HPO} 72$ & & \\
\hline 750 & 650 & 1 & 11111 & & \\
\hline 750 & 550 & .15 & $\mathrm{HPO} 73$ & & \\
\hline 750 & 550 & 5 & HPO 74 & & \\
\hline 750 & 550 & 1 & & & \\
\hline
\end{tabular}


Tests which have been eliminated are designated by the rows and columns marked with the vertical and slanted lines. Eliminations have so far been based upon two criteria: (1) equilibrium constraints and (2) the apparent adverse effect of the highest calcination temperature on carbonation kinetics. Examination of Figure 1 shows that the equilibrium $\mathrm{CO}_{2}$ partial pressure at 750 and $650^{\circ} \mathrm{C}$ are approximately 0.07 and 0.007 atmospheres, respectively. Consequently, 36 tests at 650 and $750^{\circ} \mathrm{C}$ carbonation temperature in which the $\mathrm{CO}_{2}$ partial pressure was below or quite near the equilibrium limit were eliminated (vertical lines). An additional 21 tests involving $900^{\circ} \mathrm{C}$ calcination temperature have been eliminated based upon the perceived adverse effect of this calcination temperature on subsequent carbonation kinetics (slanted lines). In total, runs at 39 test conditions have been completed while 57 test conditions have been eliminated, leaving 147 openings in the test matrix.

Reaction Reproducibility

Reproducibility tests are important to establish a baseline expectation of normal run-to-run variation so that the effects of reaction parameter changes may be evaluated. Figure 24 compares the W/W $W_{0}$ versus tirne behavior for runs HP067 and HP068 using sample 7. Reproducibility is quite good in this and other tests leading to the conclusion that relatively minor changes in reactivity in response to reaction parameter changes are significant.

The Effect of Calcination Ternperature

$$
\begin{aligned}
& \text { As shown in the previous section, calcination in a } \mathrm{CO}_{2} \text {-free } \\
& \text { atmosphere is complete by the time the temperature reaches } 750^{\circ} \mathrm{C} \text {. }
\end{aligned}
$$




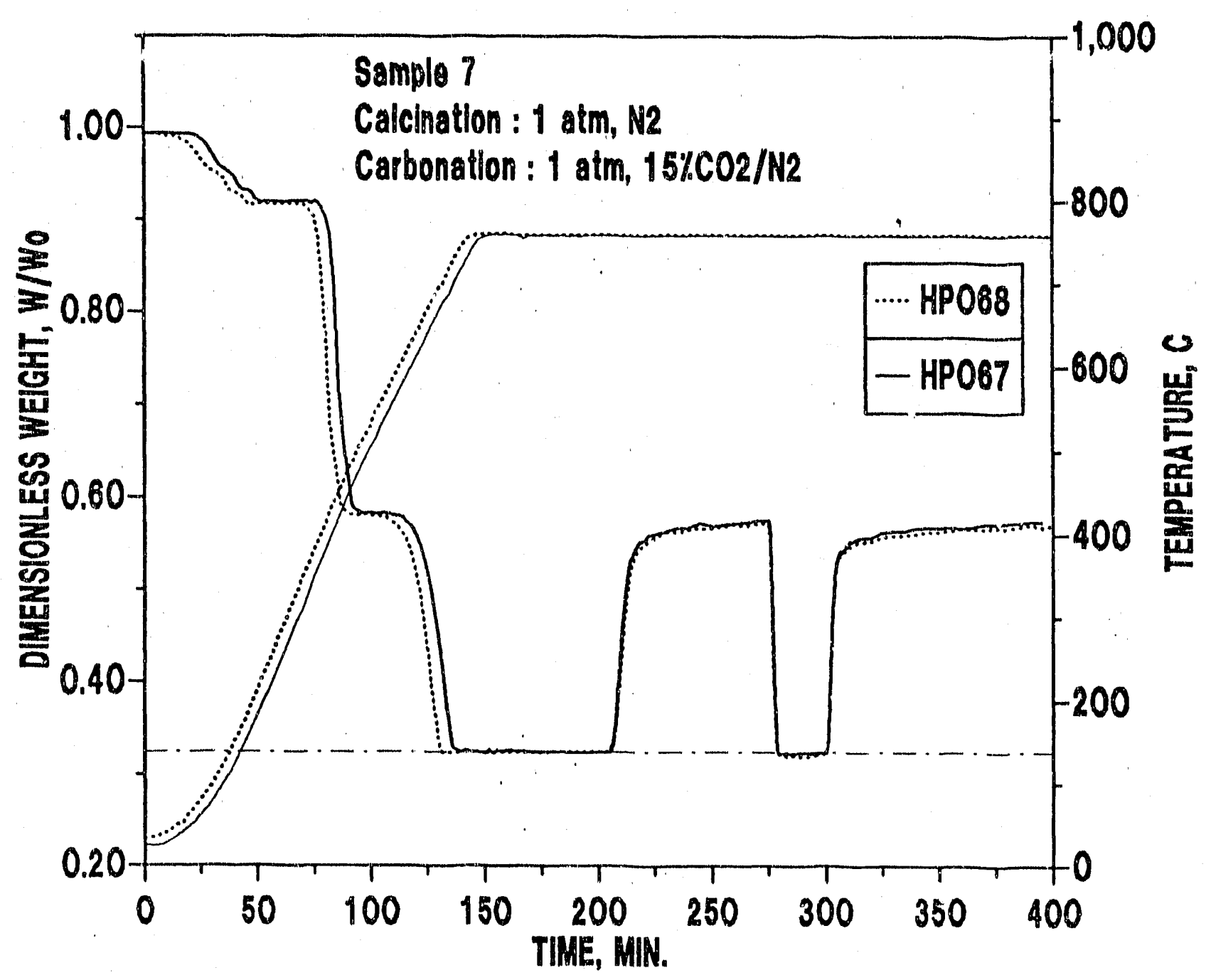

Figure 24. Reaction Reproduclbility: Runs HP067 and HP068 Using Sample 7. 
Consequently, the objective of the study of calcination temperature is t) determine any effect on the subsequent carbonation kinetics. Three calcination temperatures of 750,825 , and $900^{\circ} \mathrm{C}$ have been studied. Figures 25 and 26 show the fractional carbonation-time data for the first and second carbonation cycles, respectively, for sample 9 as a function of calcination temperature. Carbonation conditions were identical in each test. Figure 25 shows a relatively minor decrease in the carbonation rate with increasing calcination temperature during the rapid reaction phase. The final conversion (after 60 minutes) was also slightly lower following $900^{\circ} \mathrm{C}$ calcination. Second-cycle results (Figure 26) are similar but the negative effect of calcination temperature is magnified. There is a clear reduction in both the rate during the rapid reaction period and the final fractional carbonation. The graphical results are reinforced by the following numbers which report $\times(60)$, the fractional carbonation after 60 minutes, for each calcination temperature for the first- and second-cycles:

$\begin{array}{rcccc}\text { Calcination Temp. },{ }^{\circ} \mathrm{C} & 750 & 825 & 900 \\ X(60) & \text { First-Cycle } & 0.93 & 0.95 & 0.92 \\ & \text { Second-Cycle } & 0.94 & 0.92 & 0.86\end{array}$

The apparent small increase in second-cycle conversion following $750^{\circ} \mathrm{C}$ calcination is probably not significant; however, the decrease following $900^{\circ} \mathrm{C}$ calcination is believed to be significant. Similar negative effects of high calcination temperature have been noted with the other base sorbents as well.

These results led to the decision to eliminate numerous $900^{\circ} \mathrm{C}$ calcination runs from the test matrix. While other tests involving $900^{\circ} \mathrm{C}$ caclination will probably be eliminated in the future, some 


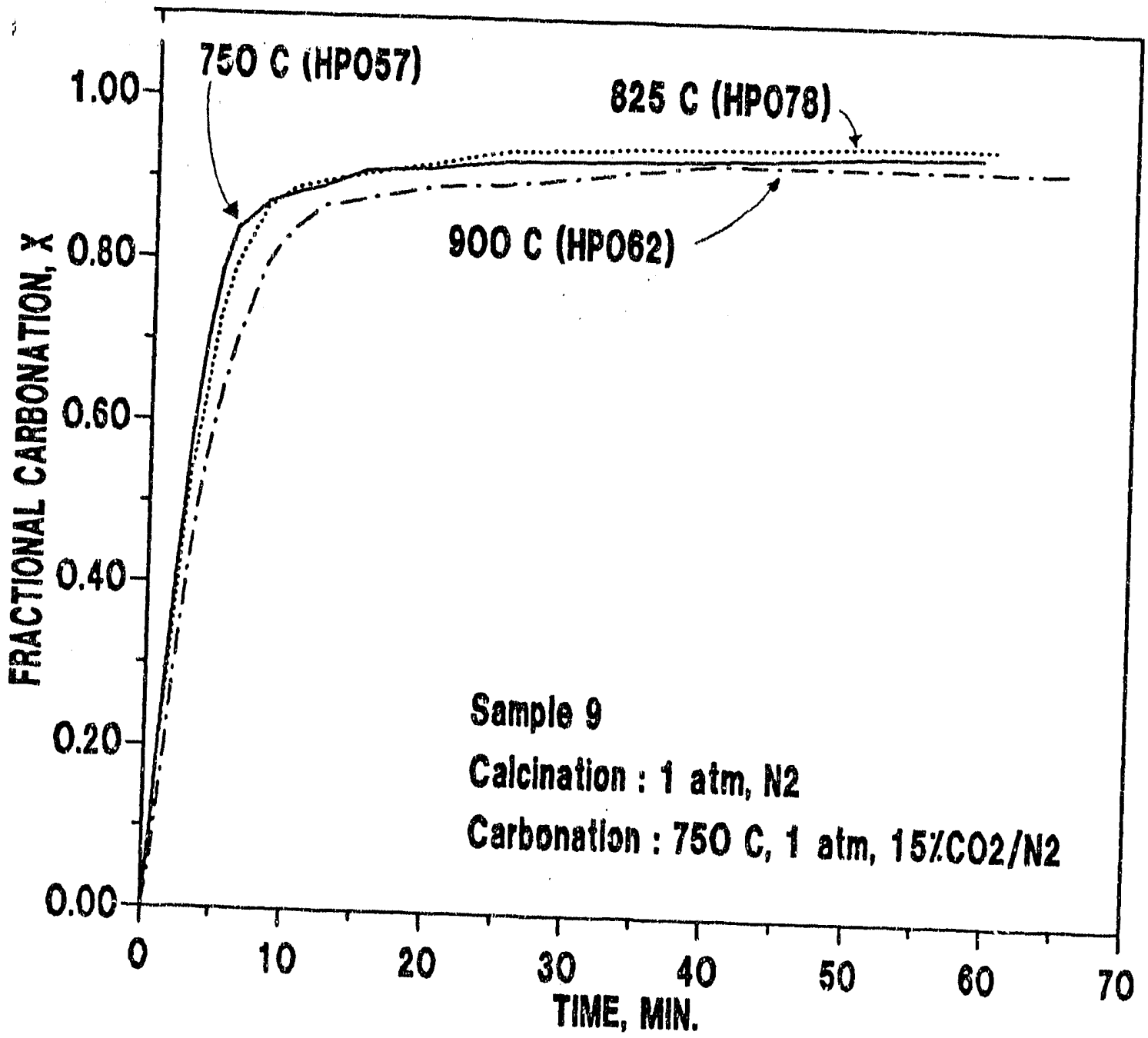

Figure 25. The Effect of Calcination Temperature on FirstCycle Carhonation Kinetics: Sample 9. 


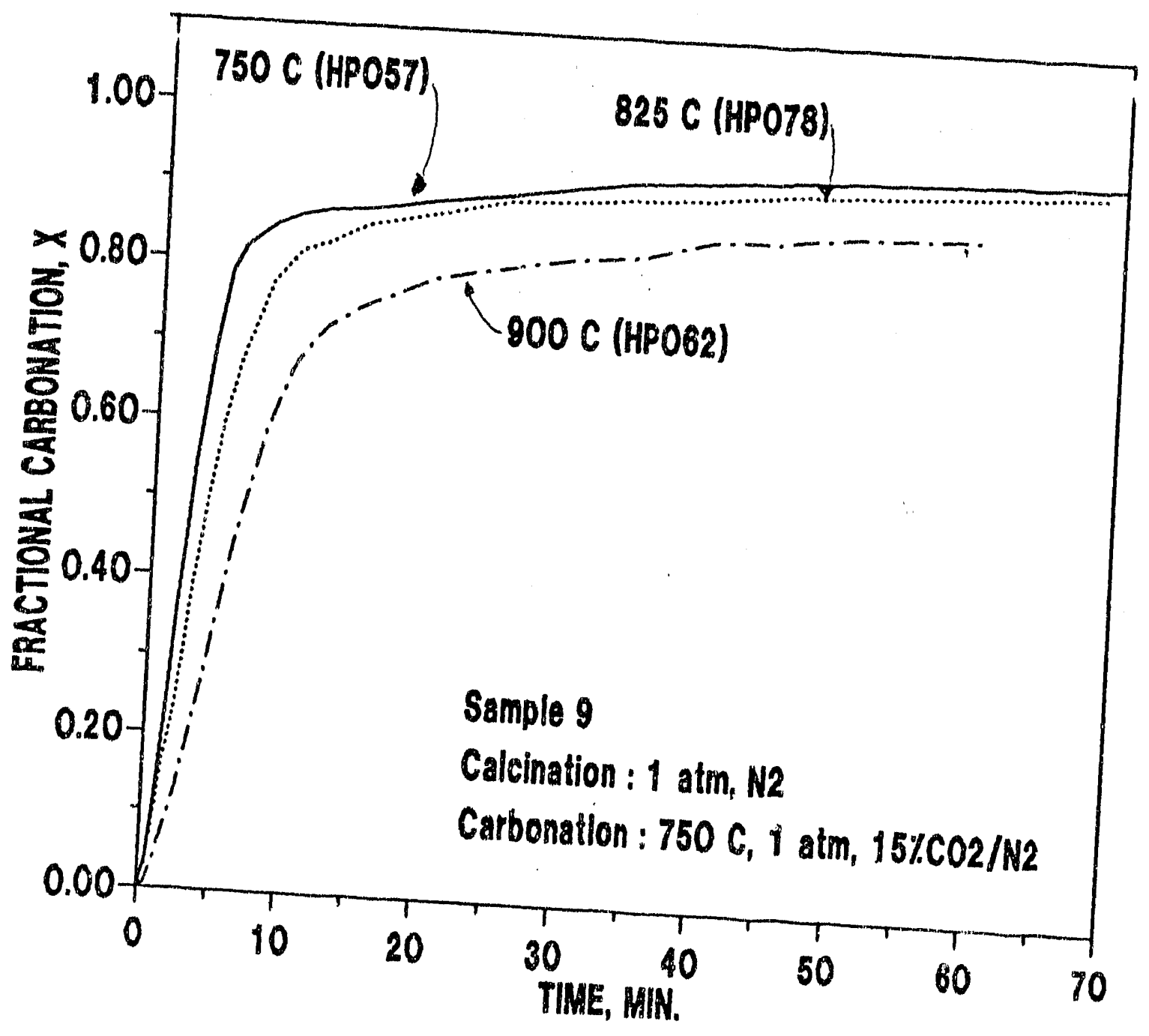
Figure 26. The Effect of Calcination Temperature on Second-
Cycle Carbonation Kinetics: Sample 9 . 
additional runs are planned to confirm that the present conclusions are not premature.

The Effect of Carbonation Temperature

Quite interesting and unexpected results concerning the effect of carbonation temperature, particularly on second-cycle kinetics, have emerged from the tests completed to date. Figure 27 shows the first-cycle carbonation results for a series of tests at different carbonation temperatures using sorbent sample 1 . Carbonation was preceeded by calcination at the minimum temperature of $750^{\circ} \mathrm{C}$. The results are generally consistent with the previously reported screening results on the effect of carbonation temperature (Figure 8). Both the duration of the rapid reaction phase and the fractional carbonation at the end of the rapid reaction phase increased with increasing temperature. The rate during the rapid reaction phase showed little effect of temperature at 550 and $650^{\circ} \mathrm{C}$, but a large decrease in rate was observed at $750^{\circ} \mathrm{C}$. This decrease is attributed to the increasing importance of the equilibrium $\mathrm{CO}_{2}$ pressure at the highest temperature.

The surpxising result concerns a large drop in second-cycle carbonation activity associated with $550^{\circ} \mathrm{C}$ carbonation temperature. A typical example is shown in Figure 28 where first-and second-cycle carbonation data for a sample 7 test are shown. After 20 minutes the fractional carbonation in cycle two was $20 \%$ less than observed in the same time in cycle one. In contrast, second-cycle conversions at the higher carbonation temperatures of 650 and $750^{\circ} \mathrm{C}$ were much closer to the first-cycle results. The adverse effect at $550^{\circ} \mathrm{C}$ seems to be common to each of the three sorbents as shown by the data in Table VIII. In this Labie, the fractional carbonation after twenty minutes in the first and 


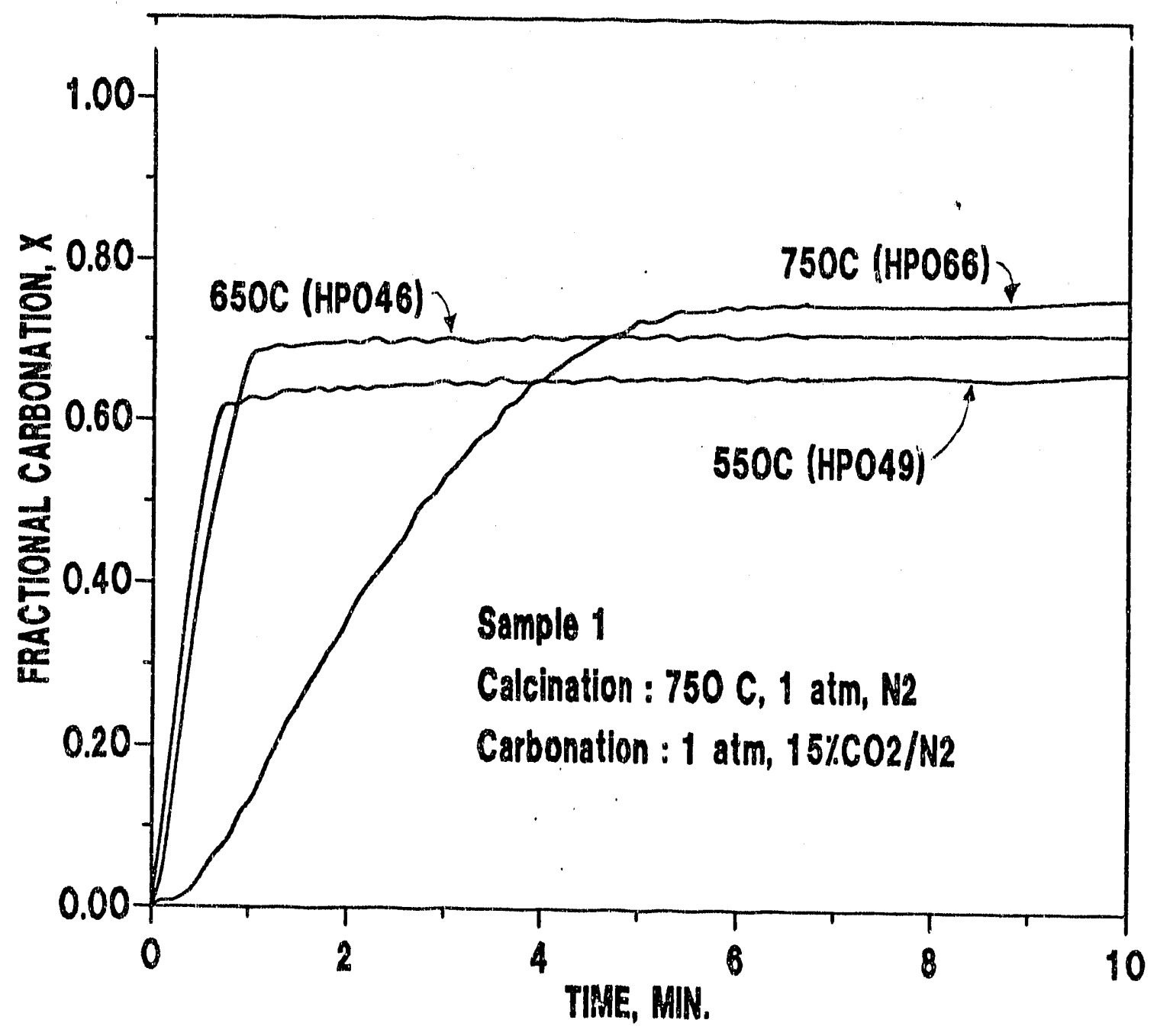

Figure 27. The Effect of Carbonation Temperature on Carbonation Kinetics: Sample 1. 


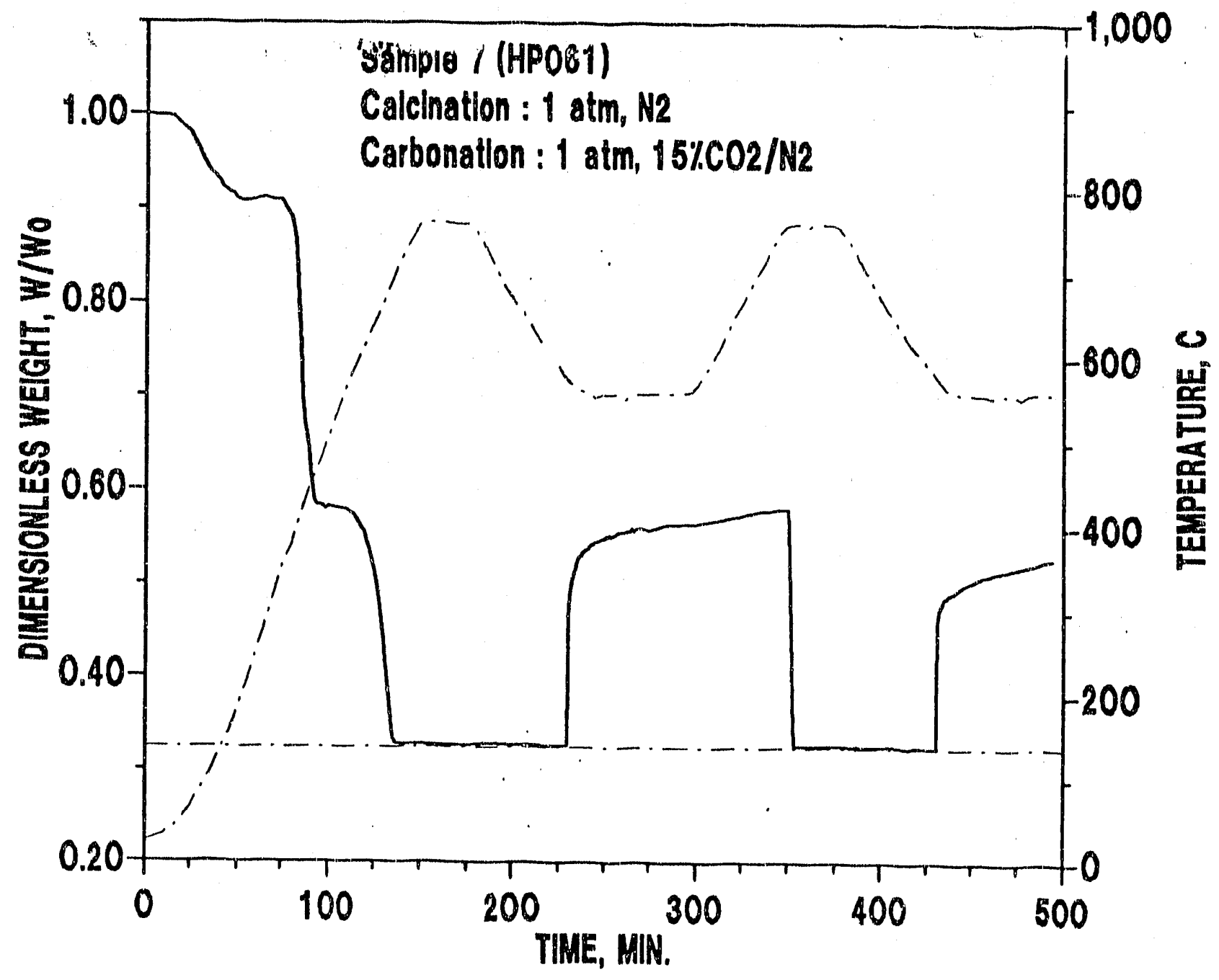

Figure 28. Comparison of First- and Second-Cycle Carbonation Kinetics at $550^{\circ} \mathrm{C}$ : Sample 7 . 
Table VIII: Comparison of First and Second Cycle Fractional Carbonations After Twenty Minutes as a Function of Temperature.

Carbonation Temp., ${ }^{\circ} \mathrm{C}$

Sample 1, Run

$$
\begin{aligned}
& x_{1}(20) \\
& x_{2}(20) \\
& x_{2}(20) / x_{1} \quad(20)
\end{aligned}
$$

Sample 7, Run

$$
\begin{aligned}
& x_{1}(20) \\
& x_{2}(20) \\
& x_{2}(20) / x_{1} \quad(20)
\end{aligned}
$$

Sample 9, Run

$$
\begin{aligned}
& x_{1}(20) \\
& x_{2}(20) \\
& x_{2}(20) / x_{1} \quad(20)
\end{aligned}
$$

550

650 750

HPO49

0.66

0.52

0.79

HP061

0.88

0.69

0.78

HPO73

0.89

0.71

0.80

1.00

0.94

HPO57

0.92

0.88

0.96

Calcination at $750^{\circ} \mathrm{C}, 1 \mathrm{~atm}, \mathrm{~N}_{2}$ Carbonation at $1 \mathrm{~atm}, 15 \% \mathrm{CO}_{2}$ 
second cycles, $x_{1}(20)$ and $x_{2}(20)$, and the ratio of these values for each sorbent at each carbonation temperature are presented. Both samples 7 and 9 show good reactivity maintenance $\left[\mathrm{x}_{2}(20) / \mathrm{X}_{1}(20) \geq 0.96\right]$ at 6.50 and $750^{\circ} \mathrm{C}$ carbonation temperatures, but a significant fall-off at $550^{\circ} \mathrm{C}$. The reactivity maintenance of sample 1 is much lower than the other samples at 650 and $750^{\circ} \mathrm{C}$, and falls off to a lesser degree at $550^{\circ} \mathrm{C}$. All three samples exhibit approximately equal reactivity maintenance at $550^{\circ} \mathrm{C}$. At the present time, we have no explanation for this unexpected behavior.

The Effect of $\mathrm{CO}_{2}$ Composition

Tests in which the $\mathrm{CO}_{2}$ concentration (mol fraction) was varied produced no unusual or unexpected results. Figure 29 compares the first cycle carbonation kinetics for sample 1 with calcination carried out at $750^{\circ} \mathrm{C}$ and 1 atmosphere in $\mathrm{N}_{2}$ and carbonation carried out at $750^{\circ} \mathrm{C}$ and 15 atmospheres using $\mathrm{CO}_{2}$ mol fractions of $0.01,0.05$, and 0.15 . As expected, the rate during the initial rapid rate period increased with increasing $\mathrm{CO}_{2}$ concentration. The final value of $\mathrm{w} / \mathrm{w}_{0}$ was effectively the same in each case. Second-cycle results for these tests were similar except for the fact that the final value of $w / W_{0}$ (after 40 minutes) was approximately 0.84 compared to 0.90 in the first cycle. This level of reduction in the extent of carbonation during the second cycle is consistent with other results for sample 1 at other reaction conditions (see Table VIII). The equivalent test series using sample 7 (calcium acetate) produced similar results except for the fact that the drop-off in reactivity during the second carbonation cycle was less severe. 


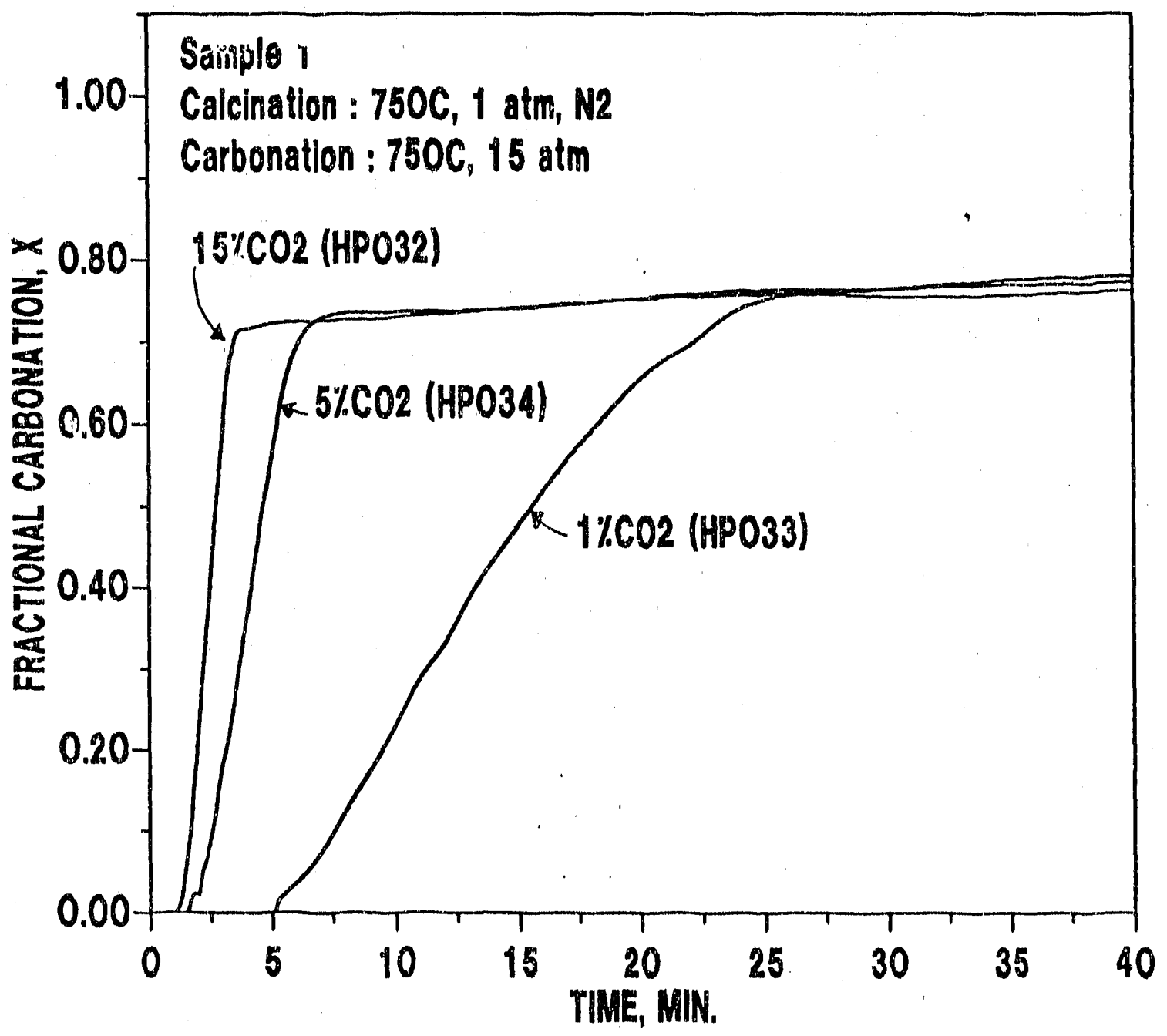

F1gure 29. The Effect of $\mathrm{CO}_{2}$ Composition on First-Cycle Carbonation Kinetics: Sample 1. 
The delay from $t=0$, when the three-way valve in the gas feed line was switched, and the beginning of the rapid reaction phase is particularly apparent in the 15 atmosphere data presented in Figure 29. Approximately 5 minutes elapsed before the reaction began with the 1\% $\mathrm{CO}_{2}$ test, while the delays at the higher concentrations were approximately 1.5 and 2 minutes. This delay is associated with the time required for the reactive gas to reach the sample after the side-aril valve is opened. The delay time increases with system pressure because of the reduced volumetric flow rate and also increases with decreasing $\mathrm{CO}_{2}$ concentration. At 1 atmosphere the delay is hardly noticeable, as seen in the previous figures reporting low pressure test results.

The Effect of Pressure

At constant mol fraction of $\mathrm{CO}_{2}$, an increase in the system pressure may produce two counteracting effects. Since $\mathrm{CO}_{2}$ concentration is directly proportional to pressure, an increase in the rate during the rapid reaction phase similar to that shown in Figure 29 should result. However, if transport resistances are important in determining the global rate, an opposing effect is introduced since both mass transfer and pore diffusion coefficients decrease with increasing pressure. The net effect, therefore, of an increase in system pressure could even be a decrease in global rate.

The effect of reactor pressure at constant $\mathrm{CO}_{2}$ mol fraction is illustrated in Figure 30 for sample 9. Although the varying time delay with pressure complicates the data somewhat, there is a clear increase in the rapid reaction rate between 1 and 5 atmospheres. However, the rates during the rapid reaction phase are approssimately equal at 5 and 15 atmosphere. This latier observation suggests that the opposing 


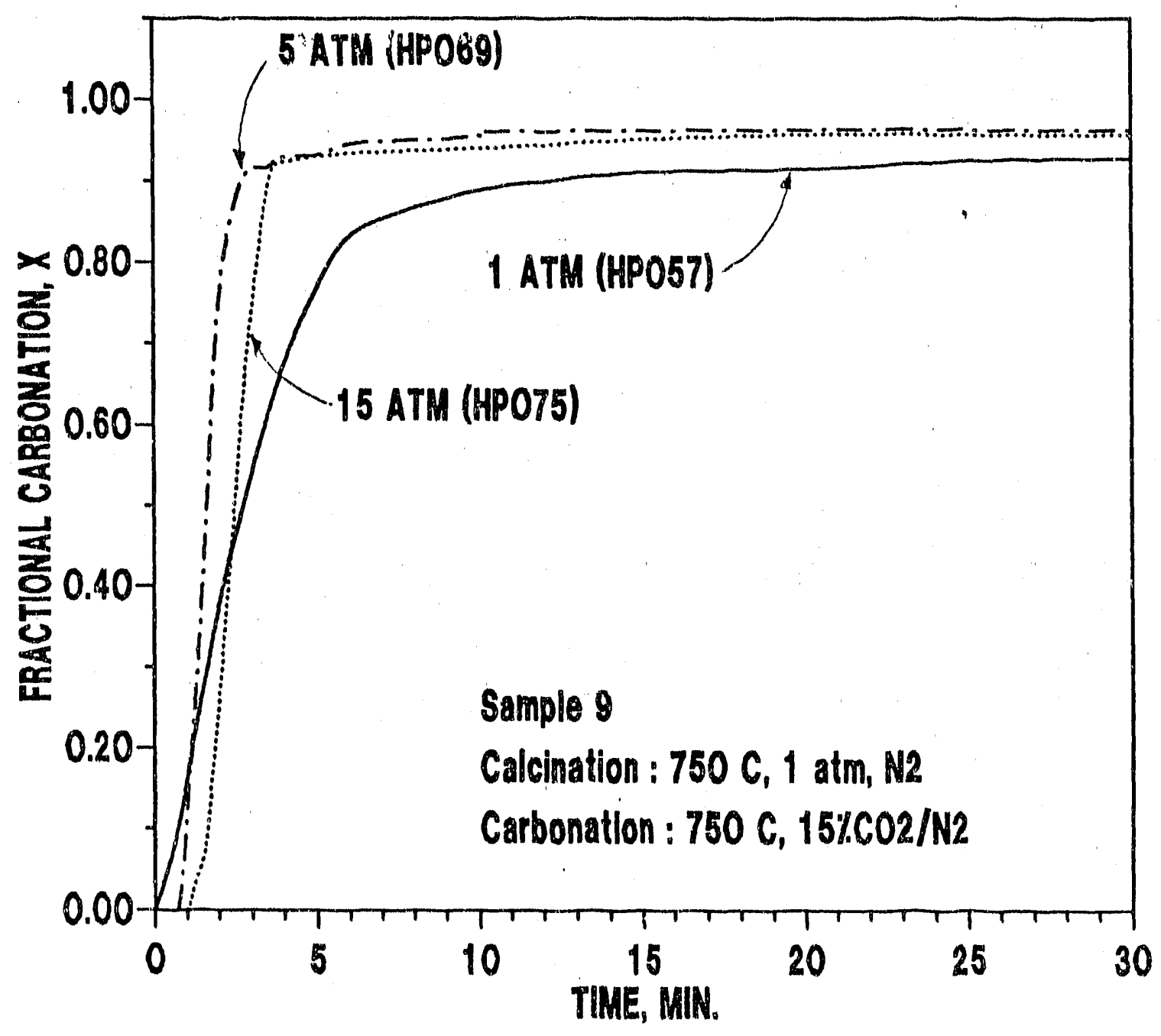

Figure 30. The Effect of Pressure at Constant $\mathrm{CO}_{2} \mathrm{Mo1}$ Fraction: Sample 9. 
effects of Increased concentration and decreased transport coefficients essentially cancel at these conditions. There is a slight increase in the final conversion between 1 and 5 atmospheres, with essentially no further increase between 5 and 15 atmospheres.

The isolated effect of pressure alone on the carbonation kinetics can be deduced by comparing results at $15 \% \mathrm{CO}_{2}$ and 1 atmosphere to results at $1 \% \mathrm{CO}_{2}$ and 15 atmospheres. Since $\mathrm{CO}_{2}$ concentration in the bulk gas is the same in these cases, the rate during the rapid reaction phase should be equal if transport resistances are unimportant. In contrast, if transport resistances are important the reduced transport coefficients at high pressure should result in a reduction in the global rate during the rapid reaction phase. Such results for sample 1 using $750^{\circ} \mathrm{C}$ calcination and carbonation temperatures are shown in Figure 31. Although the time delay for initiation of the reaction at high pressure somewhat complicates the comparison, it is clear that the rate in the rapid reaction phase iss much higher at 1 atmosphere than at 15 atmospheres. Once again, however, there is relatively little difference in the final fractional conversions for the two runs.

\section{Direct Comparison of the Three Base Sorbents}

While results presented previously have shown the effect of various reaction parameters on the carbonation kinetics for each of the sorbents separately, no direct comparison of the performance of the three sorbents at equivalent reaction conditions has been presented. Such data are shown in Figure 32. Calcination conditions of $750^{\circ} \mathrm{C}, 1$ atmosphere, in $100 \% \mathrm{~N}_{2}$, and carbonation conditions of $750^{\circ} \mathrm{C}, 1$ atmosphere, in $15 \% \mathrm{CO}_{2} / 85 \% \mathrm{~N}_{2}$ were used in each test. Fractional carbonation is plotted against time fur buth the first and second cycles 


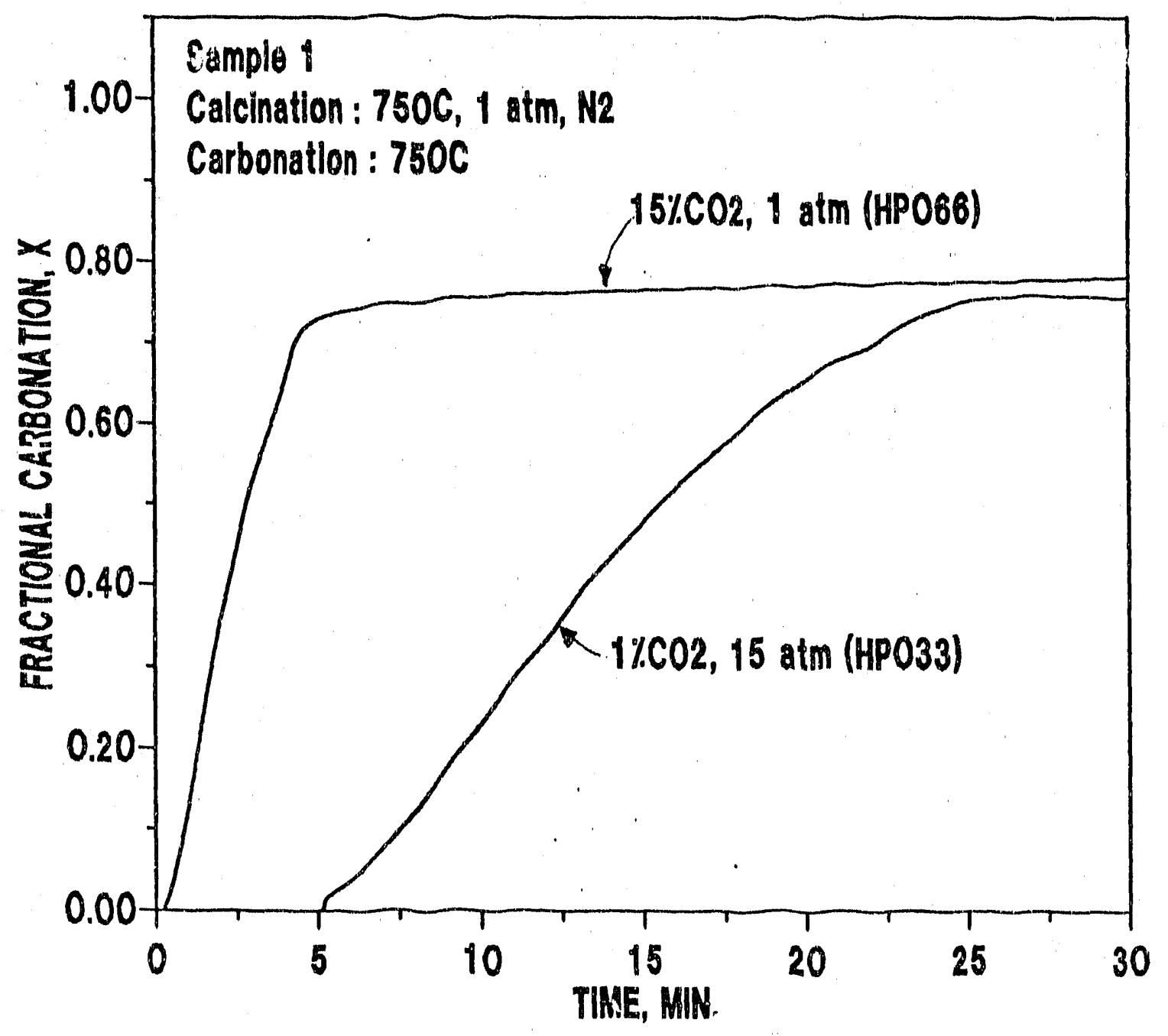

Figure 31. The Effect of Pressure at Constant $\mathrm{CO}_{2}$ Concentration: Sample 1 . 


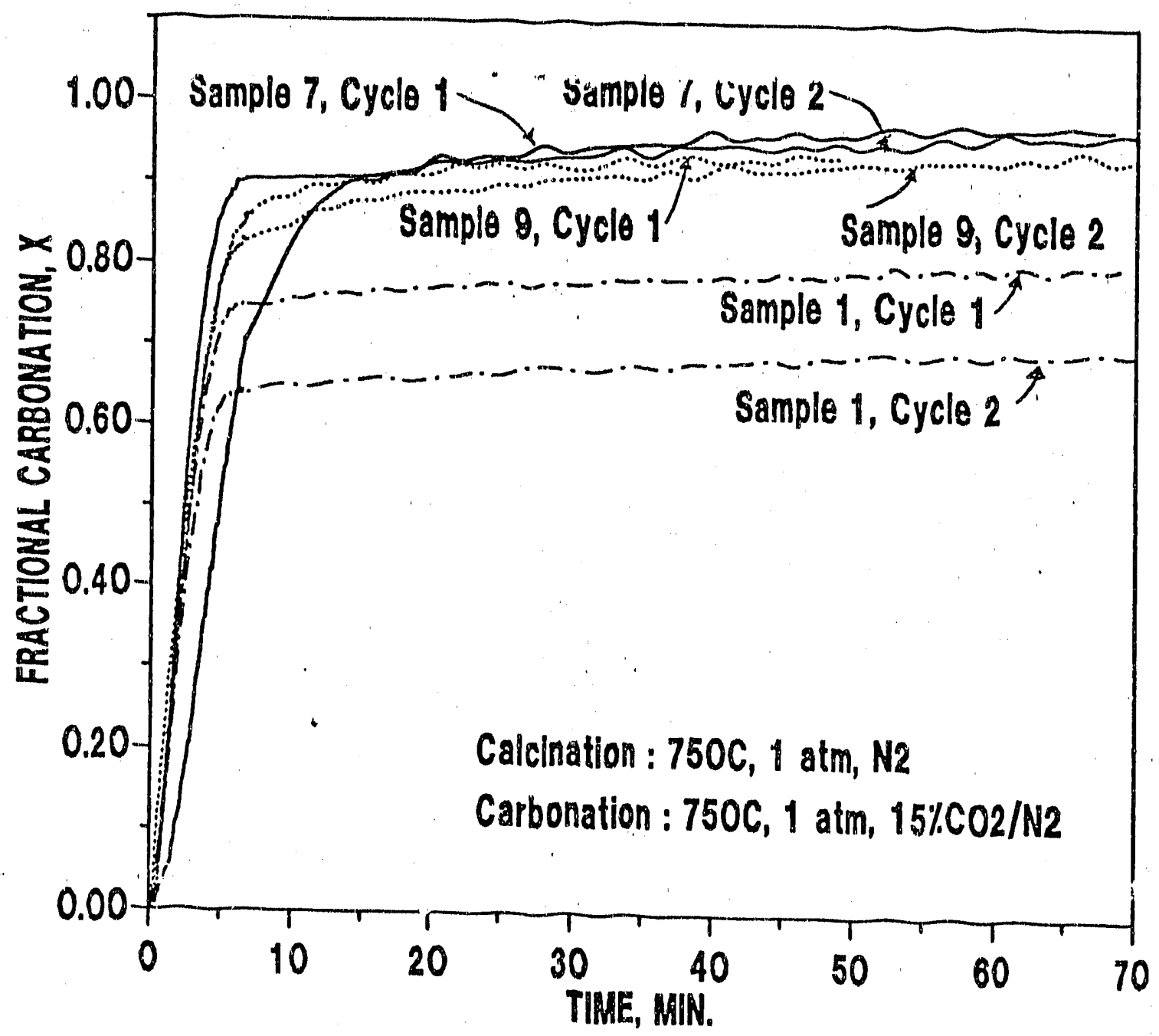

Figure 32. Comparison of Carbonation Kinetics: Three Sorbents Through Two cycles. 
for each of the three sorbents. Within reasonable limits, the rate during the rapid reaction period is equal for each of the six carbonation tests. Important differences are associated with the fractional carbonation at the end of the rapid reaction phase, and the change in that quantity between the first and second cycles. In the first cycle, the end of the rapid reaction phase for sample 1 occurs at $x \sim 0.75$ while he comparable values for samples 7 and 9 are in the range of 0.85 to 0.9 . By the end of the 70 minute carbonation period, the fractional carbonation of sample 1 increased to about 0.8 , while bcth samples 7 and 9 reacted to greater than $90^{\circ}$ completion. The decrease in reactivity between the first and second cycles was more severe for sample 1 . At the end of the test, sample 1 esperienced a decrease of about $14 \%$ between cycles, from $x \sim 0.8$ to $x \sim 0.69$, while the decrease for samples 7 and 9 was no more than $5 \%$.

Although the absolute numbers change somewhat depending upon reaction conditions, the general treuds exhibited by figure 32 have been found to be rather consistent. There is relatively little difference in the rate during the rapid reaction period, but samples 7 and 9 consistently produce higher fractional carbonation levels and a smaller decrease in reactivity between cycles 1 and 2 . The most significant exception to this general result is the unexpected decrease in seconacycle reactivity ex libited by samples 7 and 9 at $550^{\circ} \mathrm{C}$ carbonation temperature. This effect was illustrated by the data in Figure 28 and Table VIII. 
TASK 4: DETAILED PARAMETRIC TESTS

In this task, one sorbent will be selected and a more detailed examination of the effects of calcinaticn and carbonation reaction parameters will be conducted. In addition, small quantities of $\mathrm{H}_{2} \mathrm{~S}$ will be added in selected tests to examine the extent of the sulfidation reaction. Activities in this task are scheduled for year 02 . 
TASK 5: MULTICYCLE TESTS

The primary objective of this task, also scheduled during year 02 , is to extend the number of cycles to which the sorbent is exposed to approximately 10 , and to evaluate the sorbent performance in a synthetic coal gas containing $\mathrm{CO}, \mathrm{H}_{2}, \mathrm{H}_{2} \mathrm{O}$ and (sometimes) $\mathrm{H}_{2} \mathrm{~S}$ as well as $\mathrm{N}_{2}$ and $\mathrm{CO}_{2}$ 
TASK 6: STRUCTURAL PROPERTY MEASUREMENTS

The importance of sorbent structural properties in determining the kinetics of the carbonation reaction has been discussed in the literature review. A number of techniques to characterize the structure of the sorbents in various states have been, and will be, used throughout the project. During year 01 the techniques of primary emphasis have been mercury porosimetry to determine total pore volume and pore size distribution, and physical adsorption of methane to determine surface area using the BET method. The use of methane instead of the more common nitrogen for suface area determinations has been found to produce results having greater sensistivity and reliabi]ity for these relatively low surface area solids. During year 02, structural characterization techniques will be expanded to include scanning electron microscopy and helium pycnometry. The sorbents are being characterized in their as-received form, after calcination at various conditions, after carbonation at various conditions, and at selected stages of multiple calcination-carbonation cycles.

An overview of surface area and pore volume results for as-received and calcined samples is presented in Table IX. Surface area measurements have recently been plagued with instrument problems so that the surface area of sample 9 is not yet available. Neither surface area or pore volume results are available for sample 8 (calcium sulfate), and, because of the failure to obtain a usable sorbent from this sample, there are no plans at present to carry out such tests. The surface areas of the uncalcined (as-received) sorbents range from $0.4 \mathrm{~m}^{2} / \mathrm{g}$ for sample 1 to $11.8 \mathrm{~m}^{2} / \mathrm{g}$ for sample 3 . Similarly, the pore volumes range from a low of $0.05 \mathrm{~cm}^{3} / \mathrm{g}$ for sample 1 to $0.48 \mathrm{~cm}^{3} / \mathrm{g}$ for sample 3 . Pore 
Table IX. Comparison of Surface Area and Pore Volume Results for Calcium-Based Sorbents: Uncalcined and Calcined Forms

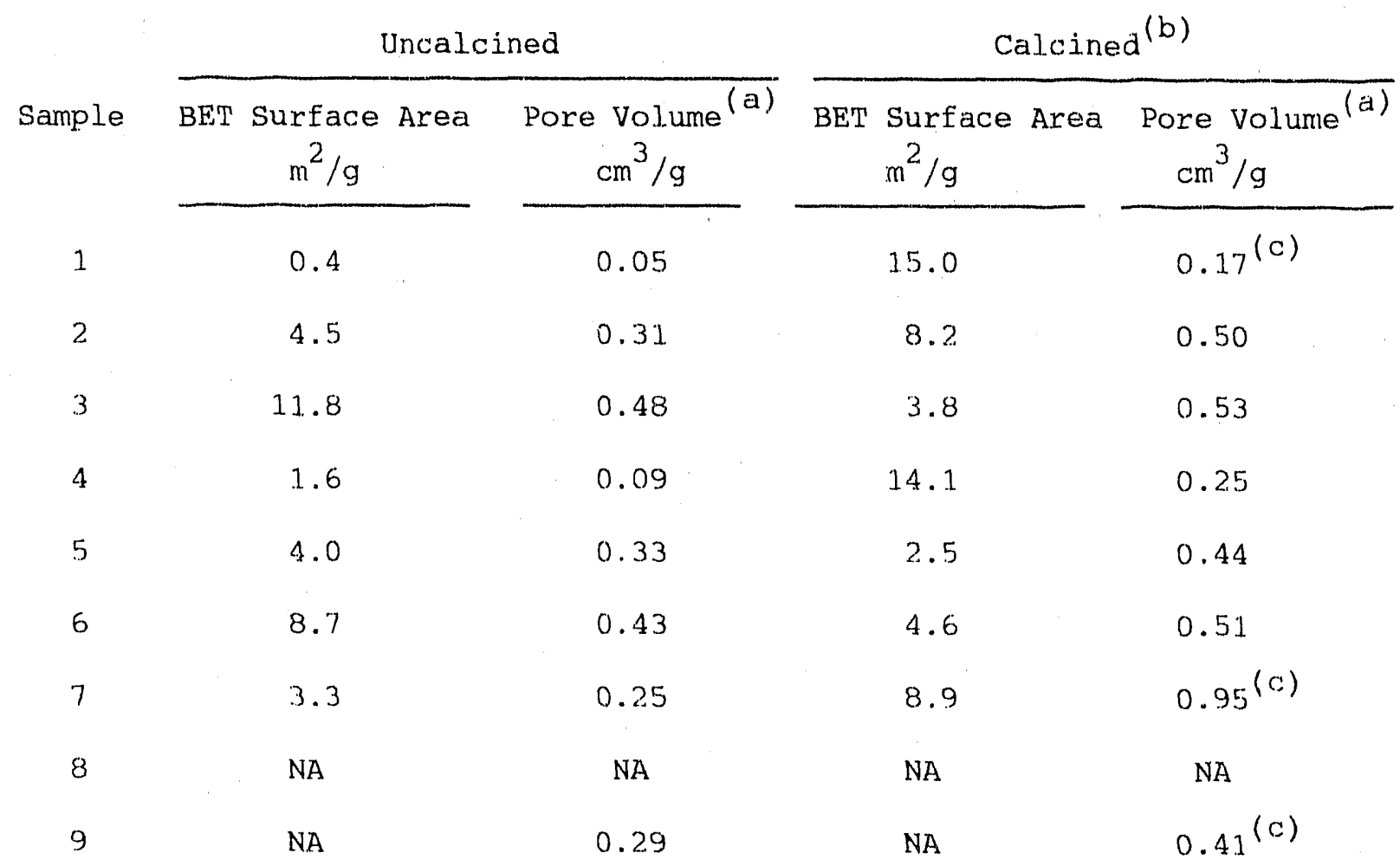

(a) 0.003 to 4 micron diameter range

${ }^{(b)}$ Calcination temperature $=900^{\circ} \mathrm{C}$

(c) Calcination time $=1 \mathrm{hr}$, calcination time somewhat variable in other tests. 
volume is reported over a range of pore diameter diameters from 0.003 to 4.0 microns, with the upper limit being somewhat arbitrary. With powdered samples, j, is impossible to distinguished between volume which is between thof poder particles and true pore volume within a single particle. The cut-off atameter of 4 microns, while arbitrary, has been chosen in an effort to exclude the inter-particle volume component.

As shown in Table IX, calcination always results in an increase in pore volume while surface areas of the calcined sorbent both larger and smaller than those of the uncalcined precursor have been measured. Both the surface area and pore volume of the calcined sorbent are reported per unit mass of the original sorbent. In order to convert to the basis of unit mass of calcined product it is necessary to multiply by the ratio of the mass of the original precursor to the mass of the calcined sorbent. For sample 1 this ratio is $1.0 / 0.56=1.79$, so that the actual. surface area and pore volume of calcined sample 1 are $26.8 \mathrm{~cm}^{2} / \mathrm{g}$ and $0.30 \mathrm{~cm}^{3} / \mathrm{g}$, respectively.

It is surprising that, although the structural properties of the carbonate samples (samples 1-6) in both the as-received and calcined forms are quite different, their carbonation behavior, as shown in F'igures 18 and 19, was quite similar. It seems probable that impurities in the commercial products could be responsible for many of the observed differences in the structure of the carbonate samples. One common feature among samples $1-6$ is that calcination produces a significant increase in pore volume, ranging from 0.03 to $0.12 \mathrm{~cm}^{3} / \mathrm{g} \mathrm{CaCO}_{3}$, for pore diameters in the range of 0.02 to 0.2 microns. We conclude that these pores are found by $\mathrm{CO}_{2}$ release during calcination. This is illustrated in Figure 33 where the cumulative volume versus pore diameter curves for as-received and calcined sample 1 are comrared. In 


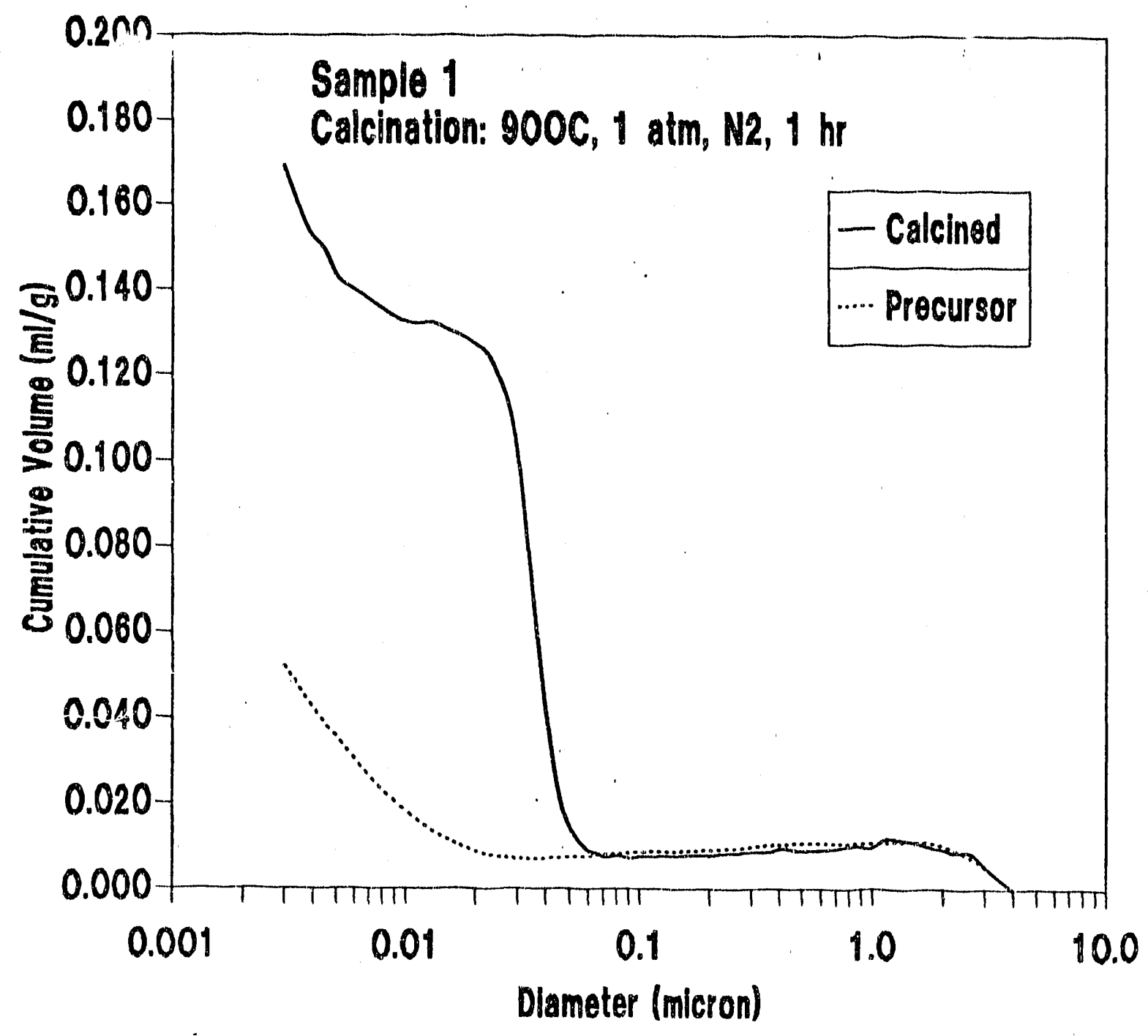

Figure 33. Pore Size Distribution Before and After Calcination: Sample 1 . 
this example the incremental pore volume of $0.12 \mathrm{~cm}^{3} / \mathrm{g}$ is primarily in the diameter range of 0.03 to 0.06 microns. Sample 5 produced similar results with an increase in pore volume of $0.10 \mathrm{~cm}^{3} / \mathrm{g} \mathrm{CaCO}_{3}$, primarily in the diameter range of 0.06 to 0.10 microns. Sample 3 provided an exception to the above general statement. Upon calcination, sample 9 (dolomite) exhibited an increase in pore volume which was similar to the other carbonate samples. The increase in pore volume was approximately $0.11 \mathrm{~cm}^{3} / \mathrm{g}$ dolomite and the majority of the pores formed were in the range of 0.03 to 0.06 microns diameter. Sample 7 (calcium acetate), in contrast, exhibited a much larger increase in pore volume and the pores formed were considerably larger, primarily in the range of 0.2 to 1.0 micron diameter.

The creation of pore volume during calcination along with subsequent changes which are caused by sintering and by the carbonation reaction have been examined in greatex detail for the three base sorbents. Figure 34, for example, compares the pore size distribution for as-received and calcined sample 7 as a function of calcination temperature. Calcination was carried out for 1 hour in nitrogen at 1 atmosphere at the indicated temperature. The large increase in pore volume and the dominance of larger diameter pores are evident from this figure. More careful study also shows an incremental increase in pore volume in the vicinity of 0.04 micron diameter, similar to that shown in Figure 33 for sample 1 . We attribute the formation of large pores to the loss of water of hydration and decomposition of the acetate group with the smalier increment at 0.04 microns diameter attributed to the decomposition of carbonate to oxide.

For practical purposes, it appears that the total pore volumes and pore size distributions are effectively the same following, calcination 


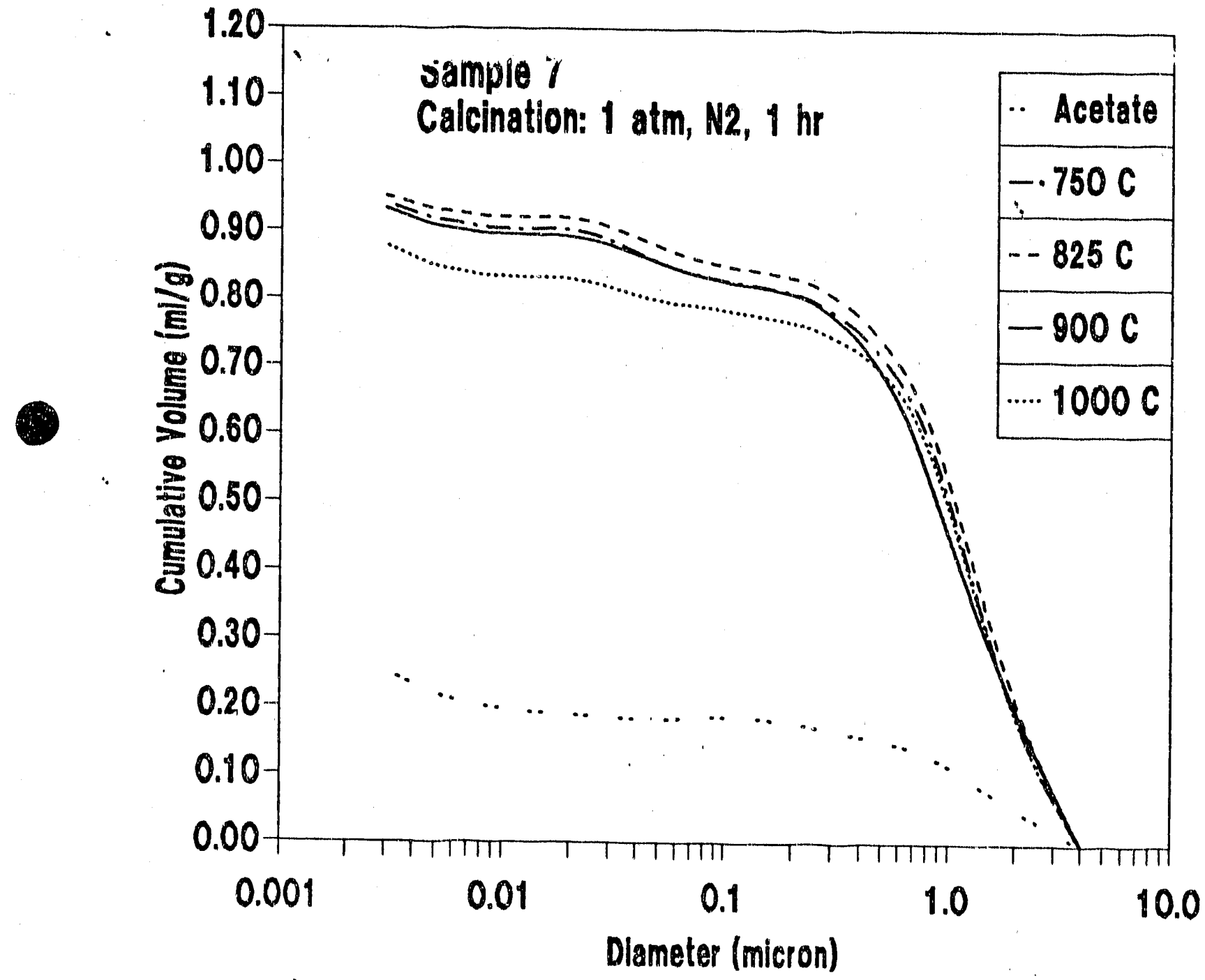

Figure 34. The Effect of Calcination Temperature on Pore Size Distribution: Sample 7. 
at 750,825 , and $900^{\circ} \mathrm{C}$. The latter temperature, however, appears to be near the limit as a significant change in size distribution and reduction in pore volume result at $1000^{\circ} \mathrm{C}$ calcination temperature. This result seems to be consistent with the tentative conclusion from kinetic tests that $900^{\circ} \mathrm{C}$ calcination temperature certainly should not be exceeded. Similar results were obtained when samples 1 and 9 were calcined at varying temperatures up to $1000^{\circ} \mathrm{C}$.

The effect of calcination time at a constant calcination temperature of $900^{\circ} \mathrm{C}$ has been determined for samples 1, 7, and 9. Example results for sample 9 are shown in Figure 35. The decrease in pore volume associated with pores of greater than 0.1 micron diameter following calcination was unexpected, but appears to be real. The sharp increase in pore volume in the 0.03 to 0.06 micron range is similar to that observed for sample 1 (Figure 33). The distribution curves at various calcination times, while somewhat scattered, do not show any definite trends. Similar results have been obtained from samples 1 and 7. We conclude, therefore, that at $900^{\circ} \mathrm{C}$, calcination time does not have an important effect on the pore structure of the sorbent.

since ca ination is effective in creating pore volume, it is logical to presume that subsequent carbonation would reduce or possibly eliminate the pore volume. Three tests, using each of the three base sorbents, in which calcination for 1 hour at $900^{\circ} \mathrm{C}$ and 1 atmosphere in nitrogen was followed by carbonation at $750^{\circ} \mathrm{C}$ and 1 atmosphere in $100 \% \mathrm{CO}_{2}$ have been completed. Pore size distribution curves for the as-received, calcined, and carbonated solids are shown in Figures 36, 37 , and 38 for samples 1, 7, and 9, respectively.

For sample 1, we see from Figure 36 that the pore structure of the carbonated sorbent is very similar to that of the original $\mathrm{CaCO}_{3}$. If 


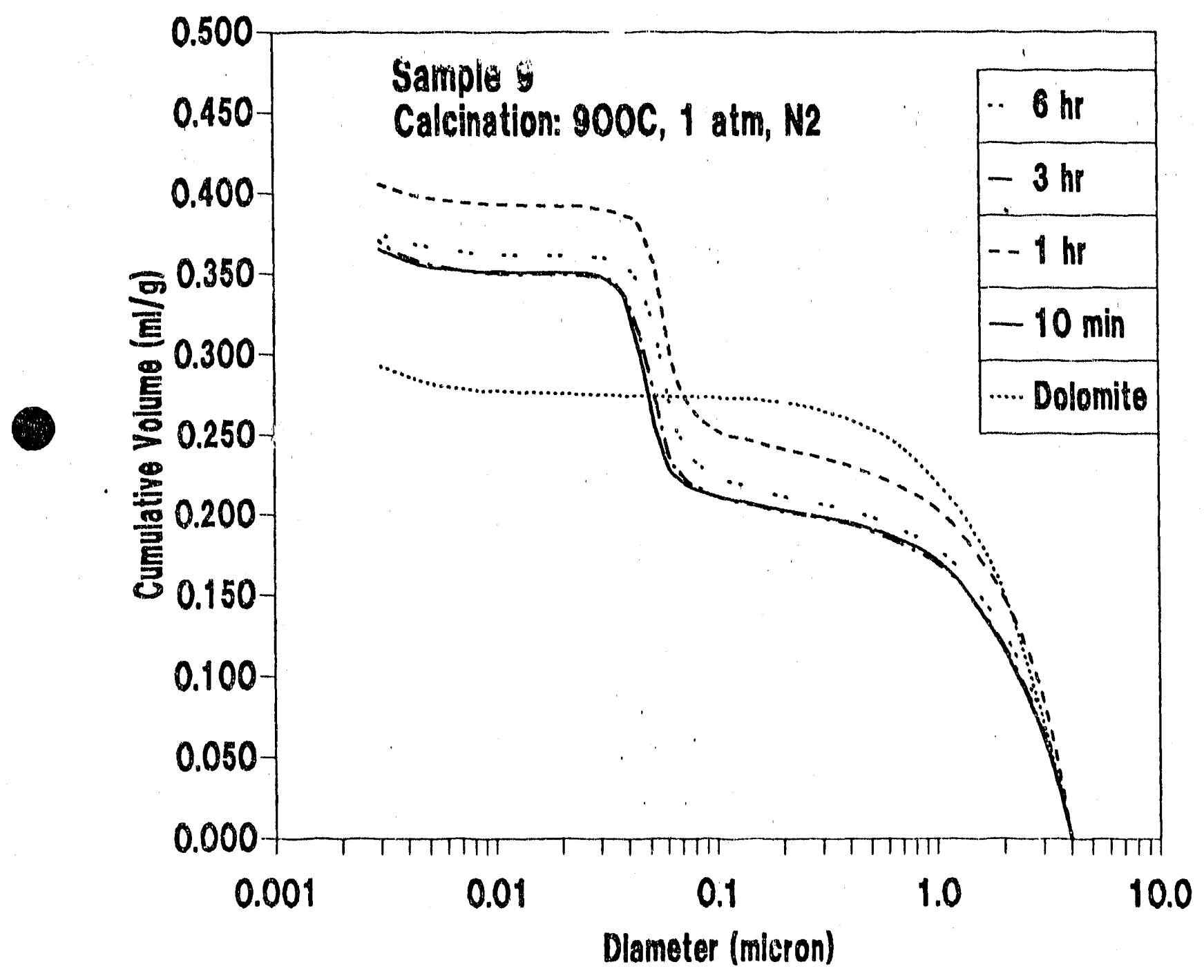

Figure 35. The Effect of Calcination Time on Pore Size Distribution: Sample 7. 


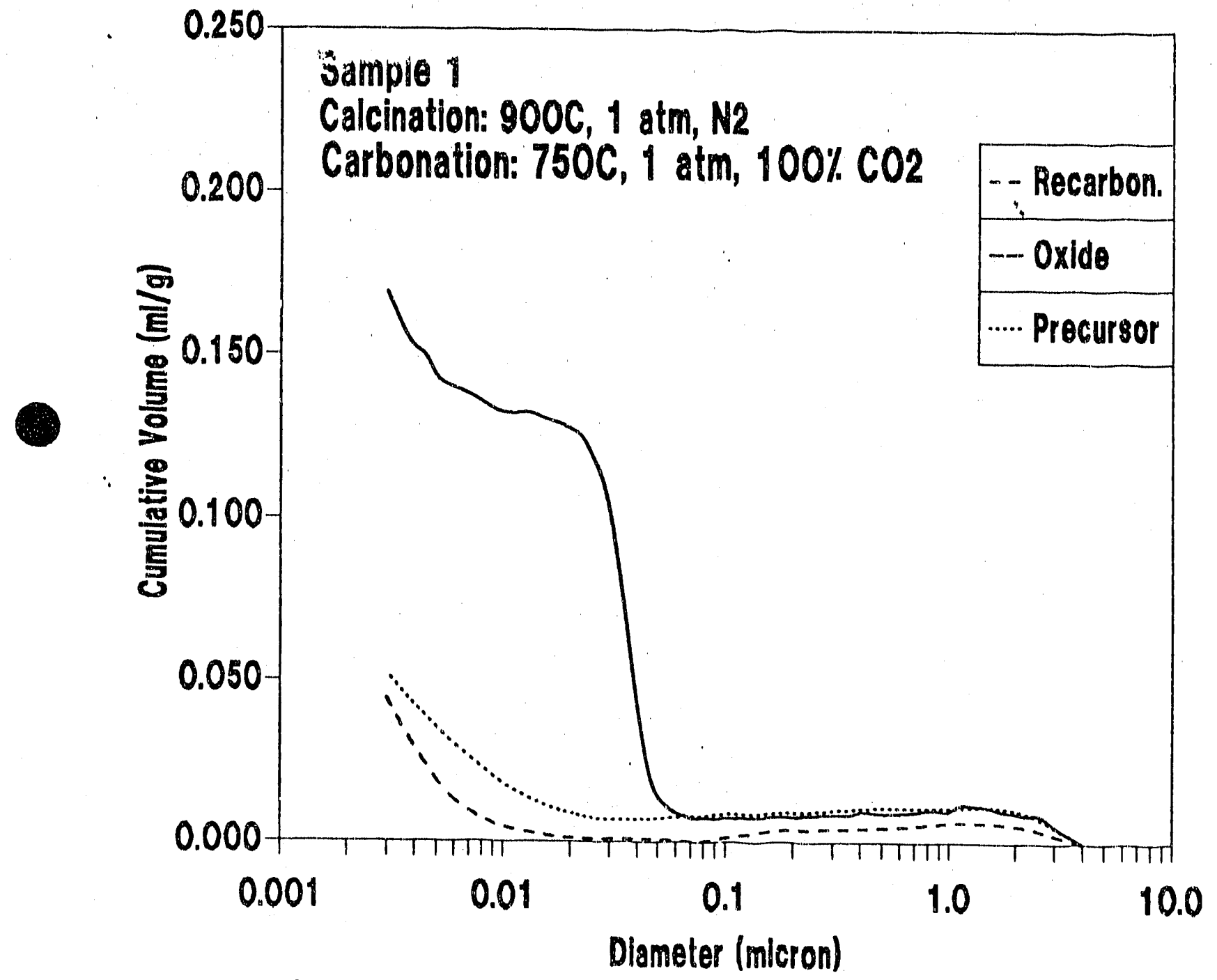

Figure 36. Pore Size Distribution of Sample 1: As-Received, After Calcination, and After Carbonation. 


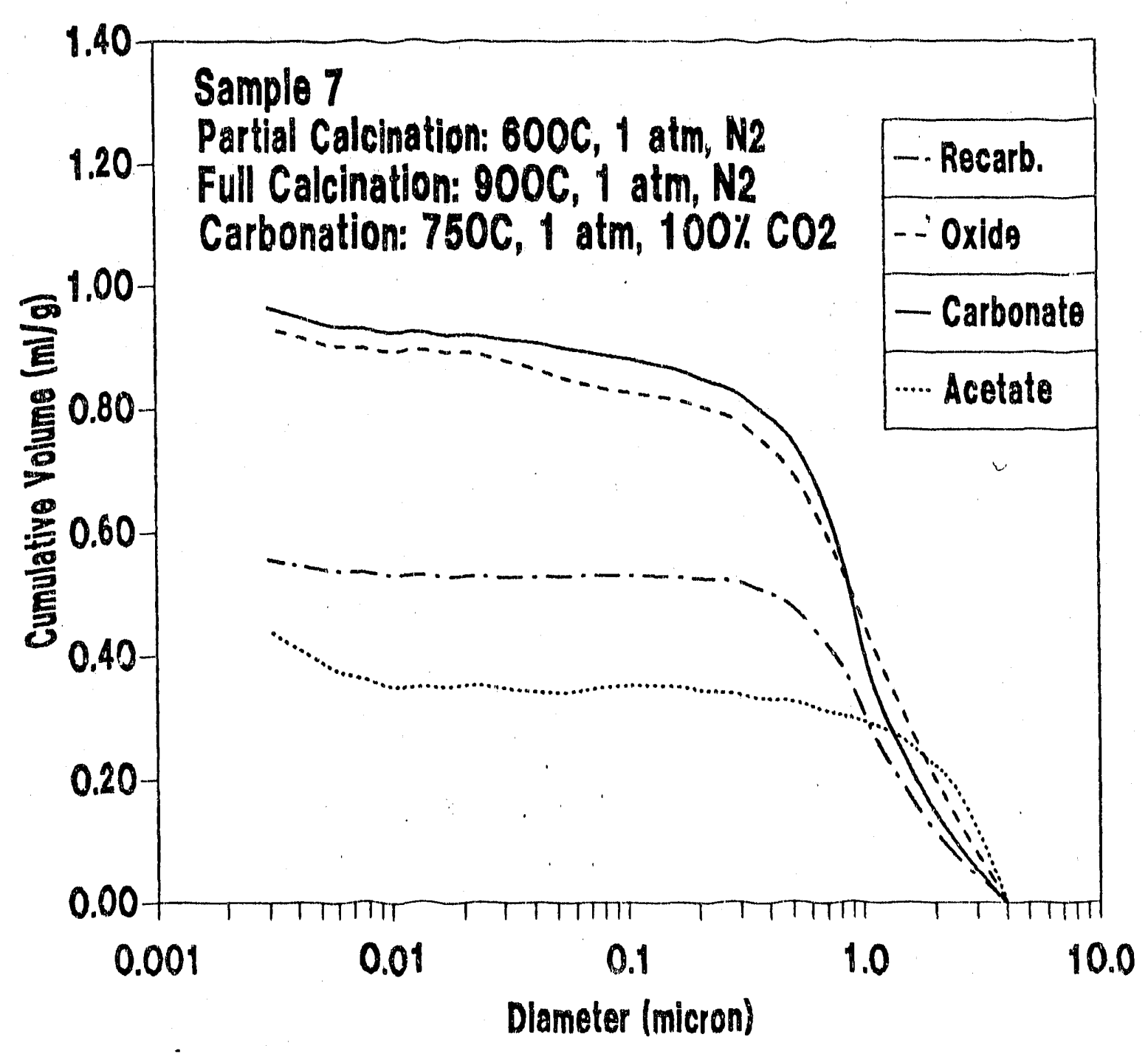

Figure 37. Pore Size Distribution of Sample 7: As-Recelved, After Calcination, and After Carbonation. 


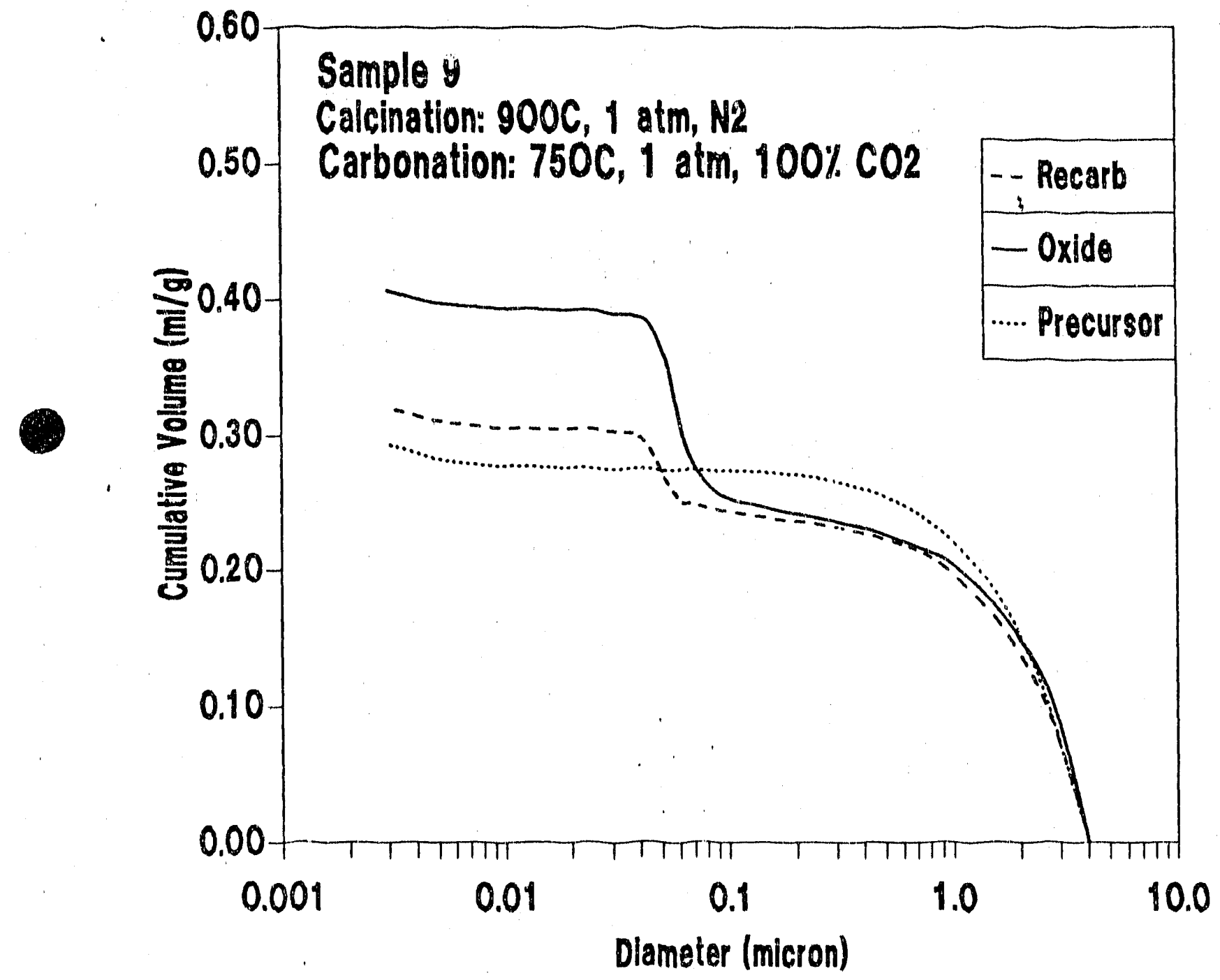

Figure 38. Pore Size Distribution of Samp1e 9: As-Recelved, After Calcination, and After Carbonation. 
any real difference exists, a slight decrease in pore volume is indicated. The very low pore volume of the sorbent after carbonation is consistent with the kinetic measurements which show that the carbonation reaction stops well short of completion. Once those pores in the 0.03 to 0.06 micron diameter range which are adjacent to the exterior of the particle are filled, further reaction becomes extremely slow as $\mathrm{CO}_{2}$ must diffuse through the carbonate product layer. Note that the absence of pore volume from the porosineter test does not imply that all pores have been filled. Isolated pores at the interior of the particle which are inaccessible to mercury may be present.

Four curves are shown in Figure 37 for sample 7 . A partial Calcination test. was carried out at $600^{\circ} \mathrm{C}$ so that the water of hydration would be driven off and the acetate group would be decomposed leaving $\mathrm{CaCO}_{3}$. As shown in the figure, this step was responsible for creating most of the pore volume and most of the large diameter pores. Additional calcination at $900^{\circ} \mathrm{C}$ to drive off $\mathrm{CO}_{2}$ and produce CaO actually resulted in a small decrease in total pore volume. However, small pores in the diameter range of 0.03 to 0.07 microns were formed in this step. Pores in this diameter range are consistent with $\mathrm{CO}_{2}$ loss as shown by calcination of the other carbonate samples. Carbonation of sample 7 was essentially complete at these conditions, and a large reduction in pore volume occurred. However, a significant volume of open pores, primarily in the diameter range of 0.3 to 1.0 microns, remained. This too is consistent with the kinetic results.

Finally, Figure 38 shows that calcination of dolomite produces pores in the 0.04 to 0.08 micron diameter range and that subsequent carbonation of calcined dolomite fills only a portion of the pores. The premise that calcination of both $\mathrm{MgCO}_{3}$ and $\mathrm{CaCO}_{3}$ would be effective in 
creating porosity and that the subsequent inert nature of the Mgo would ease the pore closure problem seems to be verified.

Additional studies of pore volume and pore size distribution responses to different reaction conditions and to multicycle operation are planned. 
REFERENCES

Barker, R., 1973, The Reversibility of the Reaction CaCo $\langle\cdots->$ CaO + $\mathrm{CO}_{2}, \mathrm{~J}$. Appl Chem. Biotechnol., 23, 733.

Barker, R., 1974, The Reactivity of Calcium Oxide Towards Carbon Dioxide and Its Use for Energy Storage, J. Appl. Chem. Biotechnol., 24, 221.

Bhatia, S.K. and D.D. Perlmutter, 1980, A Random Pore Model for Fluid-Solid Reactions: I. Isothermal, Kinetic Control, AIChE J, 26,379 .

Bhatia, S.K., and D.D. Perlmutter, 1981, A Random pore Model for Fluid-Solid Reactions: II. Diffusion and Transport Effects, AIChE J, 27,247 .

Bhatia, S.K., and D.D. Perlmutter, 1983, Effect of the Product Layer on the Kinetics of the $\mathrm{CO}_{2}$-Lime Reaction, AIChE J, 29, 79.

Borgwardt, R.H., 1989, Sintering of Nascent Calcium Oxide, Chem. Engr. Sci. 44,53 .

Boynton, R.S., 1980, Chemistry and Technology of Lime and Limestone, John Wiley and Sons, New York.

Curran, G.P., C.E. Fink, and E. Gorin, 1967, CO, Acceptor Gasification Process: Studies of Acceptor Properties, in Advances in Chemistry, 69, Fuel Gasification, F.C. Schora, ed., American Chemical Society, Washington, D.C., 141-165.

Dedman, A.J., and A.J. Owen, 1962, Calcium Cyanamid synthesis. Part 4: The Reaction $\mathrm{CaO}+\mathrm{CO}_{2} \longleftrightarrow-\longrightarrow \mathrm{CaCO}_{3}$, Trans. Farad. Soc., 58, 2027.

Delucia, D.E., 1985, The Cyclic Use of Limestone to Capture Co,, M.Sc. Thesis, Massachusetts Institute of I'echnology.

Dhupe, A.P., and A.N. Gokarn, 1987, An Experimental study of the Effect of Inert in Gas-Solid Reactions, Chem. Engr. Sci., 42, 2285

Dhupe, A.P., and A.N. Gokarn, 1990, Use of Thert Solids in Some Industrially Important Gas-Solid Reactions, Ind. Engr. Chem. Res., 29,784 .

Focht, G.D., P.V. Ranade, and D.P. Harrison, 1989, High Temperature Desulfurization Using zinc Ferrite: Regeneration Kinetics and Multicycle Testing, Chem. Engr. Sci., 44, 2919.

Gluud, W., K. Keller, R. Schonfelder, and W. Klempt, 1931, Production of Hydrogen, U.S. Patent 1,816,523. 
Hartman, M., J. Pata, and R.W. Coughlin, 1978, Influence of the Porosity of Calcium Carbonates on Their Reactivity with Sulfur Dioxide, Ind. Engr. Chem. Proc. Des. Dev., 17, 411.

Hougen, O.A., K.M. Watson, and R.A. Ragatz, 1959, Chemical Process Principles, Part II: Thermodynamics, Second Edition, John Wiley and Sons, New York.

Lamoreaux, R.H. et al., 1986, Determination of Solid Phase Boundaries in Coal Gas Desulfurization by Zinc Ferrite, Final Report, DE-AC? 1-84MC21096.

Mess, D., 1989, Product Layer Diffusion in the Carbonation of Calcium oxide, Ph.D. Thesis, Massachusetts Institute of Technology.

Oakeson, W.G., and I.B. Cutler, 1979, Effect of $\mathrm{CO}_{2}$ pressure on the Reaction with CaO, J. Am. Ceram. Soc., 62, 556.

Squires, A.M., 1967, Cyclic Use of Calcined Dolomite to Desulfurize Fuels Undergoing Gasification, in Advances in Chemistry, 69, Fuel Gasification, F.C. Schora, ed., American Chemical Society, Washington, D.C., 205-227. 

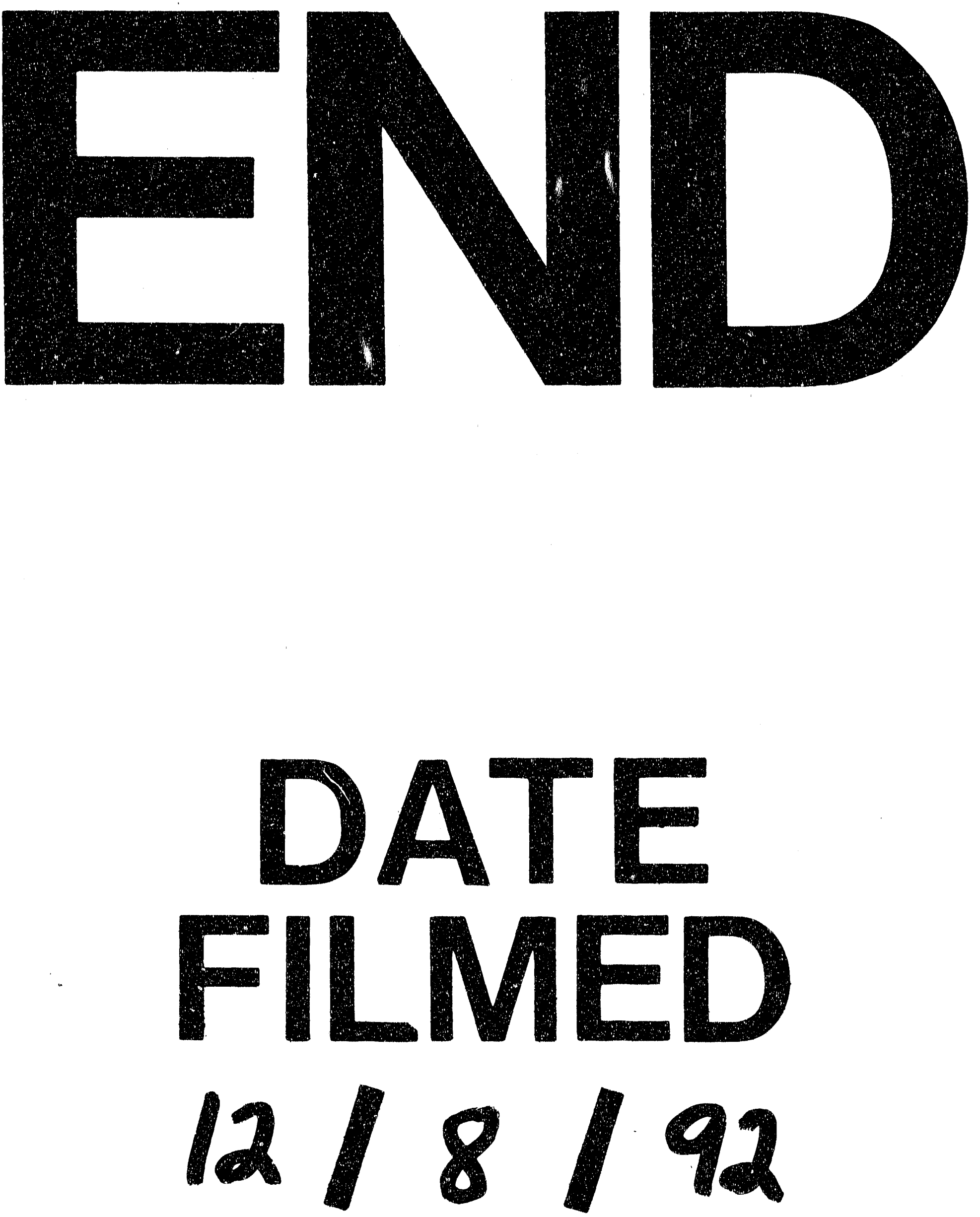
